Published in final edited form as:

Chem Soc Rev. 2018 June 18; 47(12): 4510-4544. doi:10.1039/c8cs00027a.

\title{
Recent Advances in Ruthenium-Based Olefin Metathesis
}

\author{
O. M. Ogba ${ }^{a}$, N. C. Warnera ${ }^{a}$ D. J. O'Leary ${ }^{a}$, and R. H. Grubbs ${ }^{b}$ \\ ${ }^{a}$ Department of Chemistry, Pomona College, 645 North College Avenue, Claremont, California \\ 91775, U.S.A
}

bDivision of Chemistry and Chemical Engineering, California Institute of Technology, $1200 \mathrm{E}$. California Boulevard, Pasadena, California 91125, U.S.A

\begin{abstract}
Ruthenium-based olefin metathesis catalysts, known for their functional group tolerance and broad applicability in organic synthesis and polymer science, continue to evolve as an enabling technology in these areas. A discussion of recent mechanistic investigations is followed by an overview of selected applications.
\end{abstract}

\section{Introduction}

Our laboratory has been engaged in the development and application of ruthenium-based olefin metathesis catalysts for over thirty years; the efforts of groups around the world and the chemistry of other metals, such as titanium, molybdenum, and tungsten, have also helped shape our thinking, both before and during this time period. ${ }^{1}$

The broad utility of ruthenium-based olefin metathesis catalysts rests upon their functional group, air, and moisture tolerance. In the mid-1980s, we overcame a synthetic challenge in polymer chemistry by demonstrating aqueous ring-opening metathesis polymerization (ROMP) using structurally-undefined polymeric Ru(II)-olefin complexes. ${ }^{2}$ This led to the discovery that strained olefins and $\mathrm{Ru}(\mathrm{II})$ provided a path to structurally well-defined ruthenium metathesis catalysts of the general structure shown in Scheme 1. ${ }^{3,4}$ Numerous variants (Figure 1) have emerged in the intervening years from our laboratory and others, with structural modification for enhancing catalyst initiation rate, turnover number, stereoselectivity, or lifetime. In our initial reports in the early 1990s, we used phosphine complex Ru-1-II to demonstrate ROMP ${ }^{2}$ and ring-closing metathesis (RCM) reactions in the presence of air and functional groups such as carboxylic acids, alcohols, aldehydes, and amine salts - a significant improvement when compared with known molybdenum catalysts. ${ }^{5}$ In that same timeframe, we developed procedures for the multi-kilogram-scale preparation of phosphine complex Ru-1-I, ${ }^{6-8}$ which accelerated its use in synthesis.

Ruthenium complexes with significantly improved properties were discovered by the early 2000s. Unsaturated $N$-heterocyclic carbene (NHC) complexes reported by Herrmann, ${ }^{9}$ Nolan, ${ }^{10}$ and Grubbs ${ }^{11}$ exhibited significantly greater metathesis activity and enhanced thermal stability. The saturated NHC complex Ru-2-I, disclosed by Grubbs and coworkers ${ }^{12}$ and Hoveyda's phosphine-free variant Ru-2-II, ${ }^{13}$ have found widespread use in synthetic organic and polymer chemistry. Notably, Ru-2-I provided the first examples of selective 
cross-metathesis (CM) reactions. ${ }^{14}$ The NHC family of well-defined catalysts has also enabled several metathesis processes on an industrial scale. For example, Simeprevir, a hepatitis $\mathrm{C}$ treatment identified as an essential medicine by the World Health Organization, is prepared by RCM. ${ }^{15,16}$ In another example, a bio-refinery plant in Indonesia is currently using CM to process up to 180,000 metric tons of seed oil, providing access to olefins, oleochemicals, and specialty chemicals. ${ }^{17}$ This technology harkens back to the Phillips Triolefin Process of making ethylene and 2-butene from propylene or vice-versa - an early commercial cross metathesis process that paved the way for a broadly used and fundamentally new olefin transformation. ${ }^{1}$

Developments in metathesis chemistry are global in scope and have been exhaustively reviewed in $2003^{18}$ and again in $2015 .{ }^{19}$ The aim of the present review is to provide a description of developments from our laboratory post-2005, including select applications from other laboratories. This review is divided into three sections: catalyst development and mechanistic studies, applications in organic synthesis, and in polymer chemistry.

\section{Catalyst Development}

\subsection{Olefin Metathesis Catalytic Cycle}

Extensive investigation into the olefin-metathesis mechanism have shown that the Chauvin mechanism ${ }^{20}$ is operative. ${ }^{21}$ The catalytic cycle (Figure 2) is initiated by dissociation of the phosphine in the ruthenium pre-catalyst to form an active 14-electron Ru-alkylidene intermediate (rate constant $k_{1}$ ). The active Ru-alkylidene may either re-bind to the phosphine (rate constant $k_{-1}$ ), inactivating the catalyst, or bind to an olefin in an $\eta-2$ fashion (rate constant $k_{2}$ ), continuing the catalytic cycle. 2,2-cycloaddition between the $\eta$-2-bound olefin and the Ru-alkylidene (rate constant $k_{3}$ ) results in the characteristic metallacyclobutane intermediate. Consequent 2,2-cycloreversion and olefin elimination produces the desired metathesis product and releases the active Ru-alkylidene. We have focused our mechanistic elucidation efforts on three areas: catalyst initiation kinetics $\left(k_{1}\right)$, olefin addition kinetics $\left(k_{2}\right)$ and stereochemistry, and metallacyclobutane intermediate stability, dynamics, and stereochemistry.

\subsection{Perturbing Initiation Kinetics via Phosphine Substitution}

Catalyst activity is affected by the rate of initiation/rebinding, olefin binding, cycloaddition, and catalyst decomposition. We sought to probe the effect of ligand substitution on initiation kinetics. Any modification to ancillary ligands affects all the above-mentioned elementary steps. However, close inspection of the catalytic cycle reveals that the active catalyst Rualkylidene is identical after the first cycle, regardless of the nature of the ruthenium precatalyst (Figure 3). Therefore, we reasoned that modifying the phosphine would only affect initiation kinetics without affecting the rate of the remaining steps in the catalytic cycle.

Table 1 depicts the work our lab has done to probe the effects of phosphine substitution on the rate of catalyst initiation. ${ }^{22}$ We found that catalyst initiation is affected by both steric and electronic properties of the phosphine ligand. All other factors being equal, phosphine ligands with larger cone angles will dissociate more rapidly than those with small cone 
angles. Regardless of steric size, a weak donor ligand dissociates faster than a strong donor ligand. For example, a significant decrease in initiation rates is observed between Ru-2-I$\mathbf{P C y}_{3}$ and Ru-2-I-P(n-Bu) $)_{3}$ (Entries I and II, respectively). The origin of this discrepancy arises from the difference in cone angles between the former $\left(170^{\circ}\right)$ and the latter $\left(132^{\circ}\right)$. In another example, Ru-2-I-P(Ph) $)_{2}(\mathbf{O M e})$ has a ligand cone angle of $132^{\circ}$, but exhibits an

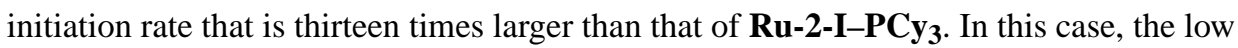
donor strength of the $\mathrm{P}(\mathrm{Ph})_{2}(\mathrm{OMe})$ ligand relative to $\mathrm{PCy}_{3}$ overrides the steric factor.

\subsection{Side- vs Bottom-Bound Olefin Addition}

Olefin binding may take two forms: one in which the olefin is bound cis to the L-type ligand (side-bound) and one in which the olefin is bound trans (bottom-bound, Figure 4). Both sideand bottom-bound complexes have been observed in the literature. Snapper and co-workers isolated bottom-bound complex $\mathbf{1}$ where the olefin is tethered via Ru-alkylidene moiety, suggesting bottom-bound mechanism. ${ }^{23}$ We isolated side-bound ruthenacyclobutane intermediate complex 2, suggesting olefin binding and 2,2-cycloadditon occurs via sidebound mechanism. ${ }^{24}$ In order to explore these modes of binding, we chose to use 1,2divinylbenzene $\mathbf{3}$ due to its ability to chelate to the ruthenium center without undergoing ring-closing metathesis, as well as its expected slow homodimerization. ${ }^{25}$ We monitored via ${ }^{1} \mathrm{H}$ NMR the reaction of diene 3 with pyridine-ligated ruthenium catalyst Ru-3-I and did not find evidence for the formation of the bottom-bound complex 4 (Figure 5). However, we observed two side-bound isomers $\mathbf{5 a}$ and $\mathbf{5 b}$ differentiated by the orientation of the $\eta-2$ bound chelated olefin at the ruthenium center. Although both were observed by ${ }^{1} \mathrm{H}-\mathrm{NMR}$, 5b was isolated and characterized by X-ray crystallography. ${ }^{26}$

\subsection{Stability, Dynamics, and Stereochemistry of Metallacyclobutane Intermediate}

While our previous work (vide supra) lent insights into the thermodynamic preference for olefin binding, the kinetic preference for subsequent metallacyclobutane formation was still largely elusive. Piers and co-workers reported the first direct observation of a ruthenium metallacycle. ${ }^{27}$ In this report, ruthenium-alkylidenium 6 was treated with 2.2 equivalents of ethylene at $-50{ }^{\circ} \mathrm{C}$, resulting in a $\mathrm{C}_{2 \mathrm{v}}$-symmetric ruthenacyclobutane 7 species observed by ${ }^{1} \mathrm{H}-\mathrm{NMR}$ (Figure 6). Their results suggested bottom-bound metallacyclobutane orientation.

In our 2006 report, we prepared an unsymmetrical catalyst to investigate the preference for side- vs. bottom-bound metallacyclobutane formation, the dynamics of NHC ligand rotation and metallacycle formation/reformation, and the stereochemical orientation when substituted metallacycles are generated. ${ }^{28}$ We treated unsymmetrical ruthenium-alkylidenium $\mathbf{8}$ with ethylene (Figure 7A). The resulting ruthenacycle 9 exhibited a distinct two-proton signal at 2.66 ppm corresponding to the enantiotopic $\beta$-hydrogens. Furthermore, 2-D COSY and ROESY NMR data indicated that Ru-NHC rotation in 9 is sufficiently slow on an NMRtime scale at $-40{ }^{\circ} \mathrm{C}$. Furthermore, we reacted 6 with approximately 35 equivalents of propene. Three bottom-bound ruthenacyclobutane intermediates were observed (Figure 7B); $45 \%$ was ethylene-derived ruthenacycle 10, $29 \%$ propene-derived 11 , and $2 \%$ butenederived 12. Exchange cross-peaks at the $a$ - and $\beta$-positions of $\mathbf{1 0}$ were indicative of nonproductive metallacycle cycloreversion and re-formation occurring on an NMR time scale. In our more recent 2011 paper, we conducted similar studies with propene, 1-butene, and 1- 
hexene. ${ }^{29}$ We found that decreasing ethylene concentration favored an increase in populations of a-monosubstituted and a, a'-disubstituted ruthenacycles such as $\mathbf{1 1}$ and $\mathbf{1 2}$ (cis and trans), respectively. Moreover, trans-substituted metallacycles were favored over the cis counterpart by a factor of ca 2 . Together with studies by Piers and coworkers, we showed that olefin cross metathesis reactions proceed via the formation of a bottom-bound, highly dynamic metallacyclobutane intermediate, with stereoisomeric preference for trans-1,3 substituted metallacycles.

\subsection{Catalyst Decomposition}

Despite advancements made toward developing functional-group-tolerant Ru-1 and Ru-2 catalysts for olefin metathesis, limitations such as high dilution, elevated temperatures, and extended reaction times were still required for closure of large rings. Thermal stability of the catalyst (i.e., the ability of a catalyst to avoid decomposition) plays a critical role in determining catalyst lifetime and turnover number.

We explored the first well-characterized decomposition products from the active $\mathrm{Ru}$ methylidene intermediate of Ru-2-I in the presence and in the absence of ethylene (Figure $8 \mathrm{~A}) .{ }^{30}$ In the absence of ethylene, we showed via ${ }^{31} \mathrm{P}$ NMR spectroscopy and X-ray crystallography the formation of a dinuclear ruthenium complex 13 . Three features are observed: (1) The ruthenium centers are bridged via a carbide, shown by a ${ }^{13} \mathrm{C}$ chemical shift of $414.0 \mathrm{ppm}$ and a carbide-hydride coupling constant of $10.4 \mathrm{~Hz}$. (2) One ruthenium center uniquely consists of a hydride ligand $(\delta-8.6 \mathrm{ppm})$ and $\eta^{6}$-binding to an $\mathrm{N}$ heterocyclic carbene mesityl ring from the other ruthenium ( $\delta$ mesityl proton $5.6 \mathrm{ppm})$. (3) A complete loss of a phosphine ligand from the starting complex Ru-2-I resulting in a byproduct with a ${ }^{31} \mathrm{P}$ chemical shift of $34.5 \mathrm{ppm}$. Furthermore, complex $\mathbf{1 3}$ has been shown to promote olefin isomerization and migration, and we showed that $p$-benzoquinone additives can prevent this side reaction, if undesired (vide infra) ${ }^{31}$ In the presence of ethylene, we found that the major decomposition product of Ru-2-I is the $C_{2}$-symmetric complex 14, isolated via X-ray crystallography.

Both Ru-2-III and Ru-2-IV are highly active for ring-closing metathesis. ${ }^{32}$ However, Ru-2III decomposes faster than Ru-2-IV. ${ }^{33,34}$ We have shown that the Ru-2-III benzylidene carbon inserts into an ortho $\mathrm{C}-\mathrm{H}$ on one of the $\mathrm{N}$-phenyl rings (Figure $8 \mathrm{~B}$ ) ${ }^{35}$ Consequent $\eta^{6}$-binding of ruthenium to the benzylidene phenyl group results in complex 16. We also showed that further ruthenium insertion into another ortho $\mathrm{C}-\mathrm{H}$ can occur, resulting in complex 17. These studies indicated that substitutions at the ortho position may hinder unwanted $\mathrm{C}-\mathrm{H}$ insertion reactions and hence reduce the propensity for catalyst decomposition.

\subsection{Catalyst Development for Asymmetric Olefin Metathesis}

There are three major classes of asymmetric olefin-metathesis: (1) asymmetric ring closing metathesis (ARCM), (2) asymmetric ring opening cross metathesis (AROCM), and (3) asymmetric cross metathesis (ACM). In ARCM, there is only one propagating alkylidene species. Consequently, to afford asymmetric catalysis, only the orientation of that propagating species, and enantiotopic olefin selection must be controlled. In AROCM, both 
the identity of the propagating species and its orientation must be controlled. Facial selectivity is however substrate-controlled when using norbornene as the substrate. In ACM, the identity of the propagating species, its orientation, and enantiotopic olefin selection all must be controlled, making this the most challenging class of asymmetric olefin metathesis. In this section, we summarize our work identifying ruthenium-based catalysts that can control for the factors described above.

2.6.1. Asymmetric Ring-Closing Metathesis (ARCM)—We initially showed that chiral ruthenium NHC catalyst Ru-2-X induced ARCM of prochiral trienes. ${ }^{36}$ Following this discovery, we explored a range of ruthenium olefin metathesis catalysts (Table 2), with varying substitution patterns at the NHC $N$-phenyl groups, for ARCM,${ }^{37}$ using the conversion of $\mathbf{1 8}$ to $\mathbf{1 9}$ as a test case for catalyst screening (Table 3). High percent conversion is observed in all cases. However, Ru-2-XI and Ru-2-XVII afforded $90 \%$ ee; the highest reported for the reaction in this study.

2.6.2. Asymmetric Ring-Opening Cross Metathesis (AROCM)—Following our initial exploration of Ru-2 catalysts for ARCM, we investigated the ability of the best ARCM catalysts for AROCM. ${ }^{38}$ Anhydride 20 was treated with 10 equivalents of styrene in DCM using 1 mol \% of Ru-2-XVI, Ru-2-X, Ru-2-XII, or Ru-2-XIV (see Table 4). Out of the four catalysts, Ru-2-XIV was the most selective (76\% ee). Additionally, no change in selectivity was observed when reaction was performed in various aprotic organic solvents.

We further explored the effectiveness of Ru-2-XIV and the diiodide variant Ru-2-XV for AROCM on a variety of substituted norbonene compounds. In all cases the $E / Z$ ratio was close to 1:1, and ee values for the cis product were less than that for the trans. Within the trans product, enantioselectivities ranged from $57 \%$ to $81 \%$. Aspects of the AROCM mechanism were elucidated from these studies: (1) $E / Z$ ratios remained constant over $3 \mathrm{~h}$, and secondary cross-metathesis is not observed, indicating that the $E / Z$ ratio is a direct consequence of singular catalyst-substrate interactions. (2) Because the ee values of the $E$ and $Z$ - products were significantly different, the nature of the important propagating species was inferred to be the ruthenium-benzylidene, not the ruthenium-methylidene species. (3) Further evidence supporting bottom-bound olefin binding was provided.

Given that catalyst Ru-2-XVI yielded the ent-21 and Ru-2-XIV yielded 21, and the propagating species is believed to be the ruthenium-benzylidene, we rationalized that a ciscoordinating species would lead to severe steric strain between the approaching norbonene and the Ru-NHC-phenyl substituents.

\subsubsection{Asymmetric Cross Metathesis (ACM)_ACM reactions are the most} challenging of the asymmetric metathesis reactions because the propagating species, its orientation, and enantiotopic olefin selection must be controlled. In our first report identifying an ACM catalyst, we employed substrate-control of both enantiotopic olefin selection and propagating species by using meso-diene substrates and an excess of the alkene metathesis reagent. ${ }^{38}$ Catalysts Ru-2-XVI and Ru-2-XII emerged as the most effective ACM catalysts, albeit in relatively moderate efficiency (ee up to $52 \%$ ). 


\subsection{Cyclic (Alkyl)(Amino) Carbene Ru-Catalysts}

Bertrand and coworkers first reported the synthesis of olefin metathesis catalysts bearing cyclic (alkyl)(amino) carbenes (CAACs). ${ }^{39,40}$ The replacement of an $\mathrm{sp}^{2}$-hybridized nitrogen to an $\mathrm{sp}^{3}$-hybridized carbon results in: (i) greater $\sigma$-donor ability, ${ }^{41,42}$ (ii) a change in steric environment around the $\mathrm{NHC}$, and (iii) a change in symmetry from $C_{2} V$-symmetric in NHCs to $C_{\mathrm{S}}$ or $C_{1}$-symmetric in CAACs that possibly affects the microreversibility of the olefin-binding and cycloreversion steps in the metathesis catalytic cycle. ${ }^{43,44}$ Our investigations show that upon tuning of steric bulk of the CAAC ligand, CAAC-bearing Ru-4 catalysts are comparable to the NHC variants in ring-closing metathesis for the formation of di- and tri- substituted olefins. ${ }^{45}$ However, of note, we have shown that CAACbearing ruthenium olefin metathesis catalysts are remarkably effective for ethenolysis, achieving turnover numbers (TONs) of up to 340,000, at a catalyst loading of only $1 \mathrm{ppm}$ (see Ethenolysis section below). ${ }^{46,47}$

\subsection{Catalyst Development for Z-Selective Olefin Metathesis}

The ability to selectively form the $Z$-olefin product in cross-metathesis reaction remains a significant challenge in metathesis research. In this section, we describe the recent progress made in our lab to design ruthenium-based $Z$-selective olefin metathesis catalysts. Hoveyda and Schrock reported the first example of a $Z$-selective olefin metathesis catalyst using tungsten and molybdenum. $Z$-selectivity was reported to be induced by a difference in size of the two apical ligands of the metallacyclobutane complex. ${ }^{48-53}$ From our lab, we reported a family of functional-group-tolerant $Z$-selective ruthenium based catalysts ${ }^{54,55}$ consisting of a chelating NHC ligand, derived from intramolecular carboxylate-driven C-H bond insertion of an $N$-bound substituent (Figure 1, Ru-5 catalysts). ${ }^{56,57}$ Of note, Ru-5-II and Ru-5-IV exhibit activity and $Z$-selectivity rivalling tungsten and molybdenum catalysts. Substituting the carboxylate ligand in Ru-5-II with a nitrato group such as in Ru-5-IV results in greater stability, $Z$-selectivity, and increase in turn-over number (TON) for homodimerization reactions. Altogether, the Ru-5 catalyst family has been used for olefin homodimerization, ${ }^{58}$ ring opening, ${ }^{59}$ ring-closing, ${ }^{60}$ cross $^{61}$ metathesis, and ethenolysis. ${ }^{62}$ In this section, we highlight experimental and computational efforts by us and collaborators to elucidate the mechanism of action and catalyst decomposition.

We collaborated with Houk and coworkers to investigate the mechanism and origins of $Z$ selectivity in olefin metathesis using the chelated Ru-5-based catalysts. ${ }^{63}$ Structures were optimized using the B3LYP method and a mixed LANL2DZ/6-31G(d) basis set for Ru and other atoms, respectively. Both side- and bottom-bound mechanisms were computationally explored. In both mechanisms, four pathways, three involving a bidentate acetate and one involving a monodentate acetate, were computed, resulting in a total of eight possible pathways for the metathesis reaction. The minimum energy pathways for the side- and bottom- bound mechanism are shown in Figure 9. Computations revealed that the sidebound mechanism was energetically favored over the bottom-bound. The favored side-bound pathway proceeds via addition of ethylene to the ruthenium methylidene 22 to form the $\mathrm{Ru}$ olefin $\pi$ complex 23. Facile 2,2-cycloaddition (TS-24, $\Delta \mathrm{G}^{\ddagger}=4.1 \mathrm{kcal} / \mathrm{mol}$ ) leads to the exergonic metallacyclobutane intermediate $25(\Delta \mathrm{G}=-4.9 \mathrm{kcal} / \mathrm{mol})$. Ligand isomerization to intermediate $\mathbf{2 6}$ and consequent rate-determining 2,2-cycloreversion (TS-27, $\Delta \mathrm{G}^{\ddagger}=11.4$ 
$\mathrm{kcal} / \mathrm{mol}$ ) leads to ruthenium-alkyldene $\mathbf{2 8}$, where the resulting alkylidene is cis to the strong $\sigma$-donor adamantyl group.

2.8.1. Side- vs. Bottom- Bound Selectivity-The bottom-bound Ru-olefin $\pi$ complex 29 is more stable that the side-bound 23 by $6.3 \mathrm{kcal} / \mathrm{mol}$. However, consequent bottombound 2,2-cycloaddition TS-30 is less stable than side-bound TS-24 by $10.4 \mathrm{kcal} / \mathrm{mol}$. Moreover, all bottom-bound metallacyclobutane ground and transition state complexes proceeding TS-30 are higher in energy than the corresponding side-bound complexes due to two main factors: (i) Steric compression: Computations indicate that the strong preference for side-bound complexes can be readily explained via steric effects. The syn orientation of the metallacyclobutane and adamantyl groups in the bottom-bound complex TS-30 and TS-32 leads to unfavourable van der Waals interactions between adamantyl and metallacycle protons (Figure 10, Left). In the side-bound TS-24 and TS-27, the metallacyclobutane is positioned anti to the adamantyl group, and hence, no steric contact is observed between the two groups. (ii) $\boldsymbol{d}$ Orbital Backdonation: Both NHC and alkylidene ligands are strong $\boldsymbol{\sigma}$ donors and $\pi$-acceptors. Consequently, the preferred conformation situates the Ru-NHC $\pi^{*}$ orbital in the same plane as the Ru-alkylidene bond (Figure 10, Right). In the side-bound mechanism, two different ruthenium $d$ orbitals are involved in backdonation into the $\pi^{*}$ orbitals of the NHC and alkylidene. However, in the bottom-bound complexes, the same Ru $d$ orbital is involved in backdonation between both the NHC and alkylidene $\pi^{*}$ orbitals (Figure 10). ${ }^{64-66}$ This weaker back-donation results in destabilization of the bottom-bound complexes.

2.8.2. Z- vs. E- Selectivity-The strong preference for the side-bound mechanism offers unique control via steric interactions for the $Z$ - over the $E$ - olefin product. Moreover, because affording $Z$-selectivity is necessarily a kinetically-controlled process, we investigated the origins of $Z$-selectivity by looking at the transition states for the $Z / E$ selectivity determining step, using propylene as our model substrate. Computations revealed that the TSs leading to $E$-olefin were less stable than those leading to the $Z$-olefin mainly because of unfavourable van der Waals interactions between one of the methyl groups in the (E)-2-butene product and the Ru-NHC mesityl group (Figure 11).

2.8.3. Decomposition of Z-Selective Catalysts-Catalyst decomposition studies shed light into improving catalyst stability, activity, and selectivity. Recently, we reported several unique catalyst decomposition products of $Z$-selective ruthenium-based catalyst Ru-5-II. ${ }^{67}$ Ru-5-II was exposed to carbon monoxide (CO) at $-78{ }^{\circ} \mathrm{C}$ in an effort to afford a novel architecture characterized by a CO-ligated ruthenium catalyst complex with an intact alkylidene. Instead, complex 33, saturated with $\mathrm{CO}$ ligands and a covalent attachment of the $\mathrm{N}$-adamantyl to the once-alkylidene carbon, was observed (Figure 12). ${ }^{68} \mathrm{We}$ rationalized that the $\pi$-acidity of the $\mathrm{CO}$ ligands reduced the capacity for ruthenium $\pi$-backbonding with the alkylidene. To relieve this destabilization, the alkylidene inserts into the $\mathrm{Ru}-\mathrm{C}_{\text {adamantyl }}$ bond to yield 33. This observation led us to propose that alkylidene insertion into the $\mathrm{Ru}-\mathrm{C}$ bond of Ru-5 catalysts could still occur in the absence of CO ligands, and that consequent hydride elimination following alkylidene insertion would yield a complex incapable of productive metathesis. 
In an effort to make a C-H activated analog of Ru-5-II, ruthenium complex $\mathbf{3 4}$ was treated with silver(I)pivalate. The expected formation of silver(I)chloride via ligand exchange with the pivalate was observed. However, instead of the desired catalyst architecture (i.e., C-H activated analog of Ru-5-II), X-ray crystal analysis revealed the formation of 35, formed from alkylidene insertion and subsequent $\beta$-hydride elimination (Figure 13). ${ }^{1} \mathrm{H}$ NMR monitoring revealed that a monocarboxylate, mono chloride ruthenium alkylidene species was initially formed during the reaction. As this species disappeared, pivalic acid and a metastable $\mathrm{C}-\mathrm{H}$ activated species was observed. This metastable species was slowly converted to a ruthenium hydride and subsequently, the $\eta^{2}$-bound olefin ruthenium complex 35.

In an effort to make another $\mathrm{C}-\mathrm{H}$ activated ruthenium catalyst analog of $\mathbf{1}$ this time with a stronger, $\mathrm{sp}^{2}$-hybridized carbon-hydrogen bond ${ }^{69} \mathbf{3 6}$ was treated with silver pivalate. Once again, the expected formation of silver(I)chloride via ligand exchange with pivalate was observed. However, in this case, a unique decomposition product 37 comprised of attachment of the benzylidene carbon to the ortho carbon of the $N$-aryl group. This suggests alkylidene insertion into a Ru-C bond followed by a-hydride elimination. Similar to the corresponding reaction with $\mathbf{3 4},{ }^{1} \mathrm{H}$ NMR monitoring showed the generation of pivalic acid as starting material alkylidene proton resonance disappeared, suggesting a $\mathrm{C}-\mathrm{H}$ activation event had occurred prior to subsequent decomposition.

Ruthenium hydride formation via $\beta$-hydride elimination is further supported by the observed olefin migration in cross-metathesis reactions. Additives, such as $p$-benzoquinone, are typically used to prevent such migrations, albeit also leading to immediate catalyst decomposition. ${ }^{31}$ We showed that $\beta$-hydride elimination plays a role in the decomposition of C-H activated Ru-5 catalysts upon treatment with $p$-benzoquinone. Addition of this additive to Ru-5-II yielded disappearance of Ru-5-II, evidenced by disappearance of alkylidene resonance in the ${ }^{1} \mathrm{H}$ NMR spectrum, and formation of ruthenium (0) dimer 44, observed by X-ray crystal analysis (Figure 14)

We collaborated with the Houk group to elucidate the two possible decomposition pathways (i.e., $\mathbf{a}$ - vs. $\beta$-hydride elimination) of Ru-5-II in the presence of $p$-benzoquinone (Figure 14). All electronic energies were calculated using $\mathrm{M} 06 / \mathrm{SDD} / 6-311+\mathrm{G}(2 \mathrm{~d}, \mathrm{p})$ on geometries optimized using B3LYP/LANL2DZ/6-31G(d) level of theory. Decomposition begins with the insertion of alkylidene into the ruthenium-carbon bond to form the thermodynamically favored alkyl ruthenium intermediate $\mathbf{3 8}(\Delta \mathrm{G}=-2.9 \mathrm{kcal} / \mathrm{mol})$. From this intermediate, either a-hydride elimination product $\mathbf{4 0}$ or $\beta$-hydride elimination product $\mathbf{4 2}$ can form via the transition state structures TS-39 and TS-41, respectively. Computations reveal that free energy barrier leading to the former is $33.3 \mathrm{kcal} / \mathrm{mol}$ higher than that leading to the latter, indicating that $\beta$-hydride elimination is energetically preferred. Computations corroborate the experimentally-observed $\beta$-hydride elimination product. Following the formation of intermediate 42 , reductive elimination of acetate leads to 43 . Ligand exchange with $p$ benzoquinone via associative mechanism and consequent homodimerization leads to the highly exergonic decomposition product $\mathbf{4 4}(\Delta \mathrm{G}=-29.8 \mathrm{kcal} / \mathrm{mol})$. 


\subsection{A Standard System for Catalyst Characterization}

In 2006, we proposed a set of six reactions and conditions to establish a standard for comparing olefin metathesis catalysts. ${ }^{70}$ The reaction set included (i) three RCM reactions forming di-, tri-, and tetrasubstituted cyclopentenes, (ii) two CM reactions with coupling partners of variable reactivity, and (iii) a ROMP reaction using cyclooctene (Figure 15). Representative results for catalysts Ru-1-I, Ru-2-I, and Ru-2-II are shown in Table 5. This study established a means for benchmarking catalysts with respect to their activity, stability, and selectivity. The RCM results showed that the NHC-based catalysts are more efficient than the phosphine-based analogues, but also pointed out that no particular catalyst was superior for all reactions. Furthermore, closure of tetrasubstituted olefins was identified as a major challenge and one that was effectively dealt with in subsequent investigations. The CM reactions of allyl benzene and cis-1,4-diacetoxy-2-butene with NHC-based catalysts were rapid and, if given enough time for secondary isomerization, provided ca. 10:1 E/Z product selectivity. CM of electron-deficient methyl acrylate, known to be difficult with Ru-1-I, proceeded well with NHC-based systems Ru-2-I and Ru-2-II (each >80\% conversion at 3 hours under the standard conditions). The standard ROMP reaction used 1,5cyclooctadiene, whose polymerization could be conveniently followed by NMR spectroscopy when using a monomer to catalyst ratio of 1000:1. Here again, the NHCderived catalysts were dramatically more reactive than the first-generation catalysts. In particular, the rapidly-initiating pyridine-derived Ru-3-II catalyzed a nearly instantaneous polymerization under the standard reaction conditions in less than 30 seconds.

\section{Applications in Organic Synthesis}

\subsection{Ring-Closing Metathesis (RCM)}

3.1.1. $\mathrm{N}$-Boc-3-pyrroline Syntheses-We documented the facile RCM of $N$-Bocdiallylamine 59 (30 g) in a 2003 Organic Syntheses preparation using $0.5 \mathrm{~mol} \% \mathbf{R u}-1-\mathbf{I}$ to provide Boc-3-pyrroline 60 in 90-94\% yield. ${ }^{71}$ Helmchen also reported an efficient largescale (100 g) preparation, using lower Ru-1-III catalyst loading $(0.1 \mathrm{~mol} \%)$ and convenient product isolation after vacuum distillation of the crude reaction mixture. ${ }^{72}$ We have utilized this reaction for screening catalysts and found that reactions run in neat as-delivered substrate in the presence of as little as $0.05 \mathrm{~mol} \%$ Ru-2-II proceeded in $87 \%$ yield (Figure 16). ${ }^{73}$

3.1.2. Synthesis of Coumarins-Our group was interested in the synthesis of substituted coumarins both at the 3 - and 4 positions (Figure 17). Synthesis of coumarin precursors 61 a-d is readily achieved via acylation of corresponding phenol. RCM of 61 using the highly active ruthenium catalyst Ru-2-I yielded coumarin 62a-d. ${ }^{74}$ Unsubstituted coumarin 62a was synthesized in high yields (89\%). Comparatively high yields were maintained in the synthesis of mono-substituted coumarins $62 \mathrm{c}$ and $\mathbf{6 2 d}(88 \%$ and $74 \%$, respectively). However, to achieve moderate yield (45\%) of the di-substituted coumarin RCM product $\mathbf{6 2 b}$, increased catalyst loading was required (10 mol\%). At the time of publication of this report, this was one of the few successful cases of RCM to form tetrasubstituted olefins, and was particularly remarkable given the electron-deficient nature of the olefins involved. 
3.1.3. Synthesis of Rotaxanes-Rotaxanes ${ }^{75}$ are interlocked, dumbbell-shaped molecules in which one or more macrocycles are trapped. Much of the research involving rotaxanes focuses on the possibility of using these architectures in molecular machinery, ${ }^{76}$ such as molecular switches. ${ }^{77,78}$ Synthetic efforts have focused on kinetically-control synthesis, ${ }^{79}$ where the desired interlocking arises form an irreversible final transformation. Alternatively, our efforts have focused on taking advantage of the reversible nature of RCM reactions to impact thermodynamic control for rotaxane synthesis. We employed two strategies for synthesizing rotaxanes in our lab: (1) using the ruthenium alklylidene catalysts Ru-1-I and Ru-2-I for the synthesis of [2]-catenane ${ }^{80,81}$ and (2) using templating synthetic partners (or synthons) to facilitate ring-closing of macrocyclic structures. ${ }^{82-85}$

Our initial efforts were to capitalize on the significant ability of dibenzo[24]crown-8 to bind to $\mathrm{R}_{2} \mathrm{NH}_{2}{ }^{+}$ions (Figure 18A). ${ }^{84}$ Treatment of macrocycle precursor $63 \mathbf{a}$ or $63 \mathbf{b}$ with ruthenium catalyst Ru-1-I resulted in the formation of macrocycle $64 \mathbf{a}$ or $64 \mathbf{b}$ in moderate yields (48\% and 50\%, respectively), as a mixture of $E$ and $Z$ isomers. ${ }^{86}$ In the presence of bis(3,5-dimethoxybenzyl)ammonium hexafluorophosphate $\mathbf{6 5}$, the corresponding [2] roxane $\mathbf{6 6} \cdot \mathrm{PF}_{6}$ and $\mathbf{6 6} \mathbf{b} \cdot \mathrm{PF}_{6}$ was formed in $73 \%$ and $30 \%$ yields, respectfully, also as a mixture of $E$ and $Z$ isomers. We attributed the increase in yield for $6 \mathbf{6 a} \cdot \mathrm{PF}_{6}$ over $\mathbf{6 4 a}$ to templating effects afforded by the ammonium ion. The product macrocycle complex was verified by ${ }^{1} \mathrm{H}$ and ${ }^{13} \mathrm{C}$ NMR spectroscopy, mass spectrometry, and single crystal X-ray analysis.

In collaboration with Stoddart and coworkers, we extended this methodology to the RCM of a tritopic receptor (precursor of 67), in which three benzo[24]crown-8 rings are fused to a triphenyl core. This was templated by a trifurcated cation $\mathbf{6 8}$, where three dibenzoammonium ions are linked to a central benzenoid core (Figure 18B). ${ }^{87}$ We showed that by exploiting multivalency, achieved via non-bonding interactions between the three $\mathrm{R}_{2} \mathrm{NH}_{2}{ }^{+}$and olefinic centers, as well as the dynamic covalent chemistry achieved via reversible ring-closing metathesis, a very stable $\left(\mathrm{K}_{\mathrm{a}}=10^{7} \mathrm{~mol} \mathrm{~L}^{-1}\right.$ in DCM) triply threaded, two-component superbundle $\mathbf{6 7}$ was formed.

The dynamic covalent nature of RCM was further employed in the clipping of the crown ether macrocycle to a cyclic secondary ammonium ion (Figure 18C). ${ }^{88}$ In this work, we were able to show that this clipped [2]catenane complex $\mathbf{7 2}$ can be formed from either a reaction between the macrocycle precursor 69 and the ammonium ion 71, or the closed macrocycle $\mathbf{7 0}$ and the ammonium ion 71. The latter of these further demonstrates the reversible nature of the olefin metathesis reaction in the synthesis of the dynamic [2]catenane.

3.1.4. Synthesis of peptide macrocycles-Intramolecular RCM is a useful method for altering the conformational and metabolic stability of a-helical peptides. The first examples of RCM-derived peptide turn and helical constraints were discovered in the mid- to late 1990s at Caltech. ${ }^{89-91}$ Later work by Verdine and co-workers showed that RCM of an olefin on the side-chain of a peptide residue position $(i)$ with another side-chain olefin that is four $(i+4)$ or seven $(i+7)$ residues away serves to rigidify the peptide a-helix backbone by approximately one or two turns, respectively. ${ }^{92}$ By 2004 , these 'stapled peptides' were shown to disrupt protein-protein interactions, have enhanced cell permeability and binding 
affinities, as well as enhanced bioavailability when compared with acyclic peptides. ${ }^{93}$ This work led to a commercialized venture (Aileron Therapeutics) seeking to develop metathesisconstrained helical peptide-based therapeutics targeting metabolic disorders and cancer. ${ }^{17,94}$

As mentioned earlier, RCM-based therapeutics have been demonstrated as a successful treatment for hepatitis C viral (HCV) infections. ${ }^{15,16}$ Ciluprevir 73 (BILN 2061) and Simeprevir 74 (Olysio $®$, TMC 345) are peptide-based macrocyclic protease inhibitors whose syntheses require efficient RCM reactions to form 15- and 14-membered rings, respectively (Figure 19). Boehringer-Ingelheim's process development with Ciluprevir has been publically disclosed and has served as a case study for optimizing challenging RCM reactions in the large-scale (>400 kg) synthesis of pharmaceuticals. ${ }^{15}$ Details of the RCM process for making Simeprevir, which is presently being prescribed, remain in the patent literature. ${ }^{95}$

In collaboration with Toniolo and coworkers, we developed minimal RCM constraints for the 310 -helix. ${ }^{96}$ An octapeptide with the sequence Boc-Aib-Aib-Aib-L-Ser(Al)-Aib-Aib-L$\mathrm{Ser}(\mathrm{Al})-\mathrm{Aib}-\mathrm{OMe}$ was used in this study. We chose this sequence because the $\mathrm{a}$ aminoisobutyric acid (Aib) residue has been shown to largely populate 3 10-helices. ${ }^{97-99}$ Reaction of the octapeptide using Ru-2-I yielded 18-membered cyclic peptide 75 (93\% yield) with unusual high $E$-selectivity (>20:1 $E / Z$ ) (Figure 20). This 310 -helical structure was validated by X-ray crystallography and circular dichroism $(\mathrm{CD})$ spectra.

In collaboration with Kwon and coworkers, we have further used this ring-closing metathesis protocol to synthesize a variety of cyclic amide $N$-alkylated peptoids of various ring sizes on a resin bead (Figure 21). ${ }^{100}$ These peptoids are more resistant to proteolytic cleavage ${ }^{101}$ and exhibit enhanced cell permeability ${ }^{102}$ compared to peptides, making this class of peptidomimetic compounds attractive for pharmacokinetic studies. We employed the 'one-bead two-compound' strategy ${ }^{103}$ with the RCM approach on a solid phase for the construction of cyclic peptoids. We screened ruthenium catalysts Ru-1-I, Ru-2-I, and Ru-2II to determine which was most effective in the RCM to the cyclic peptoid 76. Under microwave conditions, Ru-1-I and Ru-2-I afforded $\mathbf{7 6}$ in low yields (10\% and 20\%, respectively). Notably, Hoveyda-chelate ruthenium catalyst Ru-2-II afforded the macrocycle in $80 \%$ yield. Encouraged by these results, Ru-2-II was employed in the solid-phase synthesis of tetramer to heptamer cyclic peptoids (77a-d in Figure 21). High yields, calculated as transformation efficiency as determined by HPLC, were observed (70-95\% in DCM, $40{ }^{\circ} \mathrm{C}$ ). However, small amounts of dimeric and metathesis products between cyclic and linear peptoids were also observed. Ring sizes of 16- to 25-membered cyclic peptoids were successfully synthesized, making this RCM-based approach a valuable addition to the toolbox of methods for cyclic peptoid synthesis.

3.1.5. Z-Selective RCM-Using the newly developed $Z$-selective ruthenium-based catalysts (i.e., Ru-5 catalysts in Figure 1), we disclosed the $Z$-selective macrocyclic RCM (Table 6) ${ }^{60} \mathrm{RCM}$ using Ru-5-V yielded a variety of macrolactones, macrolactams, macrocyclic ketones, acetals, and alcohols in yields ranging from $30-70 \%$. Some general observations were gleaned from this study: (1) Dilute conditions and elevated temperatures were required to curb competing CM and oligomerization, and favor macrocyclic RCM. (2) 
Macrocyclic RCM to form large 16-, 17-, and 20- membered lactones gave the highest yields (see macrolactones 80 (72\%), 82 (71\%), and $\mathbf{8 1}$ (75\%), respectively). (3) $Z$-selectivity was high for all macrocyclizations, although masking of ketones and alcohols were necessary to achieve higher $Z$-selectivity (i.e., $\mathbf{8 3}(68 \% Z$ ) vs $\mathbf{8 4}(85 \% Z$ ), and $\mathbf{8 5}(65 \% Z$ ) vs $\mathbf{8 6}(75 \% Z$ ), respectively). Furthermore, because the microscopic reverse of RCM is ethenolysis reaction, we successfully isolated $E$-macrocycles via selective ethenolysis of $Z$-macrocycle isomer from an $E / Z$ mixture using the same catalyst.

We have investigated $Z$-selective RCM of olefinic amino acids for the synthesis of "stapled" peptides of varying sizes. ${ }^{104,105}$ Prior to this report, the ability to control olefin geometry (i.e., $E$ vs $Z$ isomers) was a challenge during synthesis, and separation of the isomers were infeasible. Upon catalyst screening, we show that nitrato-ligated cyclometalated Ru-5-IV and $\mathbf{R u - 5 - V}$ catalysts can be used to constrain resin-supported peptides from the $i$ to the $i$ $+2, i+3, i+4$, and $i+7$ residue positions. In search for an optimal resin, we found that resins bearing hydrophilic linkers, such as MBHA, led to increased conversions. Under optimized conditions, we synthesized the one a-helical turn-favored $i$ to $i+4$ peptide macrocycle 92 at $75 \%$ conversion and $>90 \% Z$-selective, after subjecting the resin-bound precursor to two cycles of catalyst addition. We investigated the synthesis of $\mathbf{9 3}$, a peptide constrained at the $i, i+7$ positions favoring two a-helical turns. Under optimized conditions, $85 \%$ conversion and $>90 \% Z$ selectivity was achieved. Efforts to synthesize the $Z$ isomers of the more constrained $i$ to $i+2$, or $i$ to $i+3$ olefin crosslinks proved more challenging. 105 Two example of such efforts - RCM to form $\mathbf{9 0}$ (41\% yield, 93\% Z) and $\mathbf{9 1}$ (30\% yield, $90 \%$ $Z$ ) resulting in the desired product, albeit in low yields. Lastly, we also show that the ringclosing metathesis-ethenolysis approach to isolating $E$ - and $Z$ - macrocycles can also be used in the stereoselective synthesis of $E$ - and $Z$ - macrocyclic peptides.

3.1.6. Asymmetric RCM (ARCM)—A considerable amount of our efforts have gone towards ARCM catalyst development and synthetic applications. Products of ARCM are useful in target-oriented synthesis since two differentiated olefins are present in the final enriched product. We recently reported the ARCM of prochiral trienes (Table 7). ${ }^{106}$ Catalyst screening showed that nitrato-chelate cyclometalated catalyst Ru-5-IV (see Figure 1) was most effective in affording reactivity and selectivity. Some general observations were gleaned from the study: (1) Monosubstituted olefins cyclize readily, resulting in high yields. (2) Increasing bulk from dimethyl siloxy (94) to diphenyl siloxy (95) resulted in slower cyclization. (3) Trisubstituted olefins (96) did not undergo ring closure. (4) Saturated nitrogen containing heterocycles (98 and 100) were formed in high yields and enantioselectivities.

3.1.7. Tetrasubstituted Olefins-Ring-closing metathesis to form hindered tetrasubstituted olefins using ruthenium-based catalysts is a synthetic challenge. In the course of our work on Ru-catalyzed enantioselective metathesis, we unexpectedly isolated a five-membered ring containing a tetrasubstituted olefin when using a ruthenium catalyst lacking ortho substituents on the NHC N-phenyl rings. We then reported a series of ruthenium catalysts (Ru-2-VII, Ru-2-IV, Ru-2-VIII, and Ru-2-IX), with NHC phenyl rings with reduced bulk at the ortho position that were efficient in inducing ring-closing of 
tetrasubstituted olefins. ${ }^{32,107}$ Whereas ring-closing using Ru-2-I took 24 hours to achieve poor to moderate conversion of 1,1-disubstituted substrates, with Ru-2-IX 88-95\% conversion was observed in $<1$ hour for many of the reactions. For example, the standardized reaction 3 in Table 5 proceeded in 100\% isolated yield using Ru-2-IX (5 mol $\%$ ) in benzene at $60{ }^{\circ} \mathrm{C}$ within an hour. ${ }^{107} \mathrm{We}$ proposed that the remarkable increase in catalytic activity is a result of the reduced steric bulk around the NHC ligands, thus improving the ability of the catalyst to accommodate the steric bulk of tetra-substituted olefins.

In collaboration with Stoltz and coworkers, we reported an efficient and general strategy for the total synthesis of (+)-elatol 103, a member of the chamigrene family, which is a subclass of sesquiterpenes. ${ }^{108}$ Elatol has been shown to display antibiofueling, antibacterial, and antifungal activity, as well as cytotoxicity against HeLa and Hep-2 human carcinoma cell lines. We harnessed methodology developed in both of our labs for synthesizing elatol, namely enantioselective decarboxylative allylation of vinylogous ester derivatives and RCM of chlorinated, tetrasubstituted olefins using the newly discovered Ru-2-IX. When a, $\omega$ diene $\mathbf{1 0 1}$ was subjected to RCM using Ru-2-Z, the desired fully-substituted chloroalkene 102 was formed in $97 \%$ yield. Subsequent acid-mediated elimination and hydrolysis, bisbromination, and DIBAL reduction yielded (+)-elatol 103 (Figure 23).

\subsection{Cross-Metathesis (CM)}

Over the years, olefin cross metathesis has become a powerful technique in organic chemistry for synthesizing complex, functionalized olefins from simple alkene precursors. ${ }^{109}$ However, in the early 2000's, cross metathesis was underrepresented in the literature compared to ring-opening metathesis polymerization and ring-closing metathesis due to the difficulty in achieving product selectivity, stereoselectivity, and high catalyst activity in effecting productive metathesis. The enthalpic driving force, such as ring strain that drives ring-opening cross metathesis, or the entropic driving force such as the intramolecular process for ring-closing metathesis is notably absent in cross-metathesis reactions. Despite these challenges, cross metathesis is now regarded by synthetic organic chemists as a reliable method for functionalizing simple and complex olefins, as well as for complex fragment coupling reactions. For example, since the introduction of acrolein-based CM reactions in $2000^{110}, \alpha, \beta$-unsaturated aldehydes and related derivatives have been utilized in these three applications (Figure 24). In their efforts to further develop efficient syn-1,3 diol syntheses, Evans and coworkers have reported a high-yielding coupling of acrolein with homoallylic alcohol 104, a reaction catalysed by Ru-2-II and proceeding to form olefin 105 in near-quantitative yield after in situ alcohol protection (Figure 24A). ${ }^{111}$ Krische and coworkers' 20-step (+)-roxaticin total synthesis used acrolein and Ru-2-II to functionalize an advanced intermediate to form olefin 106 in 52\% yield (Figure 24B). ${ }^{112}$ Finally, advanced intermediate 109 in Phillips and coworkers' norhalichondrin B synthesis was prepared in 62\% yield by Ru-2-IX coupling of enone 107 with allylic alcohol 108 (2 equiv) at elevated temperatures in 1,2-dichloroethane (Figure 24B). ${ }^{113}$ 


\subsection{A General Model for Selectivity in Olefin Cross Metathesis}

We developed rules for predicting product selectivity and stereoselectivity in olefin cross metathesis reactions. ${ }^{25}$ We investigated several classes of olefins, including styrenes, secondary and tertiary allylic alcohols, and generated four classifications of olefins based on their ability to undergo homodimerization (Figure 25): (1) "Type I" olefins are those that undergo rapid homodimerization, (2) "Type II" olefins undergo slow homodimerization, (3) "Type III" olefins do not undergo homodimerization, and (4) "Type IV" olefins are inert to cross metathesis and do not deactivate the ruthenium catalyst. Several olefin cross metathesis reactions performed with olefins within and between categories led to three rules for predicting product selectivity.

\subsubsection{Non-selective cross metathesis between two olefins of type I (Figure 26)}

-With two type I olefins, the rates of homodimerization are similar and reactivity of resulting homodimers and cross products are high. In this scenario, equilibration of cross products with homodimers yields a statistical product mixture. To afford cross-metathesis product selectivity of over $90 \%$, an excess of 10:1 for one olefin precursor over the other must be used.

An example of nonselective cross metathesis between type I olefins can be readily observed in the reaction between allylbenzene $\mathbf{1 1 0}$ and allylic alcohol $\mathbf{1 1 1}$ using ruthenium catalysts Ru-1-I or Ru-2-I (Figure 27). 2:1 equivalent of $\mathbf{1 1 1}$ to $\mathbf{1 1 0}$ yielded cross-metathesis product 112 in $80 \%$ yield.

3.3.2. Selective Cross-Metathesis - In the same vein, any cross-metathesis reaction between olefins of the same type will yield non-selective products. Therefore, to avoid this inefficiency, one can design a cross-metathesis reaction with olefins of two different types to take advantage of the differing rates of homodimerization to afford product selectivity.

3.3.3. Selective cross metathesis between type I and type II olefins-In reactions between type I and type II olefins, the type I olefin may initially undergo rapid homodimerization, precluding direct CM with the type II olefin, and releasing ethylene as a byproduct. The product type I homodimer will also readily undergo rapid CM with the type II olefin, releasing one equivalent of type I olefin for further CM. This results in an equilibrated mixture of type I homodimer and cross products. Product distribution can however be driven toward cross product as ethylene is driven from the system. Furthermore, the inability of the catalyst to convert cross product to the type II homodimer in a secondary metathesis event prevents the erosion of product seclectivity. For example, in the reaction between type I 5-hexenyl acetate $\mathbf{1 1 3}$ and type II $\alpha, \beta$-unsaturated ester 114, ${ }^{110}$ cross product $\mathbf{1 1 5}$ is formed with high product selectivity and stereoselectivity (Figure 28).

\subsubsection{Selective cross metathesis between type I and type II vs type III olefins}

-Earlier studies showed that using first generation ruthenium catalyst Ru-1-I, fully substituted allylic centers/quaternary centers were insusceptible to cross metathesis, and did not disrupt catalyst activity (i.e., classified as Type IV with Ru-1-I). ${ }^{114}$ However, with second generation Ru-2-I, product selectivity and excellent stereoselectivity for the $E$ - 
isomer is achieved (i.e., classified as Type II/III with Ru-2-I, see Figure 29). For example, reaction between 113 and unprotected tertiary alcohol $\mathbf{1 1 7}$ results in up to 93\% yield of cross metathesis product 120, where only the trans isomer is observed by ${ }^{1} \mathrm{H}$ NMR. Introduction of steric bulk protecting the tertiary alcohol (i.e., 118) results in almost exclusive formation of cross-product 121 (97\% yield). We rationalized that the greater steric bulk results in initial trans product formation, and cross-product is completely hindered against secondary metathesis events that may erode product selectivity.

3.3.5. Synthesis of vinyl boronates-We reported a general strategy for the synthesis of a variety of vinyl boronates, ${ }^{115}$ which most notably are excellent cross-coupling partners. 116-120 Importantly, this strategy was used in the preparation of $\beta, \beta$-disubstituted vinyl boronates, which cannot be synthesized by alkyne hydroboration, an alternate route for vinyl boronate synthesis. Upon realizing that 1-propenyl pinacol boronate (BPin) 123 was easier to prepare and isolate than vinyl boronate 122, we utilized it and the more hindered 2isopropenyl pinacol boronate $\mathbf{1 2 4}$ in cross-metathesis with a variety of olefins, including styrenes, 1,1-disubstituted olefins, and tertiary allylic alcohols (Table 8). Yields and stereoselectivities ranged from good to excellent $(60-91 \%, E / Z 10: 1)$. We also showed that the $E$-boronates can be converted to $Z$-vinyl bromides via in situ bromination procedure, and into $E$-vinyl iodides via an analogous iodination procedure, thus affording the stereoselective formation of $E$ and $Z$ vinyl halides (Table 8, entries 1 and 2). Components of Suzuki and many other metal-catalyzed coupling reagents are thus formed simply from an alkene metathesis reaction.

Burke and coworkers introduced the CM-active vinyl $N$-methyliminodiacetic (MIDA) boronate $\mathbf{1 2 5}$ as a bench- and silica-gel stable boronic acid derivatives. ${ }^{121}$ This reagent was used by Fürstner and coworkers to prepare Suzuki coupling partner 130 using CM in $81 \%$ yield in their 2012 synthesis of leiodermatolide. ${ }^{122}$

Stoltz and coworkers' (-)-cyanthiwigin F synthesis used a sequential one-pot RCM/CM process catalysed by Ru-2-IX to rapidly form a trisubstituted seven-membered ring (30 $\mathrm{min}$ ), followed by vinyl BPin installation using 5 equivalents of vinyl boronate $\mathbf{1 2 2}(20 \mathrm{~h})$. Treatment of silica-gel plug-purified material with aqueous sodium perborate provided the requisite aldehyde $\mathbf{1 3 5}$ in $51 \%$ isolated yield (Table 8, entry 6). ${ }^{123}$ Finally, boronate 137, an intermediate in Menche and coworkers' rhizopodin total synthesis, was prepared in $90 \%$ yield by $\mathrm{CM}$ with vinyl boronate $\mathbf{1 2 3}$ and oxazole 136 using $\mathbf{R u}-2-\mathrm{II}$ in $\mathrm{CH}_{2} \mathrm{Cl}_{2}$ at $50{ }^{\circ} \mathrm{C}$ (Table 8 , entry 7). ${ }^{124}$

3.3.6. CM with conjugated dienes-We extended this strategy to the chemoselective $\mathrm{CM}$ with conjugated dienes. ${ }^{125} \mathrm{We}$ found that chemoselectivity can be achieved by installing either electron-withdrawing groups or steric bulk at one of the olefin sites, which deactivates the vicinal olefin and hinders metathesis at that site. In the course of optimizing electronic parameters, we found that the use of ethyl sorbate 139 and 5-hexenyl acetate 140, in the presence of Ru-1-I, yielded the homocoupling product 138. That is to say ethyl sorbate $\mathbf{1 3 9}$ is too deactivated to react, making it a type IV olefin in the presence of Ru-1-I. In the presence of Ru-2-I however, both olefins of the diene were subject to cross-metathesis, 
indicating that with Ru-2-I, the ester on $\mathbf{1 3 9}$ was sufficiently electron-withdrawing to selectively deactivate the vicinal olefin.

Using Ru-2-I, we found that tuning the electronics of the ester by installing a vinylic bromide yielded products $143,144,145$, and 146 in good yields (48-70\%) and stereoselectivity (Z/E 6-10:1) (Table 9). We reasoned that bromide provided both electronwithdrawing functionality and steric bulk to the vicinal olefin, further deactivating the $\alpha, \beta$ double bond and hence facilitating cross-metathesis chemoselectivity. Encouraged by these results, we investigated the possibility of replacing the ester functionality altogether with bromide. We found that reactions between 1,1-dibromo-1,3-pentadiene and methyl acrylate resulted in modest yield of product, albeit excellent stereoselectivity $(\mathbf{1 4 7}, 39 \%$ yield, $>20: 1$ ); an increase in yield (60\%) was observed between 1,1-dibromo-1,3-pentadiene and styrene to form 148.

To probe further the effects of steric bulk on chemoselectivity, we reacted various 2substituted 1,3-butadienes with functionalized olefins (Table 10). These transformations were performed in benzene solvent and at elevated temperatures to achieve conversion. Products formed in good yields and high chemoselectivity and diastereoselectivity. In fact, only the $E$ product isomer was observed in solution.

3.3.7. Z-Selective $\mathbf{C M}-$ We reported the first $Z$-selective homodimerization of terminal olefins using Ru-5-II (Figure 31A). Homodimerization of terminal olefins results in the release of ethylene, which serves to decompose the catalyst. However, through the efficient removal of ethylene from solution, homodimerization is robust - resulting in high conversions and $Z$-selectivity for a variety of terminal olefin substrates, including challenging alcohol substrates. ${ }^{58}$

We further explored the general use of chelated ruthenium catalyst Ru-5-IV for complete $Z$ selective and chemoselective CM between terminal olefins and non-conjugated dienes (Figure 31B). A strong chemoselective preference for the terminal alkene in the crossmetathesis reactions, and high $Z$-selectivity of $>95 \%$ were observed. In a series of CM with trans-1,4-hexadiene (159), a wide scope of functionalized terminal olefins carbonyls, aldehydes, ketones, esters, alkyl amines, and boronic acids - were all tolerated. ${ }^{126}$ In one application, we demonstrated concise syntheses of nine lepidopteran pheromones from renewable seed-oil derivatives using mild, economical, and safe processes ${ }^{61}$ For example, $Z$-selective CM of seed-oil-derived oleyl alcohol (158) and hexadiene 159 provided unconjugated diene 160 and only trace quantities of olefin 162, formed from internal bond CM of hexadiene Y (Figure 31C). Diene alcohol 160 and acetylated derivative 161, made in two steps, are both sex pheromones capable of disrupting the mating behaviour of the olive pyralid moth, a pest native to areas of Europe and North Africa. Previous syntheses required at least six steps from commercial materials. ${ }^{127}$

Allylic substituted olefins create a significant challenge to $Z$-selectivity due to the increased steric bulk around the olefin, which further destabilizes the cis over the trans conformation of the carbon-carbon bond. ${ }^{128}$ We reported the use of nitrato ligated Ru-5-IV to afford $Z$ selective cross-metathesis of terminal olefins with a variety of allylic-substituted olefins 
(Figure 31D). ${ }^{129}$ Notably, in cases such as vinyl pinacol boronates, important cross-coupling reagents, where high $E$-selectivity have been afforded with Ru-1-I, $Z$-cross product was achieved with up to $92 \%$ Z-selectivity using Ru-5-V.

In collaboration with Houk and coworkers, we studied the highly chemoselective, $Z$ selective cross-metathesis of dienes to alkenes (Figure 31E). ${ }^{130}$ This reaction takes advantage of the pronounced $Z$-selectivity observed when cyclometalated ruthenium catalysts (Ru-5 catalysts, see Figure 1) are employed. Mechanistically, two pathways are envisioned where the active Ru-alkylidene adds to either the diene or alkene as the first propagation step (Figure 32). Computations using propene and $E-1,3$-pentadiene as a model showed that the diene-first pathway is favored over the alkene-first pathway. Following initial olefin addition to the ruthenium, either productive cross-metathesis with the substrate alkene or non-productive diene homodimerization may occur. However, the cross-metathesis pathway is favored by $3.5 \mathrm{kcal} / \mathrm{mol}$ over dimerization. These computations are consistent with the experimentally-observed product selectivity.

3.3.8. E-Selective $\mathbf{C M}-$ Trans-olefins are thermodynamically preferred in non-selective olefin metathesis reactions. Trans-olefins can be isolated in high purity via achieving equilibrium, followed by $Z$-selective ethenolysis/alkenolysis. ${ }^{50,131}$ However, the use of equilibrium mixture as starting material limits the overall yield of $E$-olefin product, and ethenolysis/alkenolysis adds an extra step in the purification process. We reported the first highly-controlled, highly trans-selective olefin cross-metathesis reaction using dithiolateligated ruthenium complexes (see Ru-6 catalysts in Figure 1). ${ }^{132}$ These Ru-6 catalysts were shown to achieve catalysis through stereoretention of the starting material. In one example shown below, all four catalysts were evaluated for efficiency in the demanding crossmetathesis of 1-decene 163 and cis- or trans- 4-octene 164 (Table 11). Using Ru-6-II, the reaction between $\mathbf{1 6 3}$ and cis-164 afforded cis-165 in high Z-selectivity; reaction with trans-164 afforded trans-165 in low yield and moderate $E$ selectivity. We found that the slightly reduced steric bulk at the ruthenium NHC aryl ortho position (i.e., from an isopropyl in Ru-6-II to a methyl in Ru-6-I) resulted in improved stereoretention. Of note, replacing the ortho methyl groups with the much smaller fluoro group on the ruthenium catalyst (i.e., using Ru-6-III and Ru-6-IV) significantly increased $E$ selectivity in the reaction. These findings support the proposed model whereby trans-olefinic substrates are increasingly compatible with catalysts as steric encumbrance is reduced.

3.3.9. Glycopeptide-based CM-In collaboration with Kwon and co-workers, we reported, the solid-phase synthesis of glycopeptioids using CM chemistry. ${ }^{133}$ Peptoids with various side-chains were prepared on beads and alkenyl components were positioned at different chain lengths. Using Hoveyda chelate ruthenium catalyst Ru-2-II, cross metathesis of a peptoid with 20 equivalents of mannose, galactose, or glucose was achieved with up to $51 \%$ conversion (Figure 33).

3.3.10. Template-Driven CM-We reported, in collaboration with the Stoddart and Tirrell groups, the template-driven dimerization of dibenzo[24]crown-8 derivative (Figure 34). ${ }^{134}$ The template consists of two dialkylammonium ion sites allowing for the recognition 
and preorganization of two crown ether molecules for efficient acyclic diene metathesis (ADMET). We expected that the two olefin sites on the crown ether derivative would afford polymerization. However, when a $1 \mathrm{mM}$ solution of $\mathbf{1 6 7}$ in DCM was exposed to Ru-2-1 or Ru-2-2, the dimer was formed (Figure 34). Nonetheless, we observed an increase in both rate of dimerization and yield of dimerized product in the presence of dialkylammonium complex 166.

3.3.11. Ethenolysis-Ruthenium catalysts used in the CM reaction between internal olefins and ethylene (i.e., ethenolysis) are effective in producing desired low molecular weight products from renewable seed oils. Limited product selectivity and poor conversion have hampered the commercial use of this process. The use of microchemical systems provides effective strategies to overcome these challenges on an industrial scale. When reaction variables, such as surface area-to-volume are tightly controlled, waste is reduced, yields are maximized, and reaction times are reduced. Furthermore, the challenges of scaleup synthesis are avoided and replaced by parallelization of small-scale microfluidics. Consecutive reactions, such as separation, purification, and detections, can be integrated to complete the microchemical process. ${ }^{135-137}$ In collaboration with Kim and co-workers, we reported a facile and efficient microchemical ethenolysis, through a continuous segmented flow of ethylene gas and methyl oleate $\mathbf{1 6 8}$ in a capillary tube with a $0.5 \mathrm{~mm}$ inner diameter. 138 At 60 psi of ethylene, the ethenolysis efficiencies were comparable to the results of batch reactions at $150 \mathrm{psi}$. Of the catalysts explored (see Table 12), CAAC-supported ruthenium metathesis catalyst Ru-4-I (50 ppm) yielded the largest turnover number (TON $=27200)$, and gave $80 \%$ conversion and $87 \%$ product selectivity.

More recently, in collaboration with Bertrand and coworkers, we reported several new CAAC-supported ruthenium catalysts for the ethenolysis of methyl oleate using. ${ }^{47}$ Remarkably, most of these catalysts supported a turnover of over 100,000 with catalyst loading of only $3 \mathrm{ppm}$. Of note, using just $1 \mathrm{ppm}$ of Ru-4-III and 99.995\% pure ethylene source, we were able to achieve catalyst turnover of up to 340,000 - the highest reported value for ethenolysis to date!

AROCM of norbonene derivatives: We reported a homochiral stereogenic-at-ruthenium complex Ru-5-II capable of asymmetric ring-opening-cross-metathesis of norbonene derivatives with high enantioselectivity. ${ }^{139}$ A variety of terminal olefins and norbonene derivatives were studied to determine their effect on efficiency, diastereoselectivity, and enantioselectivity (Table 13). Product yields ranged from $40-65 \%$ for all reaction entries. $Z$-selectivity and enantioselectivity were not appreciably affected by the steric or electronic nature of the terminal olefin substituents. Also, substitution at the norbonene did not significantly affect $Z$-selectivity or enantioselectivity. However, of note a significant erosion of $Z$-selectivity is seen in the formation of aryl ether 182, albeit with high enantioselectivity (95\% ee). Both $Z-\mathbf{1 8 2}$ and $E-\mathbf{1 8 2}$ were formed with identical high ee, strongly supporting the rationale that the enantiodetermining step in this reaction precedes the olefin geometrydetermining step. 


\section{Ring Opening Metathesis Polymerization (ROMP)}

The application of olefin metathesis to the synthesis of macromolecular materials has been most successfully and broadly demonstrated by way of ring-opening metathesis polymerization (ROMP). ROMP is a chain growth polymerization process by which cyclic olefins are converted to unsaturated polymeric material via the Chauvin mechanism. Among many others, our group has worked extensively to advance the utility of ROMP by developing well-defined, functional group tolerant catalysts. We reported the first titanacyclobutane system capable of mediating living ROMP, and the first well-defined, single-component ruthenium-based complex capable of catalyzing ROMP in the presence of heteronuclear and protic functionalities. ${ }^{140,141}$ These developments, together with those contributed by Yves Chauvin, Schrock and countless others, have established ROMP as a powerful tool for accessing polymeric materials of complex architecture, functionality, and size with unprecedented precision and ease. While this review focuses exclusively on those innovations set forth by our group since 2005, numerous more comprehensive reviews have been previously published on early ROMP catalyst development ${ }^{142-144}$ and emergent applications ${ }^{145,146}$ thereof.

\subsection{Implications of Ruthenium ROMP Thermodynamics and Kinetics}

The ROMP reaction is thermodynamically governed by the Gibbs Equation, $\Delta \mathrm{G}=\Delta \mathrm{H}-$ $\mathrm{T} \Delta \mathrm{S}$, whereby enthalpic gains, associated with release of strain energy upon ring opening, drive the reaction forward, while entropic penalties curb the polymerization. For this reason, ideal ROMP candidates are typically widely-available cyclic olefins with excessive ring strain (e.g. norbornene (NBE), cyclobutene, dicyclopentadiene). In the case of low-strain cyclic olefins, the enthalpic reward from ring opening is often insufficient to offset the loss of entropy intrinsic to polymerization. Developing strategies for ROMP of low strain materials is thus not only an inherently challenging task, but a necessary one in order to establish ROMP's versatility and utility in accessing polymeric materials with useful electronic, biological, and mechanical properties.

Traditionally, this challenge has been overcome by reducing the temperature of the reaction and employing a highly active, early transition metal-based catalyst in high concentrations to compensate for the resulting retardation of equilibrium kinetics. However, this approach is not viable for low strain starting materials bearing polar substituents, to which the highly active catalysts tend to be intolerant. Unlike catalysts based on early transition metals such as tungsten and molybdenum, fast initiating Ru-alkylidene Ru-3-II demonstrated both high ROMP activity and functional-group tolerance, affording the previously unrealized living ROMP of 5- and 7-membered cyclic olefins bearing polar symmetrical substituents (silyl ether 183, ketone 184, and ether 185). ${ }^{147}$ (Table 14)

Ru-mediated ROMP of low strain monomers has found high utility in enhancing the ease and precision with which commercially relevant materials can be produced to scale. Our group has demonstrated the production of well-defined poly(vinyl alcohol) (PVA) copolymer derivatives by ROMP of two functionalized, low strain moieties- 3cyclopenten-1-ol and 5-cyclooctene-1,2-diol. In the former case, ROMP of unprotected 3cyclopenten-1-ol followed by ADMET of non-protected 1,6-heptadiene-4-ol gave rise to 
well-defined poly(vinyl alcohol-alt-propenylene) copolymers with high polarity and precise distribution of the hydroxyl functionalities. Moreover, these copolymers could be accessed in a single-pot synthesis, affording a desirable commercial alternative to the multi-step procedures traditionally employed. ${ }^{148}$

We later reported the synthesis of a highly analogous ethylene vinyl alcohol (EVOH) copolymer by ROMP of 1,2-cis- and 1,2-trans-cyclooctenediol monomers. Protection of the monomer diols as acetates, carbonates, or acetonides conferred a temporary increase in the system strain, affording high yield polymers by Ru-1 and Ru-2 mediated ROMP. Postpolymerization hydrogenation and deprotection gave ethylene-vinyl alcohol (EVOH) copolymers with stereo- and regio- regularity. ${ }^{149}$

In other cases, however, the relatively low polymerizability of low-strain systems has proven advantageous. For example, the equilibrium ROMP of cyclopentene offers a clean route by which durable elastomeric polypentamers may be both synthesized and recycled via the same Ruthenium catalyst system. This potential application is possible on account of the extraordinarily low thermodynamic activation enthalpy and entropy unique to Rualkylidenes. For these polymerizations, the overall cyclopentene conversion is sensitive only to the temperature of the reaction, and independent of the catalyst loading or the catalyst activity. The polymerization/depolymerization equilibrium is thereby readily and cleanly manipulated by temperature control in the presence of a single well-defined catalyst and could find potential commercial application in the environmentally friendly synthesis/ recycling of rubber analogs. ${ }^{150}$

More recently, in collaboration with the Choi group, we exploited the low ROM polymerizability of cyclopentene in the development of a novel method, multiple olefin metathesis polymerization (MOMP), by which all three olefin metathesis transformationsring-opening, ring-closing, and cross metathesis - are combined in a one-pot reaction to afford an A,B-alternating copolymer. ${ }^{151}$ Well-defined reaction pathways were achieved by strategic design of dicyclopentene monomers capable of undergoing simultaneous ringopening/ring-closing methathesis without significant thermodynamic bias towards one or the other. CM with diacrylate comonomers yielded A,B-alternating copolymers of uniform microstructure.

While low-strain cyclic olefins pose a challenge due to their low activity, unhindered alkenes have proven problematic on behalf of their unquenchable activity. In particular, the living ROMP of cyclooctene (COT) $\mathbf{1 8 5}$ to high MW polymeric materials has been historically frustrated by high rates of competing secondary metathesis on the flexible poly(COT) backbone. We showed that chain transfer associated with secondary metathesis of the unhindered backbone could be quenched nearly entirely by carrying out the Ru-1-I mediated polymerization in the presence of $\mathrm{PPh}_{3}$, a known suppressant of secondary metathesis, and a strongly coordinating solvent such as THF. ${ }^{152}$ (Table 14) Under these conditions, we demonstrated the first "living" ROMP of trans-COT as well as its protected hydroxy-functionalized derivatives and a variety of poly(NBE)-poly(COT) block copolymers. 


\subsection{Control of Polymer Microstructure in Ruthenium ROMP}

The stereochemical and regiochemical makeup of a polymer, often referred to as the polymer 'microstructure', is widely known to have dramatic influence on its physical and mechanical properties (e.g. melting point, crystallinity, etc.). A tremendous amount of research has therefore been devoted to developing methods capable of producing polymers with highly controlled microstructure, and in turn, macroscopic properties. For ROMP polymers, this effort has focused mainly on controlling the double bond configuration of the unsaturated backbone, and to a lesser extent, on controlling the polymer tacticity (isotactic v. syndiotactic) and relative configuration of dyad substituents (head-head $(\mathrm{H}-\mathrm{H})$, head-tail (HT), or tail-tail (T-T)) for polymers comprised of asymmetrically substituted monomers.

In 2012, we reported the use of Ru-5-IV to catalyze the ROMP of nine tested monomers to yield polymers of $48-96 \%$ (average: $80-95 \%$ ) cis stereochemistry, essentially qualitatively reversing the stereoselectivity of Ru-1-I. ${ }^{153}$ Shortly thereafter, we reported the use of Ru-5III, which unlike Ru-5-IV, demonstrated the capacity to mediate both polymer tacticity and stereochemistry, yielding polymers of high cis (62-95\%) character and near total syndiotacticity (>95\%). ${ }^{154}$ Notably, this system marked the first example of a ruthenium alkylidene complex capable of producing from olefin 186 a norbornene-derived polymer characterized by $>95 \%$ of a single microstructure. (Figure 35) We attribute the unique capacity of Ru-5-III to control polymer tacticity to the reduced steric bulk of the cyclometalated $\mathrm{N}$-t-butyl group as compared to the bulky $\mathrm{N}$-adamantyl chelate in Ru-5-IV.

We next explored the possibility of achieving enantiomerically pure ROMP products by kinetic resolution - a methodology that exploits the kinetic preference of a catalyst to selectively polymerize one enantiomer in a racemic monomer mixture, giving rise to both a chiral polymer and enantioenriched population of the unreacted monomer. ${ }^{155}$ Catalytic enantioselectivity was imparted by Ru-2-X (see Table 2), a chiral (4R, $5 R$ )-diphenyl Nheterocyclic carbene that we had previously shown to give up to $92 \%$ ee in ARCM (vide supra). ${ }^{36}$ Despite displaying clear kinetic preference, the catalyst's resolution selectivity (S) was found to change dramatically with the progression of polymerization, perhaps due to the increasingly dominant chiral secondary structure of the growing polymer. The trend of selectivity variance was also found to be solvent-dependent; resolution selectivity increased over the course of polymerizations performed in THF/DCM and decreased for those performed in toluene.

This recurrent, and thus far unaccounted for, inability to generalize methods of partially stereoselective ROMP across conditions and monomer types highlighted a lack of understanding in the mechanistic origins of cis selectivity and tacticity among Rualkylidenes. To this end, we initiated a detailed mechanistic investigation into the stereoselectivity of ROMP, relying heavily upon polymer microstructure as a sort of chronological "roadmap" of each catalytic cycle from which information on the propagation transition state could be gleaned. ${ }^{156}$

The ROMP of 2,3-dicarbomethoxynorbornadienes by eight stereoselective Ru-alkylidene catalysts produced polymers of predominantly cis, syndiotactic microstructure, with cis content varying from $68-99 \%$. A combination of computational and experimental evidence 
suggested stereoselectivity derives from stereogenic metal control at the Ru-alkylidene center. The prevailing cis, syndiotactic motif is mechanistically explained by step-wise inversion of the metallic center followed by the monomer's anti-approach (i.e. the approach in which the monomer bulk points away from the catalyst $\mathrm{N}$-aryl group). As a result, the incoming monomer is added to alternating sides of the $\mathrm{Ru}-\mathrm{C}$ double bond, giving a nearperfect cis, syndio-selectivity. Unlike cis-selectivity, HT bias among asymmetrically substituted monomers was found to be negligible in all tested cases. What little HT bias was observed, however, was highest for monomers polymerized at a faster rate - suggesting distinct propagating species with characteristic HT bias.

The origins of microstructural error were also investigated. The predominant erroneous motifs - trans, syndiotactic and cis, isotactic microstructures- were traced to anti or syn monomer addition to the higher energy syn alkylidene. Anti to syn isomerization of the alkylidene most likely occurs via rotation about the $\mathrm{Ru}-\mathrm{C}$ bond, as computational methods reveal non-metathesis isomerization to be energetically infeasible under relevant reaction conditions. Therefore, the prevalence of error was deduced to be intrinsically related to the relative time scales of propagation and alkylidene isomerization, with error being more pronounced when these rates are more comparable.

\subsection{Functionalized Polymers}

Our group has fabricated polymers bearing heteronuclear functionalities for use in imaging, biomedicine, photonics, and energy. Among the earliest of these examples, we synthesized tumor-targeted fluorine-18 functionalized nanoparticles for use as in vivo PET imaging agents. ${ }^{157}$ (Figure 36)

The well-defined, radiotraceable nanoparticles were synthesized in a multistep procedure starting with the Ru-3-I mediated ROMP of cinnamoyl and PEG-mesylate functionalized norbornenes 187 and $\mathbf{1 8 8}$, respectively. The resulting polymers exhibited highly controlled MWs and in turn, hydrodynamic diameters following self-assembly into discrete micelles. Micelles were readily cross-linked by a UV-induced [2+2] dimerization reaction at the cinnamoyl trans-olefins and subsequently functionalized with ${ }^{18} \mathrm{~F}$ by nucleophilic displacement of the mesylate group for PET imaging.

In addition to proving highly useful for the probing of biological systems, ROMP has allowed for greater simplicity in the fabrication of complex, biologically-inspired materials. Elastin like peptides (ELPs) have been among the most attractive of these targets for synthetic chemists given the highly unique, dynamic physical properties of tropoelastin - the chief component of human blood vessels. In particular, chemists have sought to synthetically replicate the temperature-responsive behavior of tropoelastin. Non-crosslinked tropoelastin undergoes a conformational change marked by a phase transition at a precise temperature known as the lower critical solution temperature (LCST), below which the protein is insoluble. This property is essential to the protein's characteristic elasticity and has proved challenging to reproduce synthetically. Specifically, the success of synthetic ELPs has been frustrated by the inability to access MW-independent LCSTs, a problem that is exaggerated in the case of polydisperse materials. 
We thus investigated the potential of ROMP to afford a narrowly dispersed ELP with a MWindependent LCST. ${ }^{158}$ To this end, we synthesized a polynorbornene copolymer bearing PEG $_{5}$ and ELP pendant sequences. (Figure 37) The LCST of the near-monodisperse polymers was independent of MW when the polymer was synthesized as a random copolymer with hydrophilic PEG $_{5}$ co-monomers. Moreover, the LCST of the ELPs could be predictably tuned by altering the feed ratio of the monomers. As such, this ROMP-based approach affords a facile route to ELPs exhibiting controllable temperature-responsive behavior with previously unattainable reproducibility.

\subsection{Surface-Functionalized Polymers}

The ability to tolerate a wide range of heterofunctionalities lends itself well to the incorporation of interesting linkage chemistries, including those well-suited for the surface immobilization of polymers. Our group reported the first "universal method" for surfaceinitiated ROMP (SI-ROMP) in $1999 .{ }^{159}$ Since then, we and others have explored the utility of SI-ROMP for applications in fields such as energy, photonics, biology, and medicine. 160,161 One of the most promising applications of SI-ROMP has been the fabrication of polymer dielectric layers for organic thin film transistors. ${ }^{162}$ (Figure 38) The integration of organic materials in electronic devices has driven their miniaturization, increased affordability, and streamlined production. Typically, organic polymers are incorporated into electronic devices such as FETs (field-effect transistors) as thin dielectric layers deposited on metallic surfaces by way of spin-coating, ink-jet printing, or screen printing. However, these methods-which require harsh conditions and lengthy reaction times-yield surfaces that are often dilute and non-conformal in topology, rendering the overlaying semiconductor ineffective in bridging the FET source and drain contacts. In contrast, SI-ROMP (surfaceinitiated ROMP) allows for the production of smooth, pinhole-free surfaces accessible under much more rapid, mild conditions. Moreover, film thickness, an essential parameter of the dielectric, is readily tuned by altering the identity of the surface tethered catalyst, the reaction time, or some combination thereof.

\subsection{Telechelic Polymers}

Liquid Crystal (LC) elastomers and gels have attracted much attention on account of their high flexibility and responsiveness to stimuli such as heat, light, and electric/magnetic fields. However, the challenge of accessing LC elastomers and gels of precise, well-defined microscopic architecture has impeded fundamental understanding of the structure-property relationships characteristic of these materials. We envisaged a ROMP-based approach to the fabrication of LC gels with unprecedented control. ${ }^{163}$

ROMP-derived telechelic polymers were shown to give rise to well-ordered, controlled LC gels following click-chemistry mediated crosslinking. (Figure 39) The microscopic architecture of LC networks could be tuned with respect to cross-linker functionality, intercross-links strand length, and mesogen density. The reported LC gels accessed via ROMP also displayed desirable swelling behavior and rapid, reversible, low-threshold optic switching that could be predictably tuned by altering the length of the telechelic polymers. This novel route to well-defined, tunable LC gels serves both to elucidate the microscopic 
origins of their physical and mechanical properties, as well as to facilitate the facile production of LC gels with pre-selected properties.

\subsection{Supramolecular Polymers}

The extension and contraction of fibers is an intriguing natural motif with many potential applications in material science, particularly as molecular actuators. Fabrication of macromolecular networks coordinated by reversible, supramolecular interactions has been demonstrated as a viable approach to these systems, albeit one plagued by much synthetic challenge. One of the most promising synthetic routes to these switchable networks has been the incorporation of [c2]daisy-chain dimers (DCD) into polymers. The so-called 'daisychain polymers' are mechanically interlocked, rotaxane based macromolecules formed from the polymerization of macromers - bifunctional monomers possessing both host and guest functionality. Previous reports of [c2]daisy-chains relied upon irreversible bond formation to mechanical interlocking neighboring macromers. Unfortunately, this approach yields a product distribution favoring the kinetic, cyclic dimer product instead of the linear chain. In an effort to avoid this, we employed reversible ring closing metathesis (RCM) as the final stoppering event between macromers. ${ }^{164}$ This dynamic covalent chemistry-in this case, equilibirum-controlled metathesis - affords a new means by which the resulting product distribution can be biased toward the thermodynamically-favored linear chain. The highyield [c2]daisy-chains are readily functionalized as bisolefins to undergo acyclic diene metathesis (ADMET) polymerization. (Figure 40)

Following the synthesis of the mechanically-interlocked polymers in Figure 40, we sought to design a DCD characterized by enhanced stability in the contracted state- a requisite to engineering a 'stronger' molecular actuator. In an effort to do so, we envisaged a strongly coordinating biphenyl binding site between the macromer host and guest residues, expecting the functionality to promote dimer-dimer pre-assembly via $\pi$ - $\pi$ stacking interactions and facile threading afforded by the elongated, rigid linker. When incorporated into linear polymers, the obtained DCD exhibited excellent mechanical properties such as facile switching and particularly high stability in the contractile state, owing to strong coordination. Acyl protection of the ammonium guests increased the steric bulk of the residues, inducing slippage and thereby extension. Impressively, this extended conformation was concomitant with a $48 \%$ increase in size. ${ }^{165}$

Like DCD-polymers, polyrotaxanes represent yet another class of advanced supramolecular polymers. While the macromers of DCD-polymers bear host, guest, and stoppering functionality, each monomer unit of a polyrotaxanes is characterized by a single guest residue only; monomers are threaded, polymerized and the supramolecular polymers stoppered in a tedious succession of steps. Seeking an alternative, simplified approach, we developed a one-pot synthesis of polyrotaxanes that was both efficient and scalable. ${ }^{166}$ The reported approach employs a polymerizable ammonium bisolefin salt, dibenzo [24] crown-8 ether host, and end-capping chain transfer agent. The combination of efficient complexation and rapid equilibration of ADMET polymerization affords high yield polyrotaxanes (>80\%) up to $19.3 \mathrm{kDa}$ in $\mathrm{MW}$ in a single operation. Moreover, the polymers formed from simultaneous multicomponent threading, polymerization, and capping show no loss in 
threading efficiency (82\%) compared to those polymerized from discretely pre-assembled supramolecular monomers.

\subsection{ROMP of Cyclic Polymers (REMP)}

For the larger part of ROMP's history, cyclic polymers have been accessible via ROMP only as unstable byproducts produced under dilute conditions. This, however, changed with the advent of Ring Expansion Metathesis Polymerization (REMP) and the associated development of REMP specific catalysts. Fürstner and coworkers reported the first $\mathrm{N}$-to-Ru tethered unsaturated NHC-based complexes ${ }^{167}$ and we subsequently demonstrated their use in polymerizations of cyclooctadiene to cyclic polybutadiene. ${ }^{168,169}$ We then prepared a series of saturated NHC-based cyclic Ru-alkylidene catalysts with enhanced stabilities and activities. ${ }^{170}$

The probing of four cyclic catalyst profiles revealed a high degree of kinetic tunability inherent to catalyst architecture. Catalysts bearing longer tethers were characterized by faster polymerization kinetics as compared to those with shorter tethers. The hindered kinetics of short tether catalysts could be attributed to high rates of catalyst release competing with propagation. Additionally, high intermolecular chain transfer among short tether catalysts indicated a step-growth polymerization mechanism, while longer tethered catalysts were shown to mediate chain growth polymerization.

We have used these catalysts to prepare cyclic dendronized polymers via REMP and have used atomic force microscopy to confirm their uniform cyclic topology (Figure 41). ${ }^{171}$

\subsection{Photoinitiated ROMP}

The ability to efficiently develop application-tailored derivatives of the parent Ru catalysts (Ru-1-I, Ru-2-I, Ru-3-I) has enabled technological advancements of ROMP across a diversity of fields. Among the highest impact and cross-sectional of these is photolithography - the process whereby UV light is used to cure a chemical pattern during the microfabrication of various materials, most notably integrated circuits. Despite the tremendous amount of work that has gone into developing this technique, the array of materials accessible by photolithography remains limited by the small functional diversity represented in commercially available photoresists, the light-sensitive chemicals from which a patterned surface coating is made.

Seeking a more versatile approach to patterned materials, we developed photolithographic olefin metathesis polymerization (PLOMP), a photolithography method employing a latent metathesis catalyst that reacts with olefins in the surrounding environment of the resist upon irradiation. ${ }^{172}$ The latent photocatalyst — a ruthenium vinyl ether complex 191 - is prepared by the ROMP of 1,5-cycloctadiene (COD, 189) with Ru-3-I, followed by quenching with ethyl vinyl ether 190 (Figure 42). 191 is widely recognized as being metathesis-inert However, we've shown that the catalyst activity can be regained upon exposure to UV light when under stabilizing conditions. With this in mind, we designed a viscous, olefin rich negative tone resist by dissolving 191 and poly(COD) in 5-ethylidene-2norbonene 192; this stabilized photocatalyst 191 by way of dative bonding. Exposure to UV 
light triggered the cross-linking of difunctional ROMP monomer 192 within the matrix of linear poly(COD) polymer. The protypical example demonstrates the synergistic utility of ROMP photoinitiation and functional group tolerance in the facile, one-pot fabrication of resists from which a novel family of photocurable materials could be developed.

\subsection{Bottle-Brush Polymers}

Bottle-brush polymers are novel class of macromolecules identified by their high MW, densely-packed side chains. This characteristic steric congestion forces the polymer backbone into an extended, wormlike conformation. The preparation of these unique structures is accomplished by one of three synthetic approaches. In the "grafting from" approach, monomers bearing initiation sites are polymerized and their macromolecular pendants grown directly from these sites. In the "grafting onto" approach, the polymer backbone and side chains are synthesized independently before grafting the pre-formed side chains onto the main chain polymer. In the "grafting-through", macromonomers are polymerized to yield brush polymers of complete (per-monomer) grafting.

Prior study of the Ru-1-I mediated graft through ROMP of brush polymers showed that while narrowly-dispersed, the resulting graft polymers suffered from low DPs. Having already demonstrated the capacity of Ru-3-I to catalyze the ROMP of bulky monomers with high activity, we investigated its potential to mediate the ROMP of norbornenepoly(methacrylate), poly(t-butylacrylate) and polystyrene macromonomers. ${ }^{173}$ Fastinitiating living polymerization yielded brush polymers of high $\mathrm{M}_{\mathrm{n}}$, narrow dispersity and high DP with characteristic worm-like morphology. (Table 15)

Furthermore, we demonstrated the adaptability of our approach to random and block copolymers, employing norbornene-based macromonomers bearing polyacrylate, polystyrene, and polylactic acid pendants. ${ }^{174}$ Again, the obtained polymers exhibited excellent precision and conversion. (Table 15) Unlike the brush homopolymers previously reported, however, the brush copolymers exhibited nanostructures that could be highly controlled by altering the ratios and distribution of co-macromonomers. While symmetric block copolymers (i.e., those formed from a 1:1 macromonomer ratio) formed well-ordered morphologies, asymmetric ones did not. The side-chains of block copolymers segregated into large lamellar domains the size of which could be predicted by the backbone length. In contrast, the side-chains of random copolymers arranged into lamellar domains the spacing of which was independent of backbone length, likely due to segregation of proximal domains on alternating sides of the backbone. These predictable morphologies have established graft through ROMP as a viable platform for bottom-up fabrication of discrete nanostructures with diverse applications.

Inspired by the ease with which graft through ROMP could be employed for the bottom up fabrication of polymeric structures with well-ordered morphologies, we set forth to investigate its potential application to syntheses of more advanced nantostructures. Specifically, we showed that a hybrid graft through-REMP methodology could be employed to access cyclic brush polymers with MWs among the highest yet reported for any graft/ brush polymers irrespective of structure. ${ }^{175}$ The ultrahigh MW polymers could be synthesized in a mild one-pot, single-step approach far simpler than those traditionally 
employed for the synthesis of cyclic dendrimers. Imaging techniques showed the cyclic nanostructures to have diameters ranging from $~ 100-180 \mathrm{~nm}$ - affording a novel class of cyclic structures roughly 14-40 times the size of standard cyclic dendronized polymers.

Undoubtedly, these novel, ordered nanoscale architectures afforded by graft polymers make these macromolecules excellent candidates for numerous applications, a sampling of which have been investigated by our group. First among these, we reported the use of bivalentbottle-brush polymers as synthetically accessible substitutes to PEGylated dendrimersnanoscale vehicles often employed for controlled delivery of chemotherapeutics with good success. Despite their efficacy, however, a facile synthetic route to accessing dendrimers with controlled size has yet to be reported. Alternatively, we showed that bivalent bottlebrush polymers - a sort of pseudo-alternating copolymer- loaded with an anticancer drug and PEG could be readily access by two approaches: graft through and "graft-through then click-to" ROMP. In the first of these, bivalent norbornene-PEG-drug macromonomers were prepared in advance of polymerization. ${ }^{176}$ In the latter, ROMP of bivalent norbornene-PEGchloride was followed by halide-azide exchange and subsequent copper-catalyzed azidealkyne cycloaddition ("click-to") of a photocleavable drug derivative to the polymer. ${ }^{177}$ (Figure 43) Both methods afforded polymers with tunable size $(6-50 \mathrm{~nm})$ and DP, permonomer drug loading, and stimuli-responsive (UV-triggered) drug release. Morphological characterization of the "graft-through then click-to" derived polymer revealed a unimolecular micelle morphology consisting of a hydrophobic drug core surrounded by a shielding corona of extended PEG moieties. EPR probing of these bivalent-brush polymers revealed greater structural homogeneity, increased rotational freedom of core bound hydrophobic pendants, and higher steric shielding from external reagents as compared to unbranched random copolymers of similar composition. ${ }^{178}$

In addition to their demonstrated suitability for biomedical applications, brush polymers have shown great promise in the fields of energy and photonics, most notably as photonic crystals (PCs). PCs are materials characterized by a periodic dielectric function whose photonic band gap elicits frequency-specific reflection. Fully realizing the potential of this unique property across a host of applications, however, requires an inexpensive, scalable method for the production of PCs with tunable frequencies of reflection.

Owing to the steric demand of their high MW side-chains, brush polymers are known to adopt elongated, linear conformations that reduce the incidence of multipolymer entanglement. ${ }^{179}$ In the absence of entanglement, the polymers readily self-assemble into ordered nanostructures with rapid equilibria. Self-assembly of brush block copolymers $(\mathrm{BCPs})$ into ordered structures with domains (uniform regions of stacked lamellae) $>100$ $\mathrm{nm}$ affords photonic crystals with reflection in the visible spectrum without the need for additives or complex swelling procedures required to achieve long wavelength reflectance in PCs fabricated from analogous linear BCPs.

In an effort to demonstrate the generalizability of this method, we reported the self-assembly of various brush BCPs into ordered nanostructures exhibiting tunable peak reflectances spanning the visible spectrum from ultraviolet (UV) into the near-infrared (NIR) region. For brush BCPs bearing more flexible macromonomers based on polylactides and polystyrene, 
peak reflective wavelengths as long as $540 \mathrm{~nm}$ could be achieved for PCs assembled under controlled evaporation and as long as $1311 \mathrm{~nm}$ for those assembled under thermal annealing compression. Impressively, substitution of these flexible macromonomers with ones based on rigid-rod isocyanate motifs facilitated the formation of large domains in the absence of thermal annealing, affording peak reflective wavelengths as long as $1120 \mathrm{~nm}$ under ambient conditions. ${ }^{180,181}$ In both cases, wavelengths of peak reflectance could be accessed by taking advantage of the linear correlation between polymer MW and the photonic bandgap of the crystal: a structure-property relationship unique to PCs formed from brush BCPs.

While this method affords a scalable route to PCs with application-tailored bandgaps, it necessitates the synthesis of a MW-specific block brush copolymer for each new wavelength of reflectance desired. To bypass this limitation, we developed a simple method of postsynthetically tuning the bandgap of brush copolymer PCs through blend ratios. By altering the relative compositions of high and low MW brush BCPs, we demonstrated the capacity to readily tune the peak wavelength of reflectance across the visible spectrum with high precision. ${ }^{182}$ (Figure 44)

This ability to fine tune the optoelectronic properties of brush polymer nanostructures makes them good candidates for a spectrum of electronic and optoelectronic applications. Most recently, our lab reported the synthesis of novel organic semiconductors formed from brush polymers whose pendant chains had been functionalized with conductive $\mathrm{C}_{60}$ fullerene units. 183 The highly ordered, extended conformation of the $\mathrm{C}_{60}$-linked brush polymers enabled precise, high contact spatial organization of these conducting units. The resulting strong electronic coupling between neighboring fullerenes could be predictably tailored by altering the length of the pendant chain linking the $\mathrm{C}_{60}$ fullerene to the polymer backbone; shorter pendants were found to yield stronger couplings, while longer ones weakened the capacity for electron transfer.

Despite the intrigue of these ultrahigh MW polymers, their potential utility in future applications depends upon further development of methods for precisely tuning their physical and mechanical properties. Most recently, our group has reported methods for (1) modulating physical interactions in polymer networks and (2) controlling grafting density and distribution of brush polymer side chains. In the first of these examples, we reported the previously unrealized interdigitation of linear and brush macromolecules into densely grafted brush polymers. Despite significant steric congestion, interdigitation among linear and grafted poly(L-lactide) and poly(D-lactide) was driven by the enthalpic favorability of sterocomplexation, with quantitaive formation in instances of low MW linear/brush systems. 184

Secondly, we demonstrated a method of tuning the grafting density of brush polymers and in turn, their physical properties, self-assembly, and stimuli responsiveness. Unlike previously reported protocols, ${ }^{185,186}$ this method was neither plagued by harsh conditions and long reaction times nor limited to the production of highly variable materials with capped grafting densities and high PDIs. ${ }^{187}$ Simultaneous control over grafting density and side chain distribution was achieved by rational design of a comonomer system composed of a macromonomer (norbornene-functionalized polystyrene, polylactide, or 
polydimethylsiloxane) and small molecule 'diluent' (an endo, exo-norbornene dialkylester). Variation of the macromonomer:diluent feed ratio yielded copolymers of predictably tuned grafting density, with lower diluent ratios resulting in more densely grafted polymers.

Strategically selecting comonomers of evenly matched self-propagation kinetics favored the production of randomly distributed copolymers, while those with unevenly matched selfpropagation kinetics lead to gradient distributions. (Figure 45)

\subsection{Economical ROMP}

The financial feasibility of ROMP is intrinsically linked to its scalability and in turn, its breadth of application. While efficient, traditional ROMP catalyst are expensive, required in high loadings (1/polymer chain), and often difficult to fully remove. Seeking a more costefficient alternative, we developed a method of catalyst recycling during ROMP. ${ }^{188}$ The socalled "pulsed addition" ROMP (PA-ROMP) affords homo- or block copolymers identical to those produced by traditional ROMP under conditions requiring seven-fold less catalyst. At its core, the method relies on a cyclic polymerization strategy; polymerization of an initial monomer population is followed by addition of a chain transfer agent (CTA). The CTA cleaves the initiator from the polymer end, simultaneously deactivating the growing chain and reforming the active initiator species. Addition of a second monomer population whose activity exceeds that of the CTA affords subsequent polymerization without the need to change pots. At this point, the cycle may be propagated or terminated. (Figure 46)

Ruthenium Removal from ROMP products-While PA-ROMP is unique in its cost efficiency, it comprises only one of the strategies reported for reducing Ru contamination in ROMP polymers, a challenge with ever-growing relevance as ROMP applications in the biomedical sphere continue to expand. ${ }^{189-191}$ Recently, our group reported a method for facile removal of heavy metal residues from a polymer chain by use a phase-Separable Polyisobutylene (PIB)-Supported Second-Generation Hoveyda-Grubbs Catalyst. ${ }^{192}$ The catalyst demonstrated activity analogous to its homogeneous counterpart in the polymerization of cyclopentene and a variety of its functionalized derivatives, affording commercially desirable polypentamer and poly(vinyl alcohol). The PIB Ru residue was readily removed from the concentrated crude product by a biphasic heptane-methanol wash, with the catalyst partitioning into the former and the polymer product into the latter phase. Polymer products synthesized with the PIB-bound Ru catalyst were considerably less contaminated than those synthesized by the non-supported analog even following multiple precipitations. As such, the PIB Ru catalyst holds the potential to improve purity standards and cut processing costs and time for large scale applications of ROMP-derived polymers.

The Future of Ru-ROMP-While lacking the precedent of the more established players in polymer chemistry, Ru-ROMP has quite rapidly gained recognition as a powerful, userfriendly tool for accessing well-defined materials with various applications - the breadth and significance of which can be evidenced by the medical, biological, electronic, and photonic examples discussed herein. Moreover, the highly tolerant, living nature of RuROMP has shed new light on old materials, as functionalized polymers can now be accessed with unprecedented precision; undoubtedly this will elucidate the structure-property relationships characterizing many important materials, and in turn, facilitate rational design 
of their next generation derivatives. The importance of this contribution will only grow as Ru-ROMP continues to become both more precise and diverse, likely through the mechanism-driven development of new Ru catalysts. Industrially, the identity of Ru-ROMP is still very much in its infancy, although its potential is not difficult to appreciate given the ease of catalyst handling and their enhanced substrate scope. Several companies, such as Cymetech, LLC in Houston, TX, and Materia, a small company spun off from our lab in Pasadena, CA are currently working to expedite the translation of Ru-ROMP into the industrial setting with some promising early successes. For example, Ru-ROMP has been used industrially for the production of dicyclopentadiene-based thermoset resins for applications ranging from neat resins to syntactic foams to fiber-infused composites. These resins have high performance automotive applications, such as alternative fuel storage, body panels, and structural components, and are also used in electrical and electronic components. Other large-scale industrial applications include corrosive chemical storage, chlor-alkali electrolysis units, sanitary pipe and tank applications, heavy machinery, and high-pressure, high-temperature (HPHT) environments such as those encountered in resource extraction from deepwater or other high-pressure environments. These resins are also ideal for fabrication of longer, more durable, and more efficient wind turbine blades. ${ }^{193}$

\section{Conclusions}

In conclusion, we have reviewed recent advances from our laboratory in ruthenium-based olefin metathesis chemistry. Progress made by us and our collaborators toward experimental and computational studies on the mechanism of action, including modes of decomposition, has lent insights into developing novel catalyst architecture for enantioselective, $Z$-selective, and most recently $E$-selective olefin metathesis. We have employed these catalysts for RCM to form cyclic peptides, functionalized macrocyclic structures, as well as the challenging synthesis of tetrasubstituted olefins. We have also achieved chemoselective CM reactions using conjugated and non-conjugated dienes, as well as advancing industrial-scale ethenolysis reactions using CAAC-supported ruthenium catalysts with remarkable turnover of up to 340,000. Lastly, we reviewed advancements made in our laboratory to develop ruthenium-based ROMP catalysts, which has provided access to functionalized and welldefined polymers with a range of applications in polymer science and manufacturing.

\section{Acknowledgments}

O.M.O. thanks Pomona College for provision of a Robbins Post-Doctoral Fellowship. N.C.W. thanks the Beckman Foundation for funding. D.J.O. thanks Pomona College, the National Science Foundation, and the Dreyfus Foundation for financial support. R.H.G. wishes to acknowledge the long-term support of the National Institute of Health and National Science Foundation that made this work possible. R.H.G. also acknowledges the many contributions both experimental and intellectual of the many students and postdoctoral fellows who have been associated with this research. We acknowledge the contributions of many groups who have helped push the area of ruthenium based metathesis to the present level. The commercial and practical developments in ruthenium metathesis technology resulting from the work at Materia, Inc. is gratefully acknowledged.

\section{Notes and references}

1. Grubbs RH. Angew Chem Int Ed. 2006; 45:3760-3765.

2. Novak BM, Grubbs RH. J Am Chem Soc. 1988; 110:7542-7543.

3. Nguyen ST, Johnson LK, Grubbs RH, Ziller JW. J Am Chem Soc. 1992; 114:3974-3975. 
4. Nguyen ST, Grubbs RH, Ziller JW. J Am Chem Soc. 1993; 115:9858-9859.

5. Fu GC, Nguyen ST, Grubbs RH. J Am Chem Soc. 1993; 115:9856-9857.

6. Schwab P, France MB, Ziller JW, Grubbs RH. Angew Chem. 1995; 107:2179-2181.

7. Schwab P, France MB, Ziller JW, Grubbs RH. Angew Chem Int Ed Engl. 1995; 34:2039-2041.

8. Wilhelm TE, Belderrain TR, Brown SN, Grubbs RH. Organometallics. 1997; 16:3867-3869.

9. Ackermann L, Fürstner A, Weskamp T, Kohl FJ, Herrmann WA. Tetrahedron Lett. 1999; 40:47874790.

10. Huang J, Stevens ED, Nolan SP, Petersen JL. J Am Chem Soc. 1999; 121:2674-2678.

11. Scholl M, Trnka TM, Morgan JP, Grubbs RH. Tetrahedron Lett. 1999; 40:2247-2250.

12. Scholl M, Ding S, Lee CW, Grubbs RH. Org Lett. 1999; 1:953-956. [PubMed: 10823227]

13. Garber SB, Kingsbury JS, Gray BL, Hoveyda AH. J Am Chem Soc. 2000; 122:8168-8179.

14. Chatterjee AK, Choi TL, Sanders DP, Grubbs RH. J Am Chem Soc. 2003; 125:11360-11370. [PubMed: 16220959]

15. Farina V, Horváth A. Handbook of Metathesis. Grubbs RH, Wenzel AG, O'Leary DJ, Khosravi E, editorsWiley-VCH Verlag GmbH \& Co KGaA; 2015. 633-658.

16. WHO. WHO Model Lists of Essential Medicines. http://www.who.int/medicines/publications/ essentialmedicines/en/, (accessed December 6, 2017)

17. Stoianova D, Johns A, Pederson R. Handbook of Metathesis. Wiley-VCH Verlag GmbH \& Co KGaA; 2015. 699-726.

18. Grubbs RH, editorHandbook of Metathesis. 1. Wiley-VCH; Weinheim, Germany: 2003.

19. Grubbs RH, Wenzel AG, O’Leary DJ, Khosravi E, editorsHandbook of Metathesis, 3 Volume Set. 2. Wiley-VCH; Weinheim: 2015.

20. Jean-Louis Hérissonm P, Chauvin Y. Makromol Chem. 1971; 141:161-176.

21. Adlhart C, Chen P. J Am Chem Soc. 2004; 126:3496-3510. [PubMed: 15025477]

22. Love JA, Sanford MS, Day MW, Grubbs RH. J Am Chem Soc. 2003; 125:10103-10109. [PubMed: 12914474]

23. Tallarico JA, Bonitatebus PJ, Snapper ML. J Am Chem Soc. 1997; 119:7157-7158.

24. Trnka TM, Day MW, Grubbs RH. Organometallics. 2001; 20:3845-3847.

25. Chatterjee AK, Choi TL, Sanders DP, Grubbs RH. J Am Chem Soc. 2003; 125:11360-11370. [PubMed: 16220959]

26. Anderson DR, Hickstein DD, O’Leary DJ, Grubbs RH. J Am Chem Soc. 2006; 128:8386-8387. [PubMed: 16802789]

27. Romero PE, Piers WE. J Am Chem Soc. 2005; 127:5032-5033. [PubMed: 15810833]

28. Wenzel AG, Grubbs RH. J Am Chem Soc. 2006; 128:16048-16049. [PubMed: 17165753]

29. Wenzel AG, Blake G, VanderVelde DG, Grubbs RH. J Am Chem Soc. 2011; 133:6429-6439. [PubMed: 21452876]

30. Hong SH, Day MW, Grubbs RH. J Am Chem Soc. 2004; 126:7414-7415. [PubMed: 15198568]

31. Hong SH, Sanders DP, Lee CW, Grubbs RH. J Am Chem Soc. 2005; 127:17160-17161. [PubMed: 16332044]

32. Berlin JM, Campbell K, Ritter T, Funk TW, Chlenov A, Grubbs RH. Org Lett. 2007; 9:1339-1342. [PubMed: 17343392]

33. Ulman M, Grubbs RH. J Org Chem. 1999; 64:7202-7207.

34. Hong SH, Wenzel AG, Salguero TT, Day MW, Grubbs RH. J Am Chem Soc. 2007; 129:79617968. [PubMed: 17547403]

35. Hong SH, Chlenov A, Day MW, Grubbs RH. Angew Chem. 2007; 119:5240-5243.

36. Seiders TJ, Ward DW, Grubbs RH. Org Lett. 2001; 3:3225-3228. [PubMed: 11574037]

37. Funk TW, Berlin JM, Grubbs RH. J Am Chem Soc. 2006; 128:1840-1846. [PubMed: 16464082]

38. Berlin JM, Goldberg SD, Grubbs RH. Angew Chem Int Ed. 2006; 45:7591-7595.

39. Lavallo V, Canac Y, Präsang C, Donnadieu B, Bertrand G. Angew Chem Int Ed. 2005; 44:57055709.

40. Lavallo V, Canac Y, Präsang C, Donnadieu B, Bertrand G. Angew Chem. 2005; 117:5851-5855. 
41. Lavallo V, Canac Y, DeHope A, Donnadieu B, Bertrand G. Angew Chem Int Ed. 2005; 44:72367239.

42. Lavallo V, Canac Y, DeHope A, Donnadieu B, Bertrand G. Angew Chem. 2005; 117:7402-7405.

43. Romero PE, Piers WE. J Am Chem Soc. 2007; 129:1698-1704. [PubMed: 17243686]

44. Cavallo L. J Am Chem Soc. 2002; 124:8965-8973. [PubMed: 12137552]

45. Anderson DR, Lavallo V, O'Leary DJ, Bertrand G, Grubbs RH. Angew Chem Int Ed. 2007; 46:7262-7265.

46. Anderson DR, Ung T, Mkrtumyan G, Bertrand G, Grubbs RH, Schrodi Y. Organometallics. 2008; 27:563-566. [PubMed: 18584055]

47. Marx VM, Sullivan AH, Melaimi M, Virgil SC, Keitz BK, Weinberger DS, Bertrand G, Grubbs RH. Angew Chem Int Ed. 2015; 54:1919-1923.

48. Jiang AJ, Zhao Y, Schrock RR, Hoveyda AH. J Am Chem Soc. 2009; 131:16630-16631. [PubMed: 19919135]

49. Flook MM, Jiang AJ, Schrock RR, Müller P, Hoveyda AH. J Am Chem Soc. 2009; 131:79627963. [PubMed: 19462947]

50. Marinescu SC, Levine DS, Zhao Y, Schrock RR, Hoveyda AH. J Am Chem Soc. 2011; 133:1151211514. [PubMed: 21718001]

51. Flook MM, Ng VWL, Schrock RR. J Am Chem Soc. 2011; 133:1784-1786. [PubMed: 21265524]

52. Meek SJ, O’Brien RV, Llaveria J, Schrock RR, Hoveyda AH. Nature. 2011; 471:461-466. [PubMed: 21430774]

53. Yu M, Wang C, Kyle AF, Jakubec P, Dixon DJ, Schrock RR, Hoveyda AH. Nature. 2011; 479:8893. [PubMed: 22051677]

54. Endo K, Grubbs RH. J Am Chem Soc. 2011; 133:8525-8527. [PubMed: 21563826]

55. Keitz BK, Endo K, Patel PR, Herbert MB, Grubbs RH. J Am Chem Soc. 2012; 134:693-699. [PubMed: 22097946]

56. Herbert MB, Suslick BA, Liu P, Zou L, Dornan PK, Houk KN, Grubbs RH. Organometallics. 2015; 34:2858-2869.

57. Cannon JS, Zou L, Liu P, Lan Y, O’Leary DJ, Houk KN, Grubbs RH. J Am Chem Soc. 2014; 136:6733-6743. [PubMed: 24731019]

58. Keitz BK, Endo K, Herbert MB, Grubbs RH. J Am Chem Soc. 2011; 133:9686-9688. [PubMed: 21649443]

59. Hartung J, Grubbs RH. J Am Chem Soc. 2013; 135:10183-10185. [PubMed: 23822901]

60. Marx VM, Herbert MB, Keitz BK, Grubbs RH. J Am Chem Soc. 2013; 135:94-97. [PubMed: 23244210]

61. Herbert MB, Marx VM, Pederson RL, Grubbs RH. Angew Chem Int Ed. 2013; 52:310-314.

62. Miyazaki H, Herbert MB, Liu P, Dong X, Xu X, Keitz BK, Ung T, Mkrtumyan G, Houk KN, Grubbs RH. J Am Chem Soc. 2013; 135:5848-5858. [PubMed: 23547887]

63. Liu P, Xu X, Dong X, Keitz BK, Herbert MB, Grubbs RH, Houk KN. J Am Chem Soc. 2012; 134:1464-1467. [PubMed: 22229694]

64. Tsipis AC, Orpen AG, Harvey JN. Dalton Trans. 2005; 0:2849-2858.

65. Straub BF. Angew Chem Int Ed. 2005; 44:5974-5978.

66. Straub BF. Adv Synth Catal. 2007; 349:204-214.

67. Herbert MB, Lan Y, Keitz BK, Liu P, Endo K, Day MW, Houk KN, Grubbs RH. J Am Chem Soc. 2012; 134:7861-7866. [PubMed: 22500642]

68. Weng W, Parkin S, Ozerov OV. Organometallics. 2006; 25:5345-5354.

69. Siegbahn PEM. J Phys Chem. 1995; 99:12723-12729.

70. Ritter T, Hejl A, Wenzel AG, Funk TW, Grubbs RH. Organometallics. 2006; 25:5740-5745.

71. Org Synth. 2003; 80:85.

72. Stürmer R, Schäfer B, Wolfart V, Stahr H, Kazmaier U, Helmchen G. Synthesis. 2001; 2001:00460048.

73. Kuhn KM, Champagne TM, Hong SH, Wei WH, Nickel A, Lee CW, Virgil SC, Grubbs RH, Pederson RL. Org Lett. 2010; 12:984-987. [PubMed: 20141172] 
74. Chatterjee AK, Toste FD, Goldberg SD, Grubbs RH. Pure Appl Chem. 2009; 75:421-425.

75. Amabilino DB, Stoddart JF. Chem Rev. 1995; 95:2725-2828.

76. Pease AR, Stoddart JF. Molecular Machines and Motors, Springer, Berlin, Heidelberg. 2001:189236.

77. Bermudez V, Capron N, Gase T, Gatti FG, Kajzar F, Leigh DA, Zerbetto F, Zhang S. Nature. 2000; 406:608-611. [PubMed: 10949297]

78. Collin JP, Dietrich-Buchecker C, Gaviña P, Jimenez-Molero MC, Sauvage JP. Acc Chem Res. 2001; 34:477-487. [PubMed: 11412084]

79. Griffiths KE, Stoddart JF. Pure Appl Chem. 2008; 80:485-506.

80. Leigh DA, Lusby PJ, Teat SJ, Wilson AJ, Wong JKY. Angew Chem Int Ed. 2001; 40:1538-1543.

81. Weck M, Mohr B, Sauvage JP, Grubbs RH. J Org Chem. 1999; 64:5463-5471. [PubMed: 11674608]

82. Wisner JA, Beer PD, Drew MGB, Sambrook MR. J Am Chem Soc. 2002; 124:12469-12476. [PubMed: 12381188]

83. Cantrill SJ, Pease AR, Stoddart JF. J Chem Soc Dalton Trans. 2000; 0:3715-3734.

84. Cantrill SJ, Fulton DA, Heiss AM, Pease AR, Stoddart JF, White AJP, Williams DJ. Chem Weinh Bergstr Ger. 2000; 6:2274-2287.

85. Kolchinski AG, Busch DH, Alcock NW. J Chem Soc Chem Commun. 1995; 0:1289-1291.

86. Kilbinger AFM, Cantrill SJ, Waltman AW, Day MW, Grubbs RH. Angew Chem Int Ed. 2003; 42:3281-3285.

87. Badjić JD, Cantrill SJ, Grubbs RH, Guidry EN, Orenes R, Stoddart JF. Angew Chem. 2004; 116:3335-3340.

88. Guidry EN, Cantrill SJ, Stoddart JF, Grubbs RH. Org Lett. 2005; 7:2129-2132. [PubMed: 15901151]

89. Miller SJ, Grubbs RH. J Am Chem Soc. 1995; 117:5855-5856.

90. Blackwell HE, Grubbs RH. Angew Chem Int Ed. 1998; 37:3281-3284.

91. Blackwell HE, Sadowsky JD, Howard RJ, Sampson JN, Chao JA, Steinmetz WE, O’Leary DJ, Grubbs RH. J Org Chem. 2001; 66:5291-5302. [PubMed: 11485448]

92. Schafmeister CE, Po J, Verdine GL. J Am Chem Soc. 2000; 122:5891-5892.

93. Walensky LD, Kung AL, Escher I, Malia TJ, Barbuto S, Wright RD, Wagner G, Verdine GL, Korsmeyer SJ. Science. 2004; 305:1466-1470. [PubMed: 15353804]

94. Chang YS, Graves B, Guerlavais V, Tovar C, Packman K, To KH, Olson KA, Kesavan K, Gangurde P, Mukherjee A, Baker T, Darlak K, Elkin C, Filipovic Z, Qureshi FZ, Cai H, Berry P, Feyfant E, Shi XE, Horstick J, Annis DA, Manning AM, Fotouhi N, Nash H, Vassilev LT, Sawyer TK. Proc Natl Acad Sci. 2013; 110:E3445-E3454. [PubMed: 23946421]

95. Horvath A, Wuyts S, DEPRÉ DPM, COUCK WLJ, Cuypers JLJ, HARUTYUNYAN S, BINOT GFS. Improved process for preparing an intermediate of the macrocyclic protease inhibitor tmc 435. Google Patents. 2013

96. Boal AK, Guryanov I, Moretto A, Crisma M, Lanni EL, Toniolo C, Grubbs RH, O'Leary DJ. J Am Chem Soc. 2007; 129:6986-6987. [PubMed: 17497781]

97. Toniolo C, Crisma M, Formaggio F, Peggion C. Pept Sci. 2001; 60:396-419.

98. Marshall GR, Hodgkin EE, Langs DA, Smith GD, Zabrocki J, Leplawy MT. Proc Natl Acad Sci. 1990; 87:487-491. [PubMed: 2296604]

99. Karle IL, Balaram P. Biochemistry (Mosc). 1990; 29:6747-6756.

100. Khan SN, Kim A, Grubbs RH, Kwon YU. Org Lett. 2011; 13:1582-1585. [PubMed: 21384884]

101. Miller SM, Simon RJ, Ng S, Zuckermann RN, Kerr JM, Moos WH. Drug Dev Res. 1995; 35:2032.

102. Kwon YU, Kodadek T. J Am Chem Soc. 2007; 129:1508-1509. [PubMed: 17283989]

103. Kwon YU, Kodadek T. Chem Commun. 2008; 0:5704-5706.

104. Mangold SL, O’Leary DJ, Grubbs RH. J Am Chem Soc. 2014; 136:12469-12478. [PubMed: 25102124]

105. Mangold SL, Grubbs RH. Chem Sci. 2015; 6:4561-4569. [PubMed: 26509000] 
106. Hartung J, Dornan PK, Grubbs RH. J Am Chem Soc. 2014; 136:13029-13037. [PubMed: 25137310]

107. Stewart IC, Ung T, Pletnev AA, Berlin JM, Grubbs RH, Schrodi Y. Org Lett. 2007; 9:1589-1592. [PubMed: 17378575]

108. White DE, Stewart IC, Grubbs RH, Stoltz BM. J Am Chem Soc. 2008; 130:810-811. [PubMed: 18163634]

109. O’Leary DJ, O’Neil GW. Handbook of Metathesis. Wiley-VCH Verlag GmbH \& Co KGaA; 2015. 171-294.

110. Chatterjee AK, Morgan JP, Scholl M, Grubbs RH. J Am Chem Soc. 2000; 122:3783-3784.

111. Evans PA, Grisin A, Lawler MJ. J Am Chem Soc. 2012; 134:2856-2859. [PubMed: 22296255]

112. Han SB, Hassan A, Kim IS, Krische MJ. J Am Chem Soc. 2010; 132:15559-15561. [PubMed: 20961111]

113. Jackson KL, Henderson JA, Motoyoshi H, Phillips AJ. Angew Chem Int Ed. 2009; 48:23462350.

114. Blackwell HE, O’Leary DJ, Chatterjee AK, Washenfelder RA, Bussmann DA, Grubbs RH. J Am Chem Soc. 2000; 122:58-71.

115. Morrill C, Grubbs RH. J Org Chem. 2003; 68:6031-6034. [PubMed: 12868943]

116. Nicolaou KC, Li A, Edmonds DJ, Tria GS, Ellery SP. J Am Chem Soc. 2009; 131:16905-16918. [PubMed: 19874023]

117. Nicolaou KC, Stepan AF, Lister T, Li A, Montero A, Tria GS, Turner CI, Tang Y, Wang J, Denton RM, Edmonds DJ. J Am Chem Soc. 2008; 130:13110-13119. [PubMed: 18771264]

118. Nicolaou KC, Lister T, Denton RM, Montero A, Edmonds DJ. Angew Chem Int Ed. 2007; 46:4712-4714.

119. Nicolaou KC, Tang Y, Wang J, Stepan AF, Li A, Montero A. J Am Chem Soc. 2007; 129:14850_ 14851. [PubMed: 17988130]

120. Njardarson JT, Biswas K, Danishefsky SJ. Chem Commun. 2002; 0:2759-2761.

121. Uno BE, Gillis EP, Burke MD. Tetrahedron. 2009; 65:3130-3138.

122. Willwacher J, Kausch-Busies N, Fürstner A. Angew Chem Int Ed. 2012; 51:12041-12046.

123. E JA Jr, Stoltz BM. Nature. 2008; 453:1228. [PubMed: 18580947]

124. Dieckmann M, Kretschmer M, Li P, Rudolph S, Herkommer D, Menche D. Angew Chem Int Ed. 2012; 51:5667-5670.

125. Funk TW, Efskind J, Grubbs RH. Org Lett. 2005; 7:187-190. [PubMed: 15646954]

126. Cannon JS, Grubbs RH. Angew Chem Int Ed. 2013; 52:9001-9004.

127. Ortiz A, Quesada A, Sanchez A. J Chem Ecol. 2004; 30:991-1000. [PubMed: 15274444]

128. Turner RB, Jarrett AD, Goebel P, Mallon BJ. J Am Chem Soc. 1973; 95:790-792.

129. Quigley BL, Grubbs RH. Chem Sci. 2014; 5:501-506. [PubMed: 25722847]

130. Luo SX, Cannon JS, Taylor BLH, Engle KM, Houk KN, Grubbs RH. J Am Chem Soc. 2016; 138:14039-14046.

131. Miyazaki H, Herbert MB, Liu P, Dong X, Xu X, Keitz BK, Ung T, Mkrtumyan G, Houk KN, Grubbs RH. J Am Chem Soc. 2013; 135:5848-5858. [PubMed: 23547887]

132. Johns AM, Ahmed TS, Jackson BW, Grubbs RH, Pederson RL. Org Lett. 2016; 18:772-775. [PubMed: 26840878]

133. Khan SN, Kim A, Grubbs RH, Kwon YU. Org Lett. 2012; 14:2952-2955. [PubMed: 22676892]

134. Cantrill SJ, Grubbs RH, Lanari D, Leung KCF, Nelson A, Poulin-Kerstien KG, Smidt SP, Stoddart JF, Tirrell DA. Org Lett. 2005; 7:4213-4216. [PubMed: 16146390]

135. Reyes DR, Iossifidis D, Auroux PA, Manz A. Anal Chem. 2002; 74:2623-2636. [PubMed: 12090653]

136. Auroux PA, Iossifidis D, Reyes DR, Manz A. Anal Chem. 2002; 74:2637-2652. [PubMed: 12090654]

137. Whitesides GM. Nature. 2006; 442:368-373. [PubMed: 16871203]

138. Park CP, Van Wingerden MM, Han SY, Kim DP, Grubbs RH. Org Lett. 2011; 13:2398-2401. [PubMed: 21456591] 
139. Hartung J, Grubbs RH. J Am Chem Soc. 2013; 135:10183-10185. [PubMed: 23822901]

140. Gilliom LR, Grubbs RH. J Am Chem Soc. 1986; 108:733-742.

141. Nguyen ST, Johnson LK, Grubbs RH, Ziller JW. J Am Chem Soc. 1992; 114:3974-3975.

142. Grubbs RH, Tumas W. Science. 1989; 243:907-915. [PubMed: 2645643]

143. Novak BM, Risse W, Grubbs RH. Polymer Synthesis Oxidation Processes, Springer, Berlin, Heidelberg. 1992:47-72.

144. Grubbs RH. J Macromol Sci Part A. 1994; 31:1829-1933.

145. Bielawski CW, Grubbs RH. Prog Polym Sci. 2007; 32:1-29.

146. Leitgeb A, Wappel J, Slugovc C. Polymer. 2010; 51:2927-2946.

147. Hejl A, Scherman OA, Grubbs RH. Macromolecules. 2005; 38:7214-7218.

148. Tuba R, Al-Hashimi M, Bazzi HS, Grubbs RH. Macromolecules. 2014; 47:8190-8195.

149. Scherman OA, Walker R, Grubbs RH. Macromolecules. 2005; 38:9009-9014.

150. Tuba R, Grubbs RH. Polym Chem. 2013; 4:3959-3962.

151. Lee HK, Bang KT, Hess A, Grubbs RH, Choi TL. J Am Chem Soc. 2015; 137:9262-9265. [PubMed: 26185967]

152. Walker R, Conrad RM, Grubbs RH. Macromolecules. 2009; 42:599-605. [PubMed: 20379393]

153. Keitz BK, Fedorov A, Grubbs RH. J Am Chem Soc. 2012; 134:2040-2043. [PubMed: 22239675]

154. Rosebrugh LE, Marx VM, Keitz BK, Grubbs RH. J Am Chem Soc. 2013; 135:10032-10035.

[PubMed: 23782172]

155. Daeffler CS, Miyake GM, Li J, Grubbs RH. ACS Macro Lett. 2014; 3:102-104.

156. Rosebrugh LE, Ahmed TS, Marx VM, Hartung J, Liu P, López JG, Houk KN, Grubbs RH. J Am Chem Soc. 2016; 138:1394-1405. [PubMed: 26726835]

157. Matson JB, Grubbs RH. J Am Chem Soc. 2008; 130:6731-6733. [PubMed: 18452296]

158. Conrad RM, Grubbs RH. Angew Chem Int Ed. 2009; 48:8328-8330.

159. Weck M, Jackiw JJ, Rossi RR, Weiss PS, Grubbs RH. J Am Chem Soc. 1999; 121:4088-4089.

160. Mendes PM. Chem Soc Rev. 2008; 37:2512-2529. [PubMed: 18949123]

161. Vatansever F, Hamblin MR. J Nanoparticle Res. 2016; 18:302.

162. Rutenberg IM, Scherman OA, Grubbs RH, Jiang W, Garfunkel E, Bao Z. J Am Chem Soc. 2004; 126:4062-4063. [PubMed: 15053568]

163. Xia Y, Verduzco R, Grubbs RH, Kornfield JA. J Am Chem Soc. 2008; 130:1735-1740. [PubMed: 18197667]

164. Guidry EN, Li J, Stoddart JF, Grubbs RH. J Am Chem Soc. 2007; 129:8944-8945. [PubMed: 17595085]

165. Clark PG, Day MW, Grubbs RH. J Am Chem Soc. 2009; 131:13631-13633. [PubMed: 19728719]

166. Momčilović N, Clark PG, Boydston AJ, Grubbs RH. J Am Chem Soc. 2011; 133:19087-19089. [PubMed: 22023086]

167. Fürstner A, Ackermann L, Gabor B, Goddard R, Lehmann CW, Mynott R, Stelzer F, Thiel OR. Chem - Eur J. 2001; 7:3236-3253. [PubMed: 11531110]

168. Bielawski CW, Benitez D, Grubbs RH. J Am Chem Soc. 2003; 125:8424-8425. [PubMed: 12848534]

169. Bielawski CW, Benitez D, Grubbs RH. Science. 2002; 297:2041-2044. [PubMed: 12242440]

170. Boydston AJ, Xia Y, Kornfield JA, Gorodetskaya IA, Grubbs RH. J Am Chem Soc. 2008; 130:12775-12782. [PubMed: 18729450]

171. Boydston AJ, Holcombe TW, Unruh DA, Fréchet JMJ, Grubbs RH. J Am Chem Soc. 2009; 131:5388-5389. [PubMed: 19334732]

172. Weitekamp RA, Atwater HA, Grubbs RH. J Am Chem Soc. 2013; 135:16817-16820. [PubMed: 24171659]

173. Xia Y, Kornfield JA, Grubbs RH. Macromolecules. 2009; 42:3761-3766.

174. Xia Y, Olsen BD, Kornfield JA, Grubbs RH. J Am Chem Soc. 2009; 131:18525-18532. [PubMed: 19947607]

Chem Soc Rev. Author manuscript; available in PMC 2019 June 18. 
175. Xia Y, Boydston AJ, Grubbs RH. Angew Chem Int Ed. 2011; 50:5882-5885.

176. Johnson JA, Lu YY, Burts AO, Xia Y, Durrell AC, Tirrell DA, Grubbs RH. Macromolecules. 2010; 43:10326-10335. [PubMed: 21532937]

177. Johnson JA, Lu YY, Burts AO, Lim YH, Finn MG, Koberstein JT, Turro NJ, Tirrell DA, Grubbs RH. J Am Chem Soc. 2011; 133:559-566. [PubMed: 21142161]

178. Burts AO, Li Y, Zhukhovitskiy AV, Patel PR, Grubbs RH, Ottaviani MF, Turro NJ, Johnson JA. Macromolecules. 2012; 45:8310-8318.

179. Hu M, Xia Y, McKenna GB, Kornfield JA, Grubbs RH. Macromolecules. 2011; 44:6935-6943.

180. Miyake GM, Weitekamp RA, Piunova VA, Grubbs RH. J Am Chem Soc. 2012; 134:14249_ 14254. [PubMed: 22891697]

181. Sveinbjörnsson BR, Weitekamp RA, Miyake GM, Xia Y, Atwater HA, Grubbs RH. Proc Natl Acad Sci. 2012; 109:14332-14336. [PubMed: 22912408]

182. Miyake GM, Piunova VA, Weitekamp RA, Grubbs RH. Angew Chem Int Ed. 2012; 51:1124611248.

183. Fang L, Liu P, Sveinbjornsson BR, Atahan-Evrenk S, Vandewal K, Osuna S, Jiménez-Osés G, Shrestha S, Giri G, Wei P, Salleo A, Aspuru-Guzik A, Grubbs RH, Houk KN, Bao Z. J Mater Chem C. 2013; 1:5747-5755.

184. Sveinbjörnsson BR, Miyake GM, El-Batta A, Grubbs RH. ACS Macro Lett. 2014; 3:26-29.

185. Ohno S, Matyjaszewski K. J Polym Sci Part Polym Chem. 2006; 44:5454-5467.

186. Matsuda M, Satoh K, Kamigaito M. Macromolecules. 2013; 46:5473-5482.

187. Lin TP, Chang AB, Chen HY, Liberman-Martin AL, Bates CM, Voegtle MJ, Bauer CA, Grubbs RH. J Am Chem Soc. 2017; 139:3896-3903. [PubMed: 28221030]

188. Matson JB, Virgil SC, Grubbs RH. J Am Chem Soc. 2009; 131:3355-3362. [PubMed: 19215131]

189. Vougioukalakis GC. Chem - Eur J. 2012; 18:8868-8880. [PubMed: 22689268]

190. Sommer WJ, Weck M. Coord Chem Rev. 2007; 251:860-873.

191. Buchmeiser MR. Chem Rev. 2009; 109:303-321. [PubMed: 18980343]

192. Al-Hashimi M, Tuba R, Bazzi HS, Grubbs RH. ChemCatChem. 2016; 8:228-233.

193. Thermoset Resin Applications with Infinite Formulation Flexibility. Materia; http://www.materiainc.com/products/thermoset-resins/applications, (accessed December 14, 2017) 


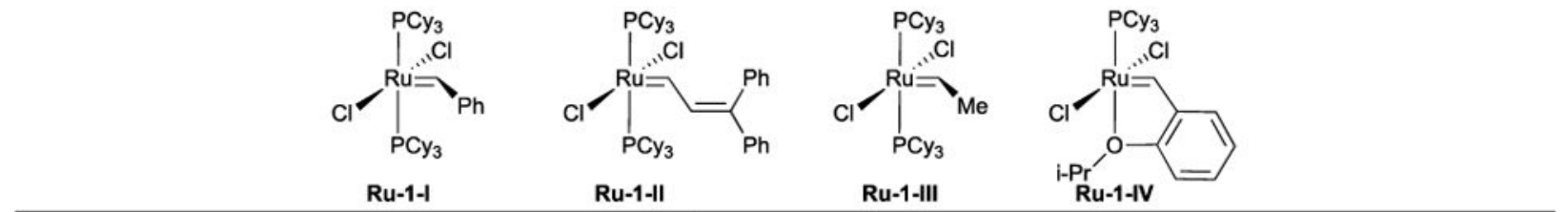

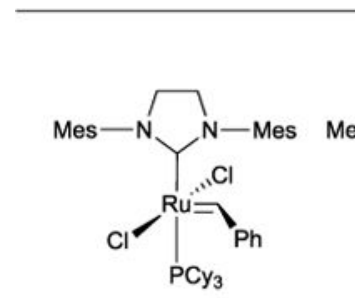

Ru-2-I

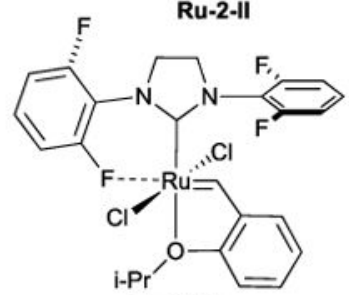

Ru-2-VII

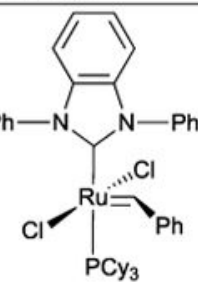

Ru-2-III

\section{(I)}

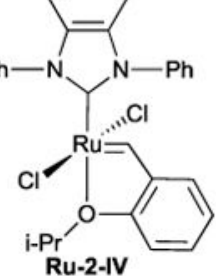

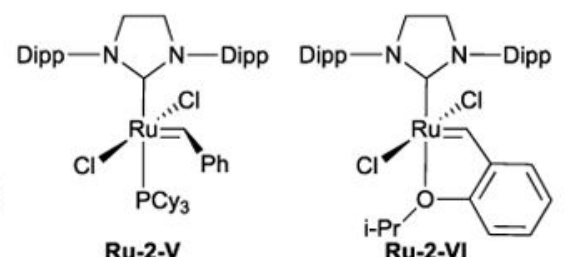

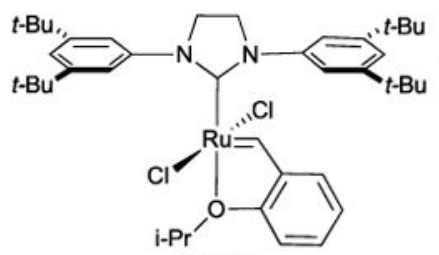

Ru-2-VIII

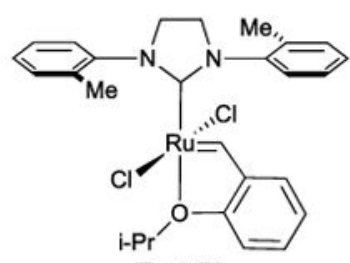

Ru-2-IX

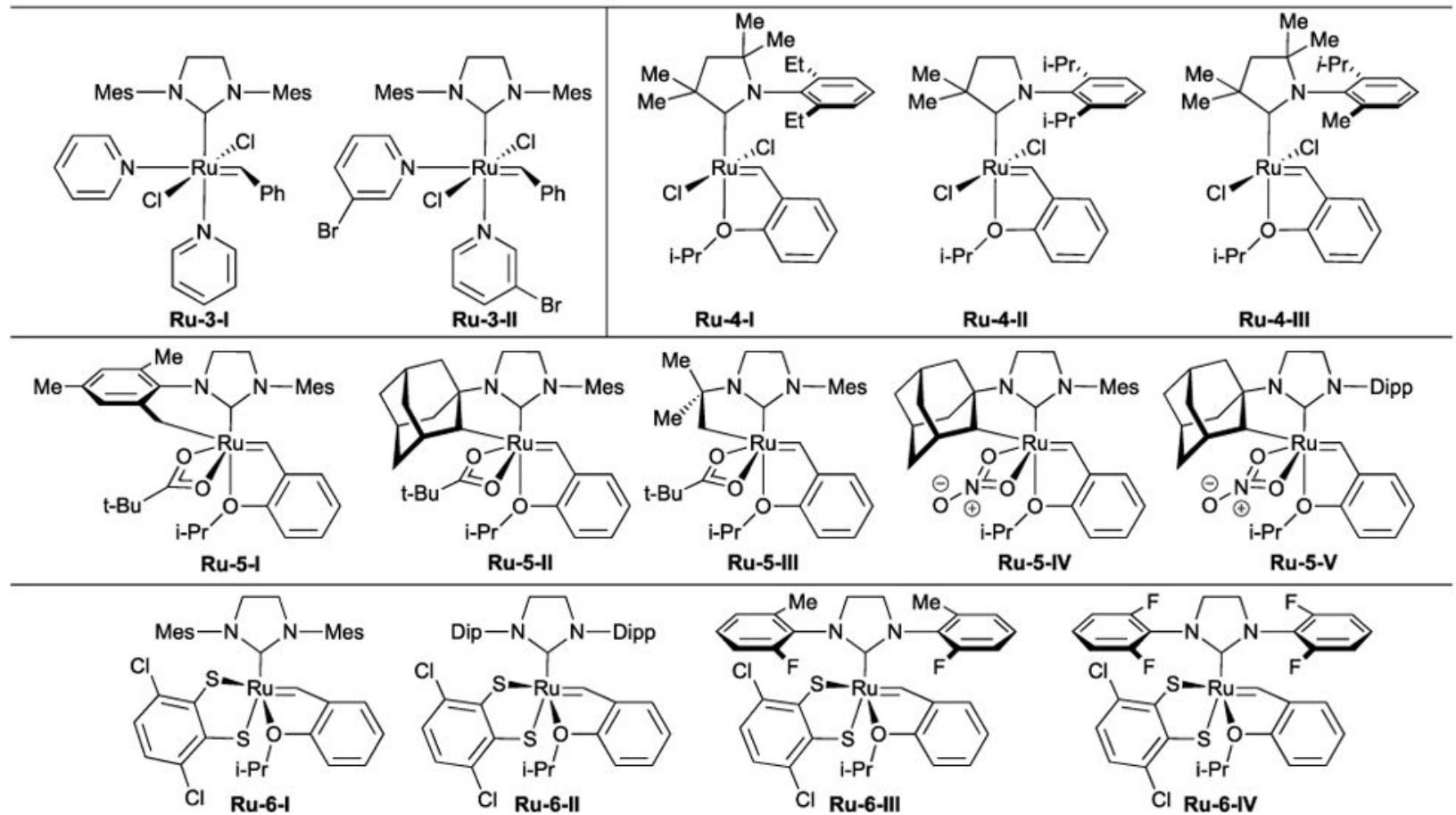

Figure 1.

Select list of ruthenium olefin metathesis catalysts. 


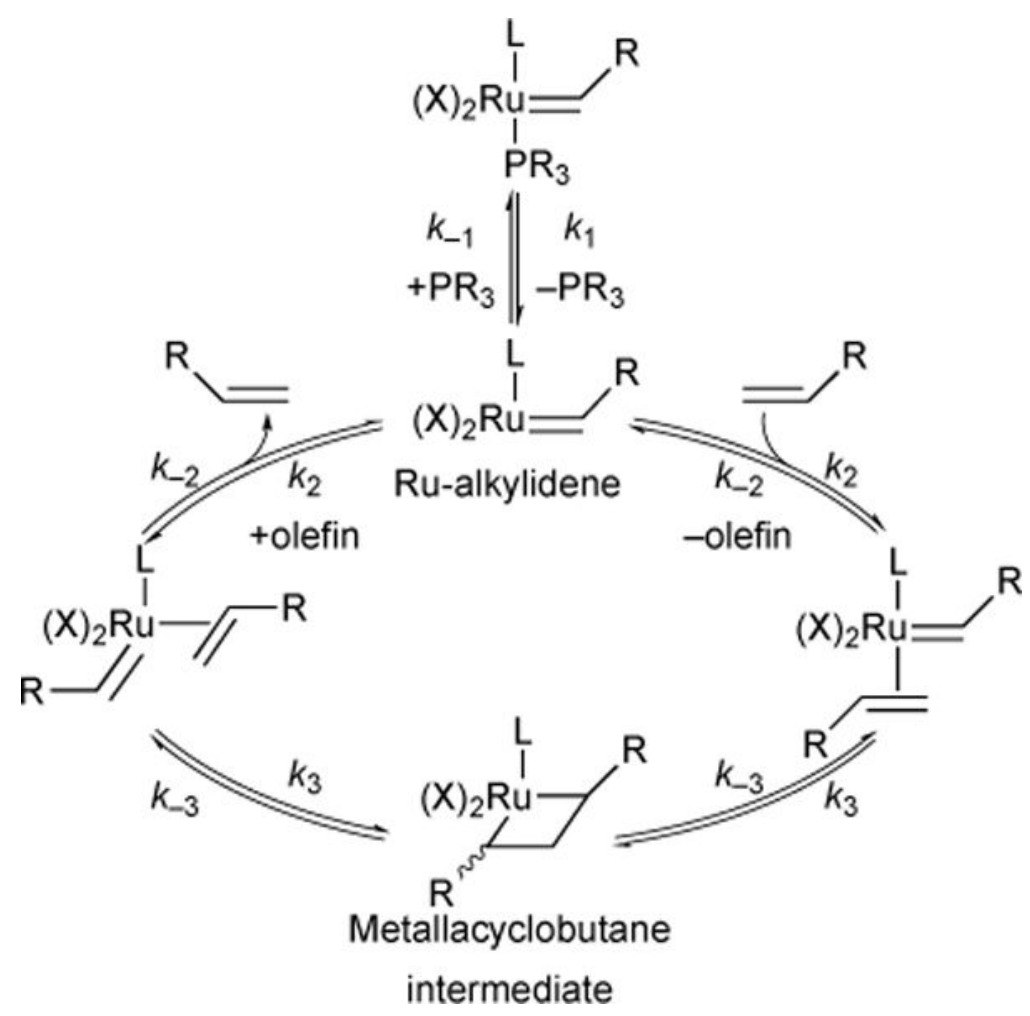

Figure 2.

Generic ruthenium olefin metathesis catalytic cycle. 


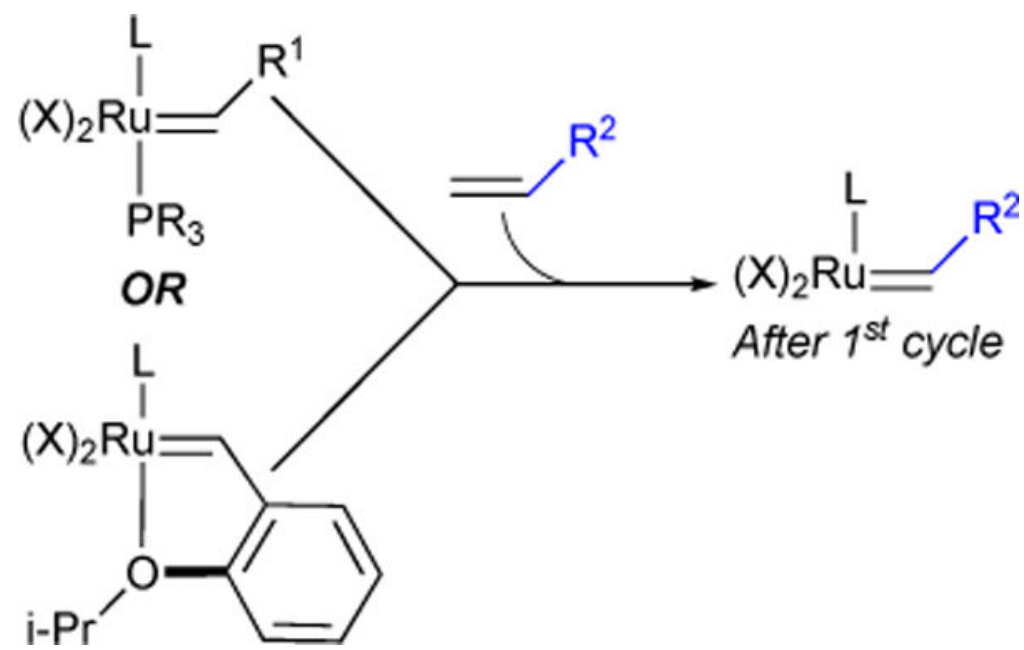

Figure 3.

Active Ru-alkylidene is identical after first catalytic cycle, regardless of pre-catalyst structure. 


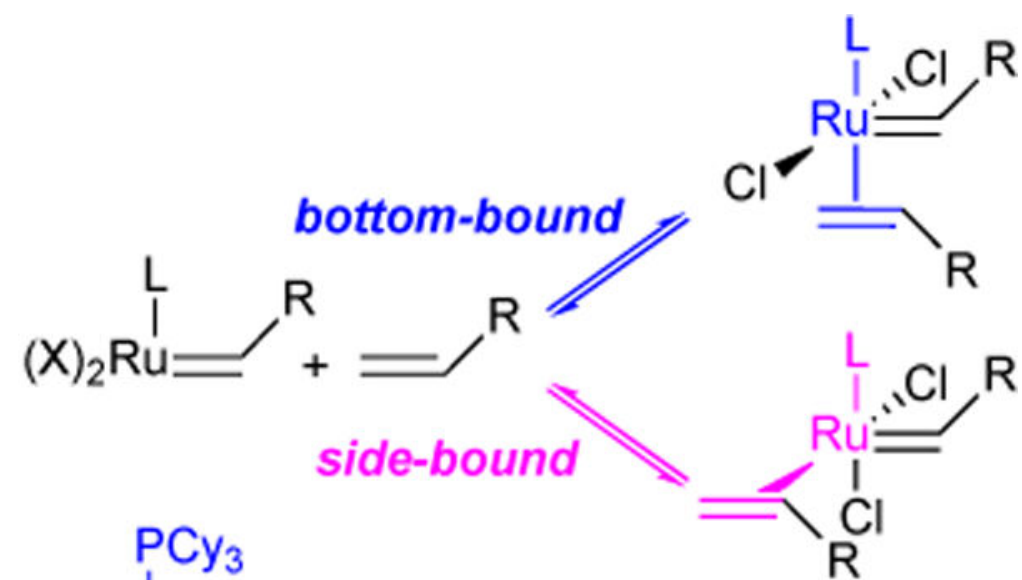

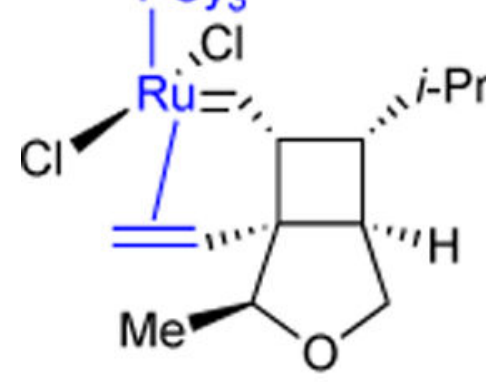

1

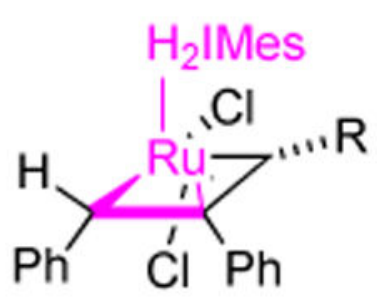

2

Figure 4.

Side- vs. bottom-bound olefin addition. 


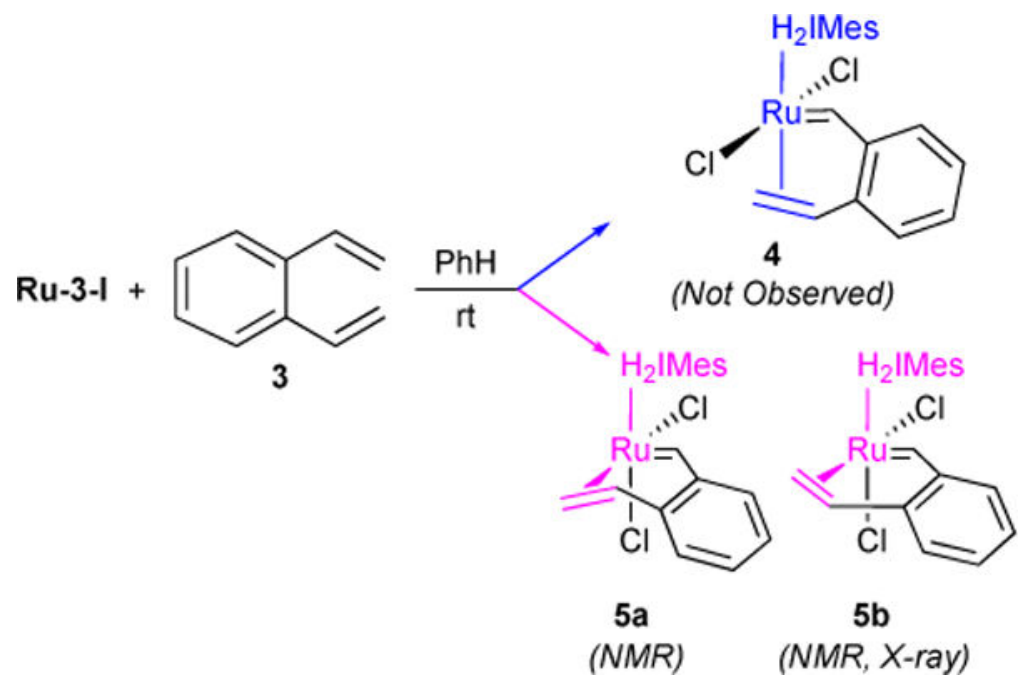

Figure 5.

Evidence for side-bound olefin substrate binding. 


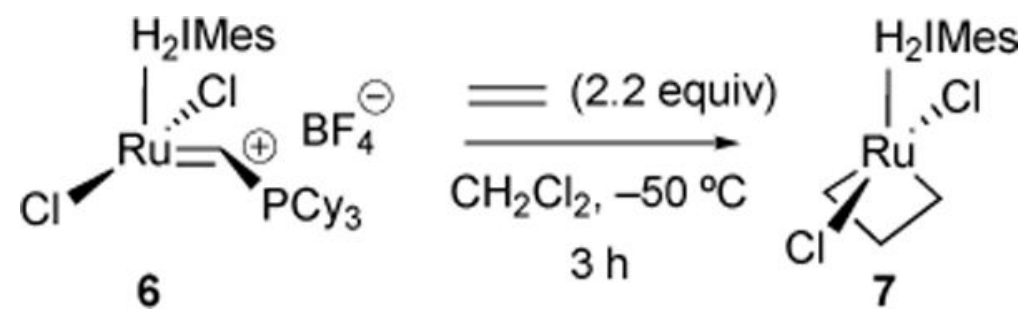

Figure 6.

First direct observation of ruthenium metallacyle. 
A
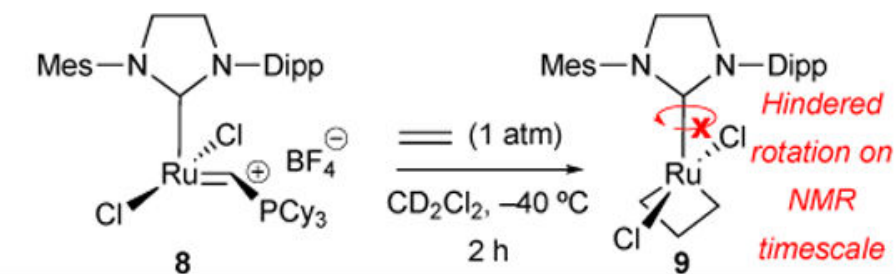

B
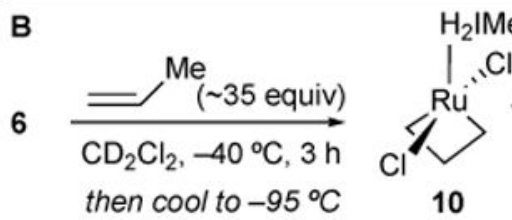

10

$(45 \%)$

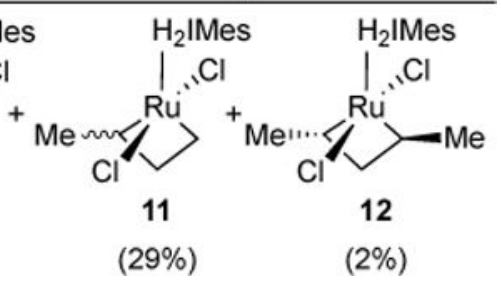

Figure 7.

Bottom-bound, highly dynamic, ruthenacyclobutane intermediates observed. 
A. Decomposition via Catalyst Dimerization

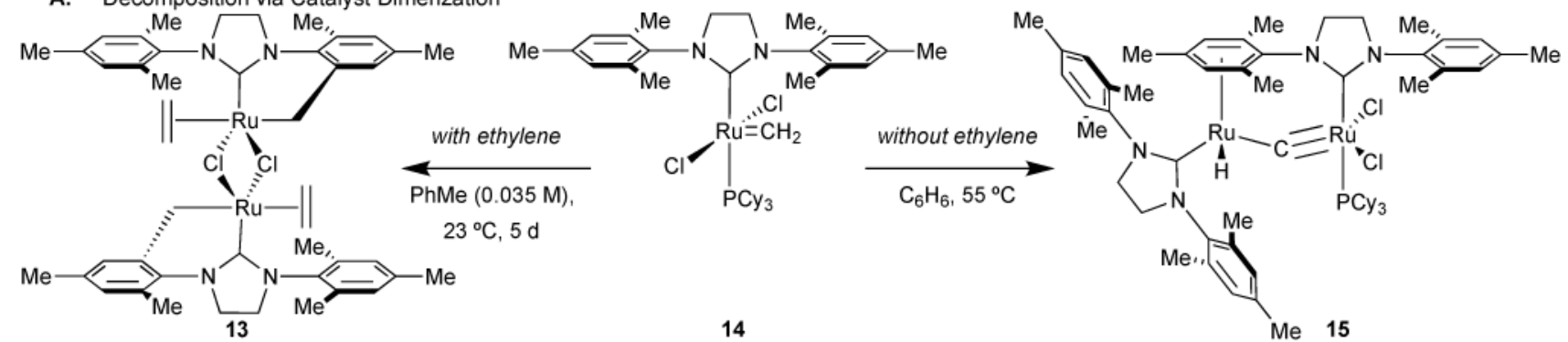

B. Decomposition via NHC ortho Phenyl C-H Activation
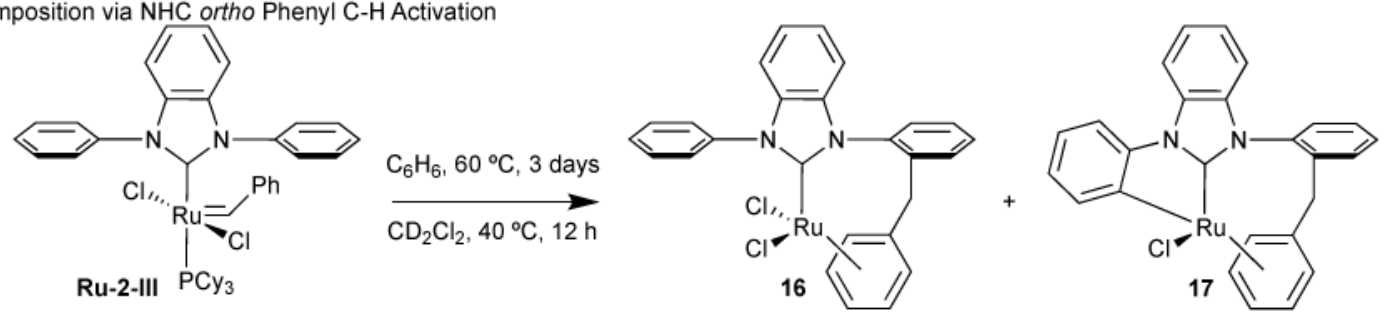

Figure 8.

Ru-2 catalyst decomposition via dimerization into dinuclear complexes (A) and via C-H activation at the NHC ortho phenyl position (B). 


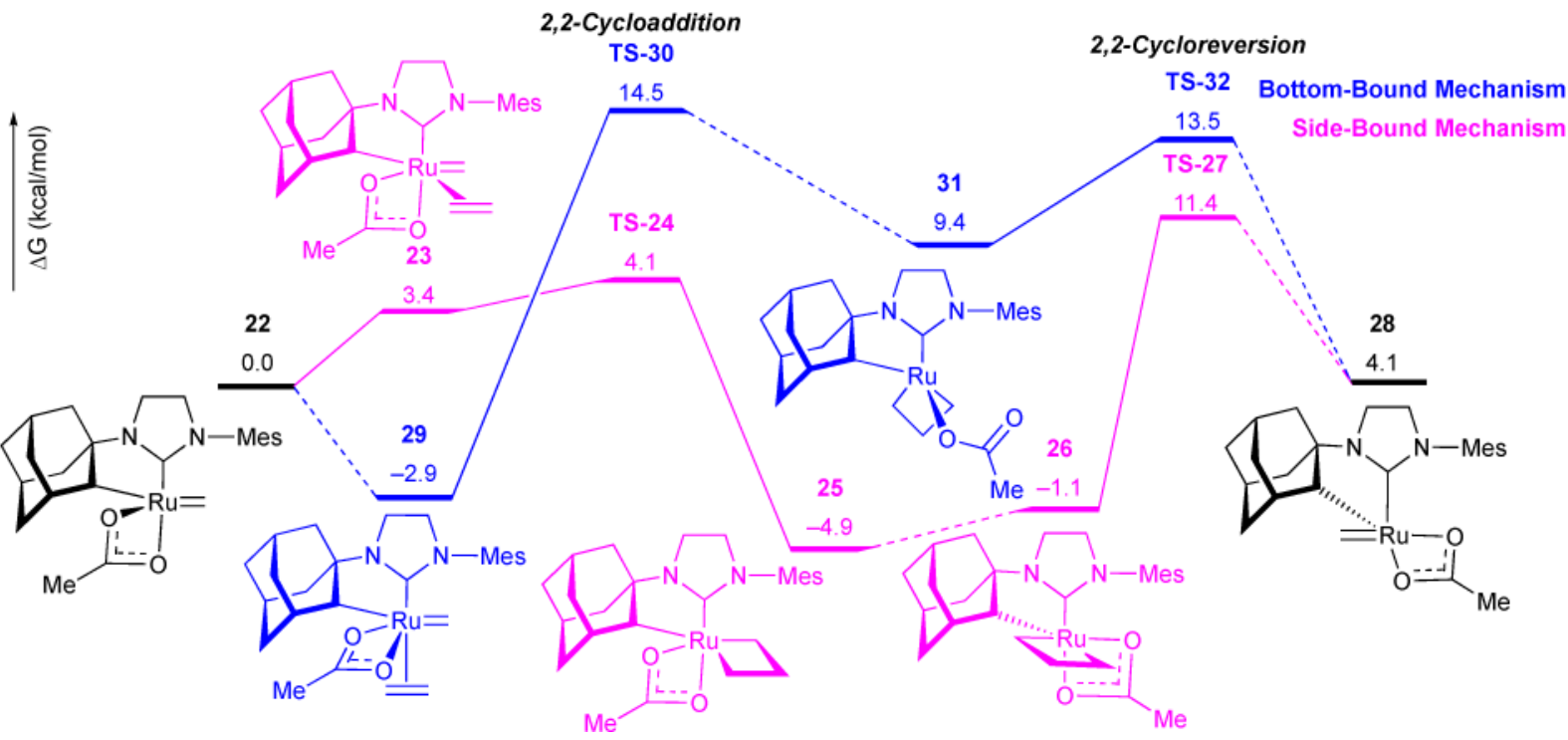

Figure 9.

Minimum energy bottom-bound and side-bound mechanism for $Z$-selective olefin metathesis. Structures were optimized in B3LYP/LANL2DZ/6-31G(d) level of theory, and energies computed in M06/SDD/6-311+G(d,p) level of theory. 


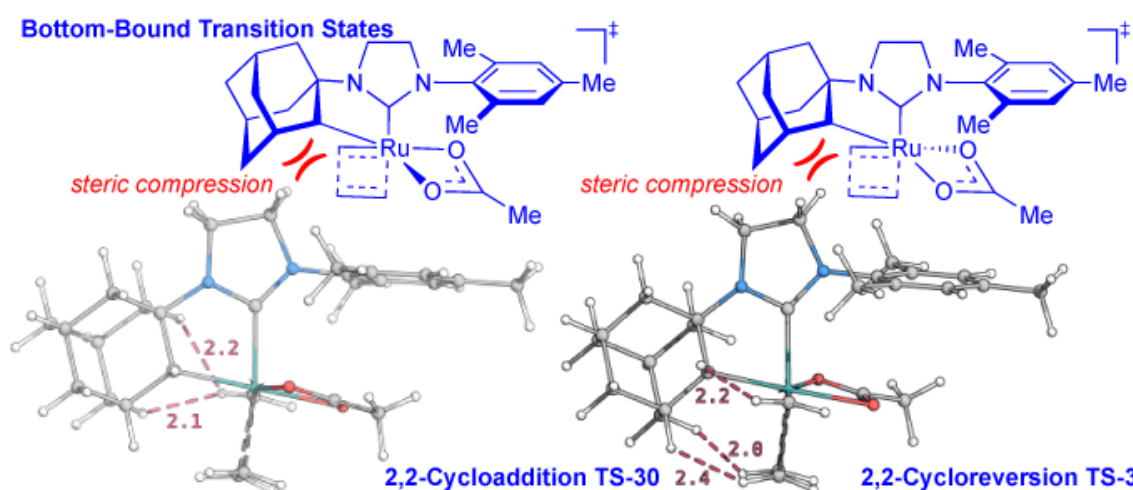

Relevant Orbital Interactions

$14.5 \mathrm{kcal} / \mathrm{mol}$ $13.5 \mathrm{kcal} / \mathrm{mol}$
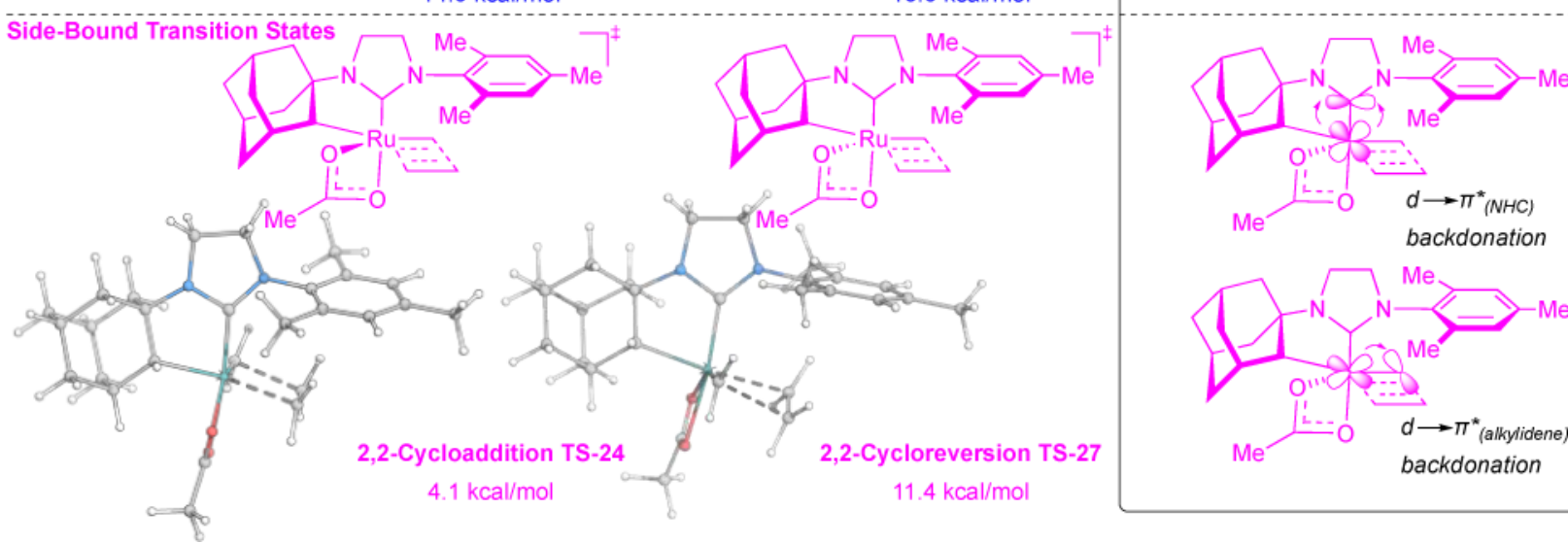

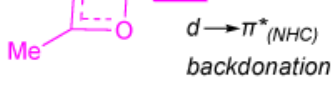

Figure 10.

Computed 2,2-Cycloaddition and cycloreversion transition state structures for minimum energy side-bound and bottom-bound mechanisms (Left). Relevant orbital interactions depicting $d$ orbital backdonation into $\pi^{*}$ of NHC and alkylidene moieties (Right). 


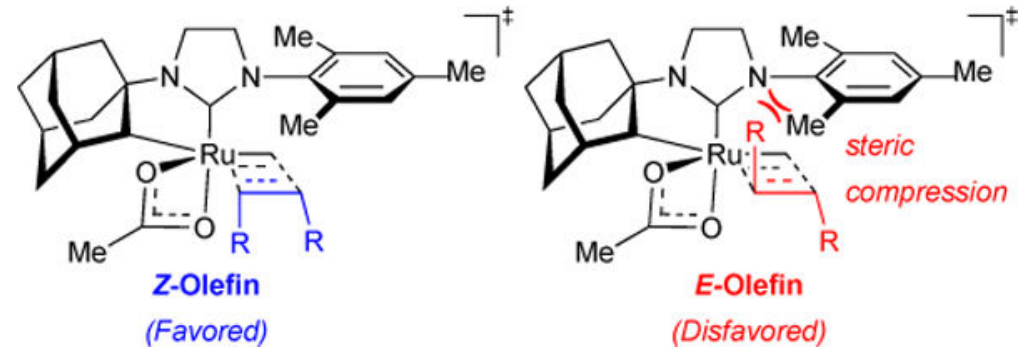

Figure 11.

$Z$ - vs $E$ - selectivity model. 


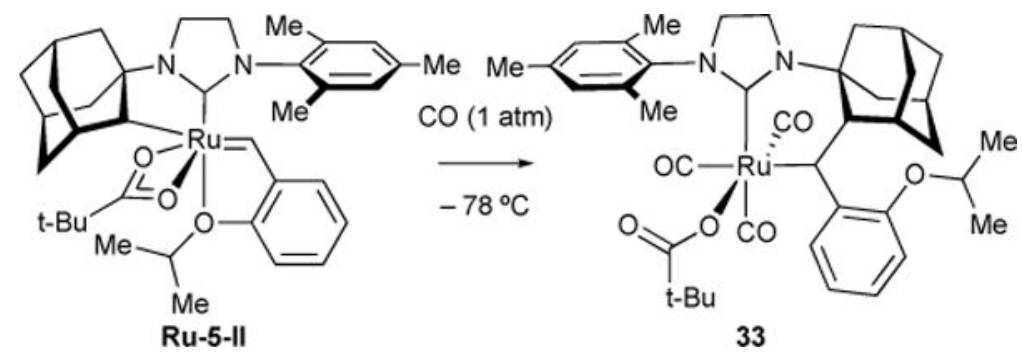

Figure 12.

Decomposition of $\mathbf{R u - 5 - I I ~ v i a ~ a l k y l i d e n e ~ i n s e r t i o n ~ i n t o ~} \mathrm{Ru}-\mathrm{C}$ bond upon exposure to carbon monoxide. 

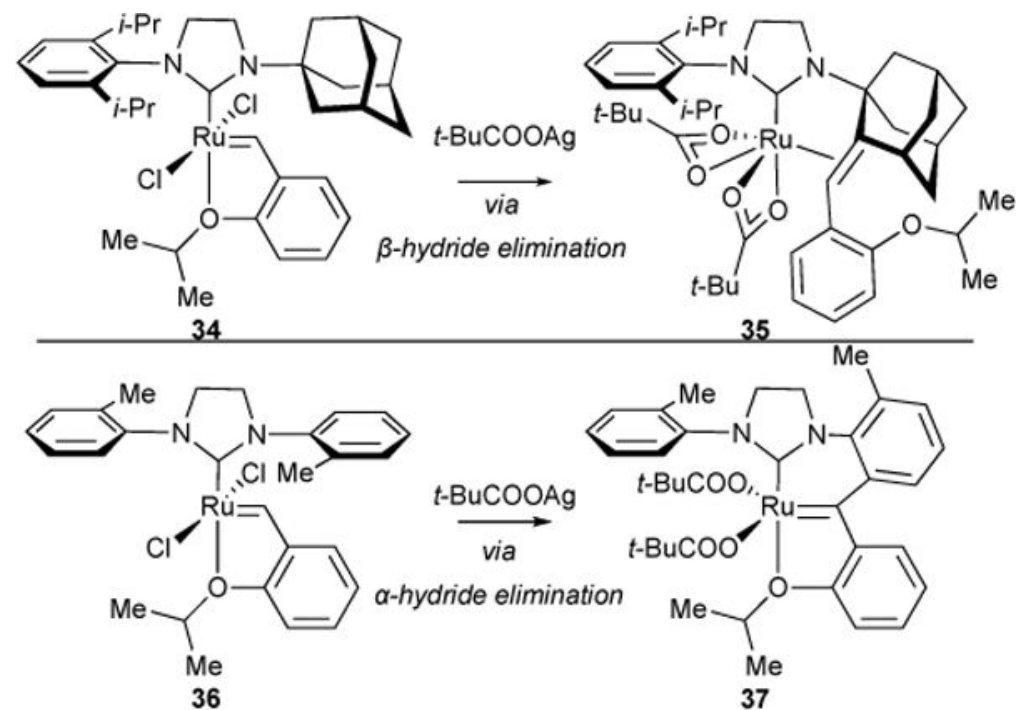

Figure 13.

Treatment of $\mathbf{3 4}$ and $\mathbf{3 6}$ with silver(I) triflate in an effort to synthesize C-H activated ruthenium catalyst analogs of Ru-5-II yielded decomposition products $\mathbf{3 5}$ and $\mathbf{3 7}$, respectively. 


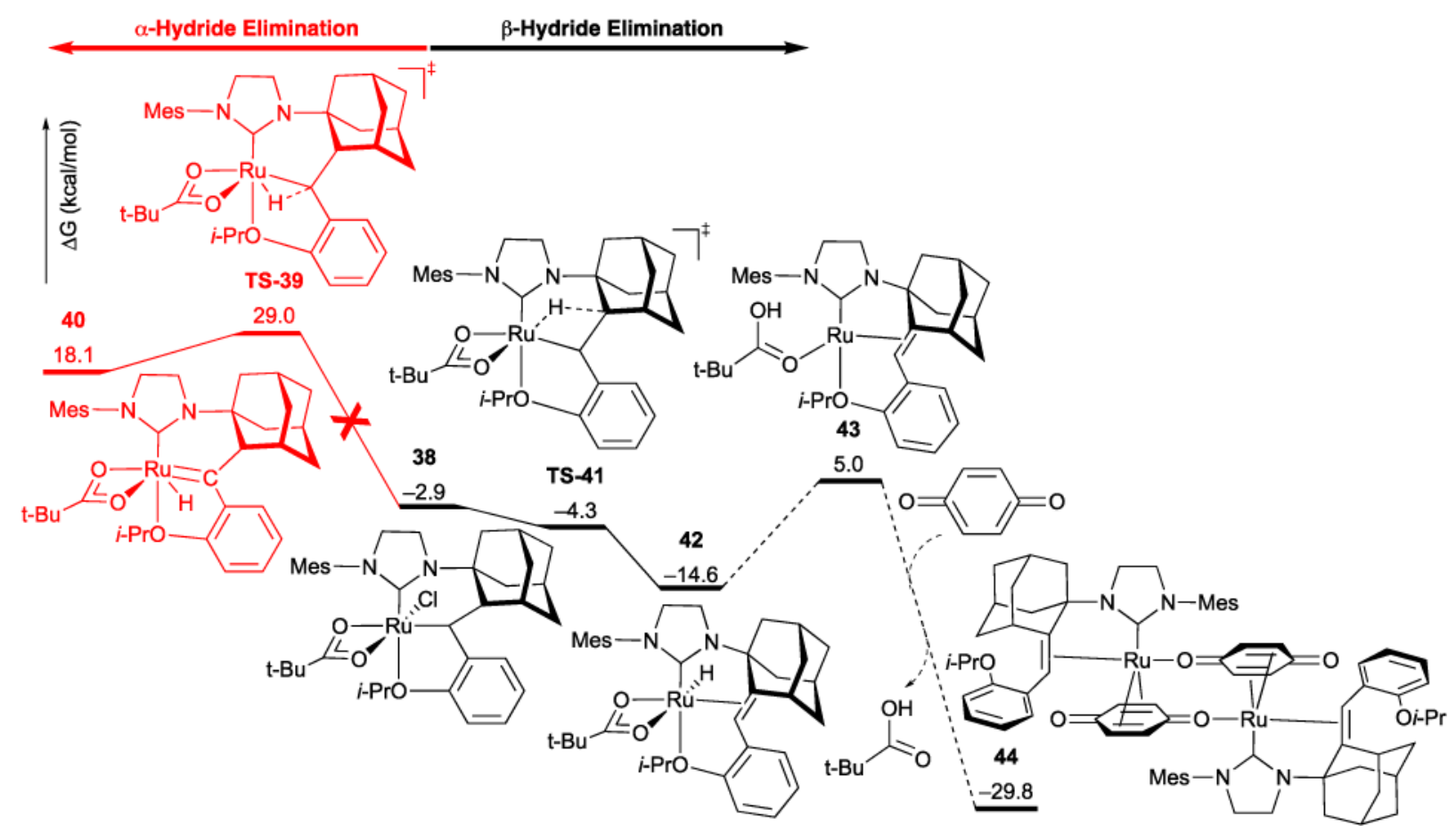

Figure 14.

Computed $\alpha$ - vs $\beta$-hydride elimination pathways. The latter is favored over the former by $33.3 \mathrm{kcal} / \mathrm{mol}$. Further decomposition of $\beta$-hydride elimination intermediate in the presence of $p$-benzoquinone leads to a dinuclear ruthenium complex. A Standard System for Catalyst Characterization 


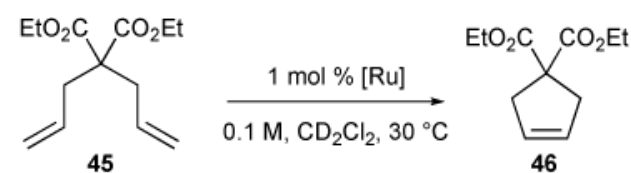

45

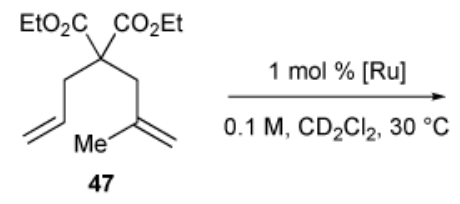

$\mathrm{EtO}_{2} \mathrm{C}$
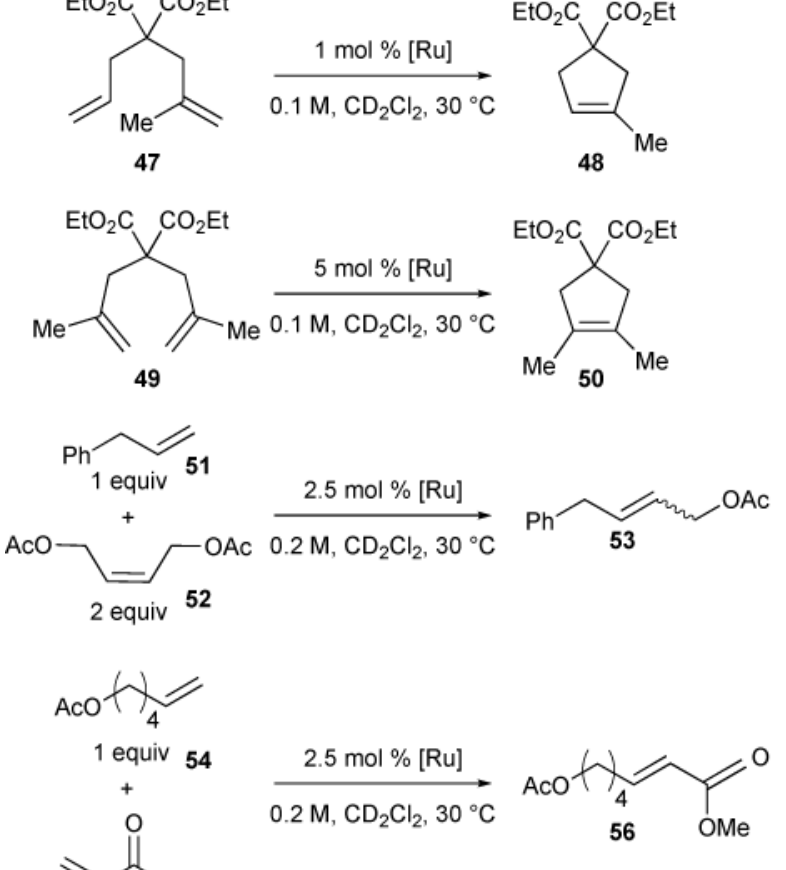

1 equiv $\mathbf{5 5}$
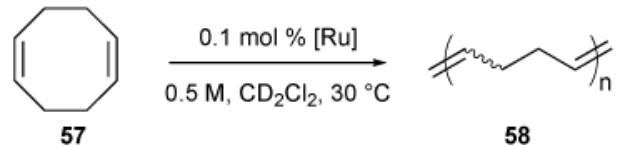

(6)

Figure 15.

Set of six metathesis reactions for catalyst characterization. 

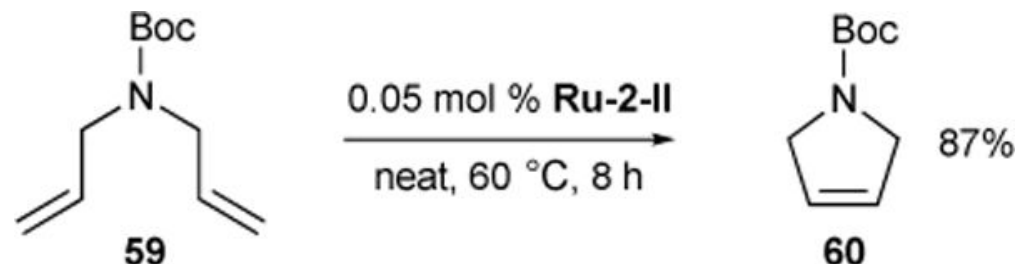

60

Figure 16.

Synthesis of Boc-3-pyrroline. 


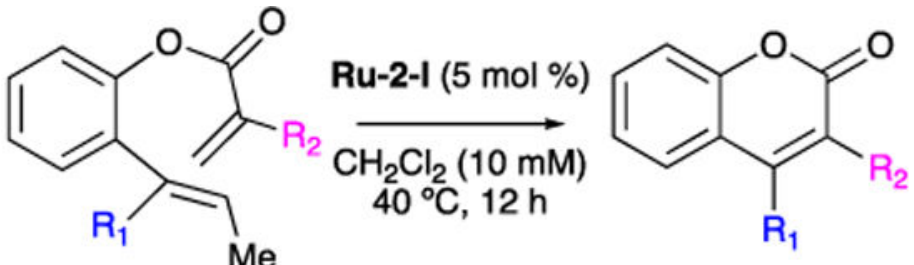

61a. $R_{1}=R_{2}=H$

62a. $R_{1}=R_{2}=H ; 89 \%$

61b. $R_{1}=R_{2}=M e$

62b. $R_{1}=R_{2}=M e ; 45 \%$

61c. $R_{1}=H, R_{2}=M e$

62c. $\mathrm{R}_{1}=\mathrm{H}, \mathrm{R}_{2}=\mathrm{Me} ; 88 \%$

61d. $R_{1}=M e, R_{2}=H$

62d. $R_{1}=M e, R_{2}=H ; 74 \%$

Figure 17.

Synthesis of coumarins. 
A

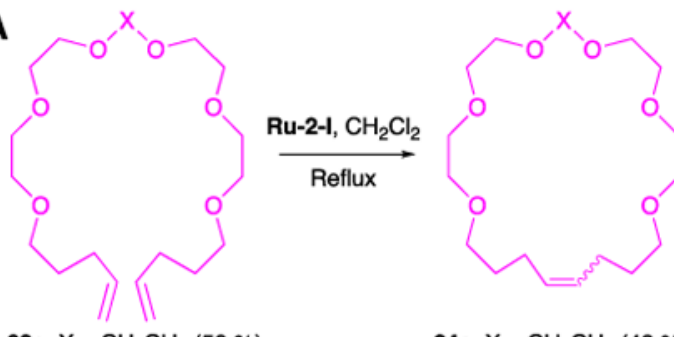

63a. $X=\mathrm{CH}_{2} \mathrm{CH}_{2}(50 \%) \quad$ 64a. $X=\mathrm{CH}_{2} \mathrm{CH}_{2}(48 \%)$

63b. $X=0-C_{6} H_{4}(45 \%)$

Ru-2-I
$\mathrm{CH}_{2} \mathrm{Cl}_{2}$
$\mathrm{Reflux}$
$\mathrm{X}=\underset{73 \%}{\mathrm{CH}_{2} \mathrm{CH}_{2}}$,
$\mathrm{X} \%$
$\mathrm{X}=0 \mathrm{C}_{6} \mathrm{H}_{4}$
$30 \%$<smiles>COc1cccc(OC)c1</smiles>

$\mathrm{MeO}$

$\stackrel{+}{\mathrm{H}_{2}}$

65

64a. $X=\mathrm{CH}_{2} \mathrm{CH}_{2}(48 \%)$
64b. $X=a-\mathrm{C}_{6} \mathrm{H}_{4}(50 \%)$
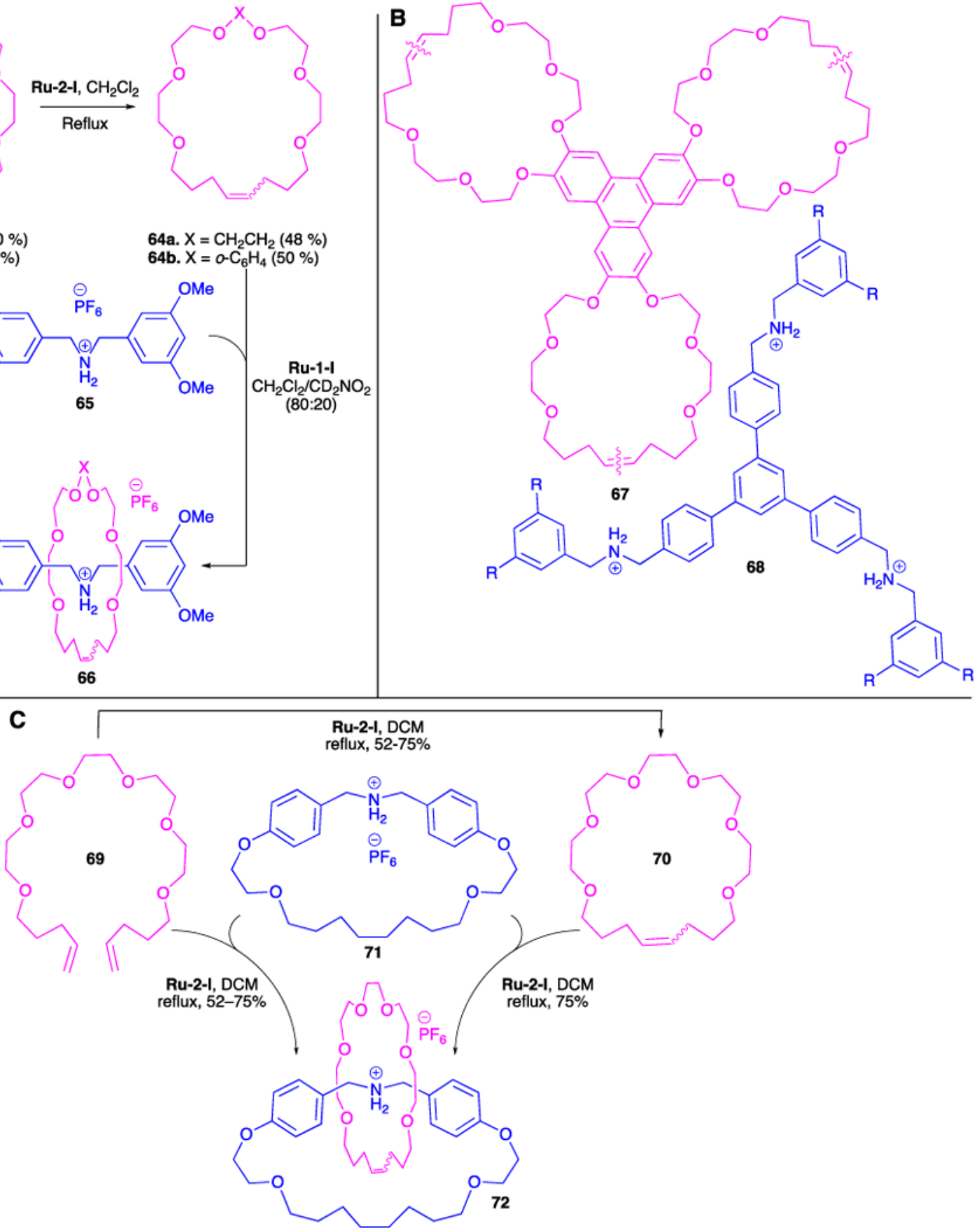

Figure 18

Synthesis of Magic Ring rotaxane macrocycles (A). Efficient preparation of a mechanicallyinterlocked bundle (B). Magic-ring catenation by olefin-metathesis $(\mathbf{C})$. 

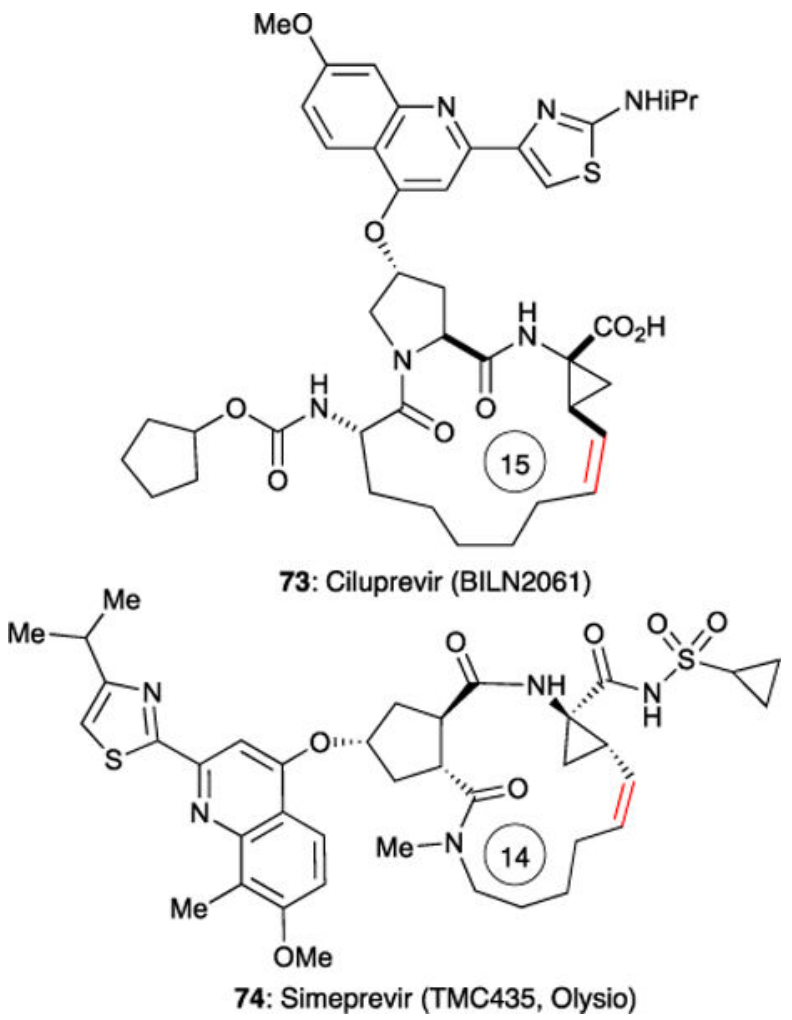

Figure 19.

Structures of HCV protease inhibitors Ciluprevir and Simeprevir (trade name Olysio). Red olefin bond indicates site of RCM. 


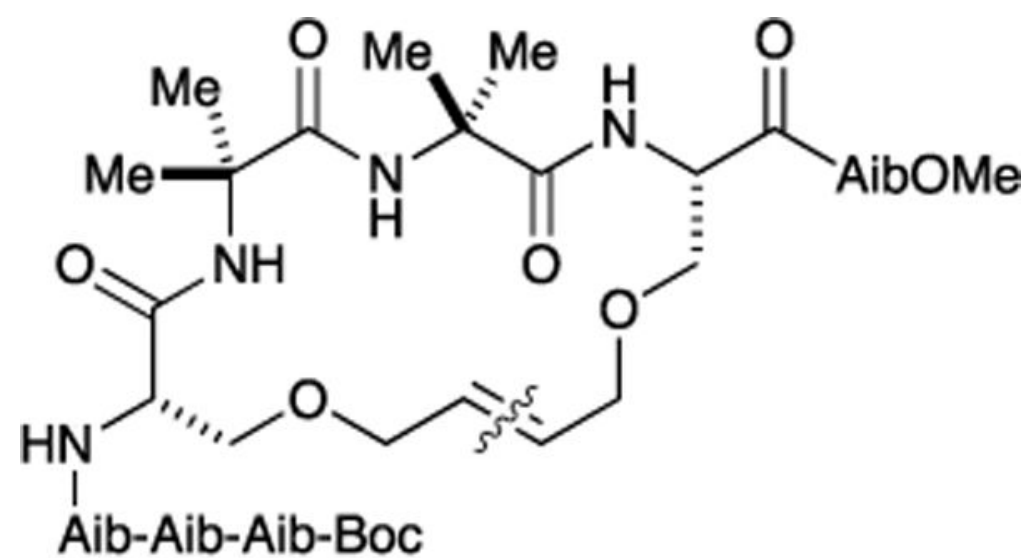

75

Figure 20.

Synthesis of macrocyclized peptide constrained for the 310 -helix. Wavy line across olefin bond indicate site of RCM. 


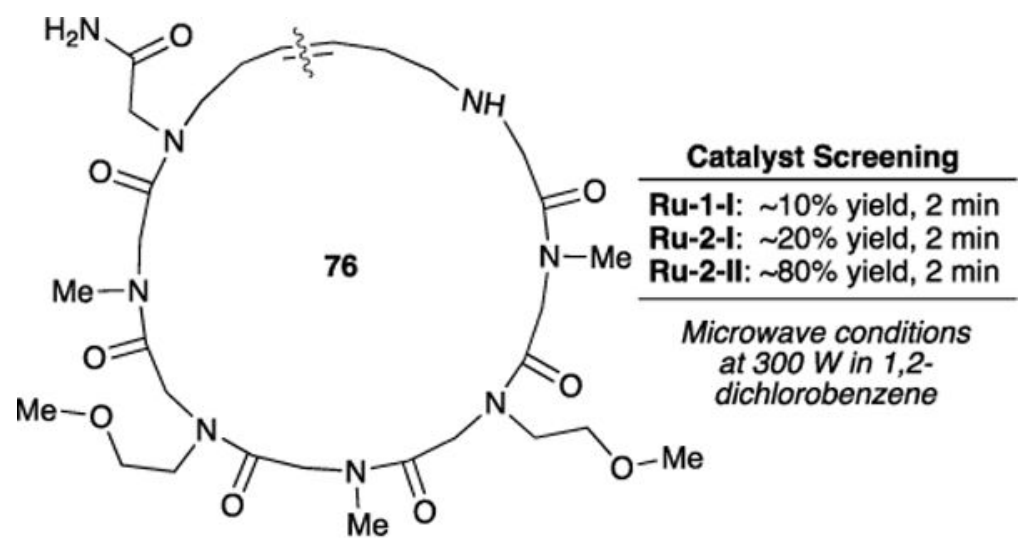

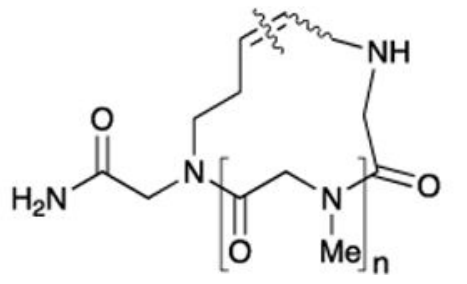

Using Ru-2-II:

77a, $n=2$ (4-mer), $\sim 70 \%$ yield

$77 \mathrm{~b}, \mathrm{n}=3$ (5-mer), $95 \%$ yield

77c, $n=4$ (6-mer), $\sim 84 \%$ yield

$77 \mathrm{~d}, \mathrm{n}=5$ (7-mer), $\sim 79 \%$ yield

Figure 21.

Solid-phase synthesis cyclic peptoids via RCM approach. Cyclic peptoids were cleaved from resin bead using trifluoroacetic acid (TFA). Wavy lines across olefin bond indicate site of RCM. 


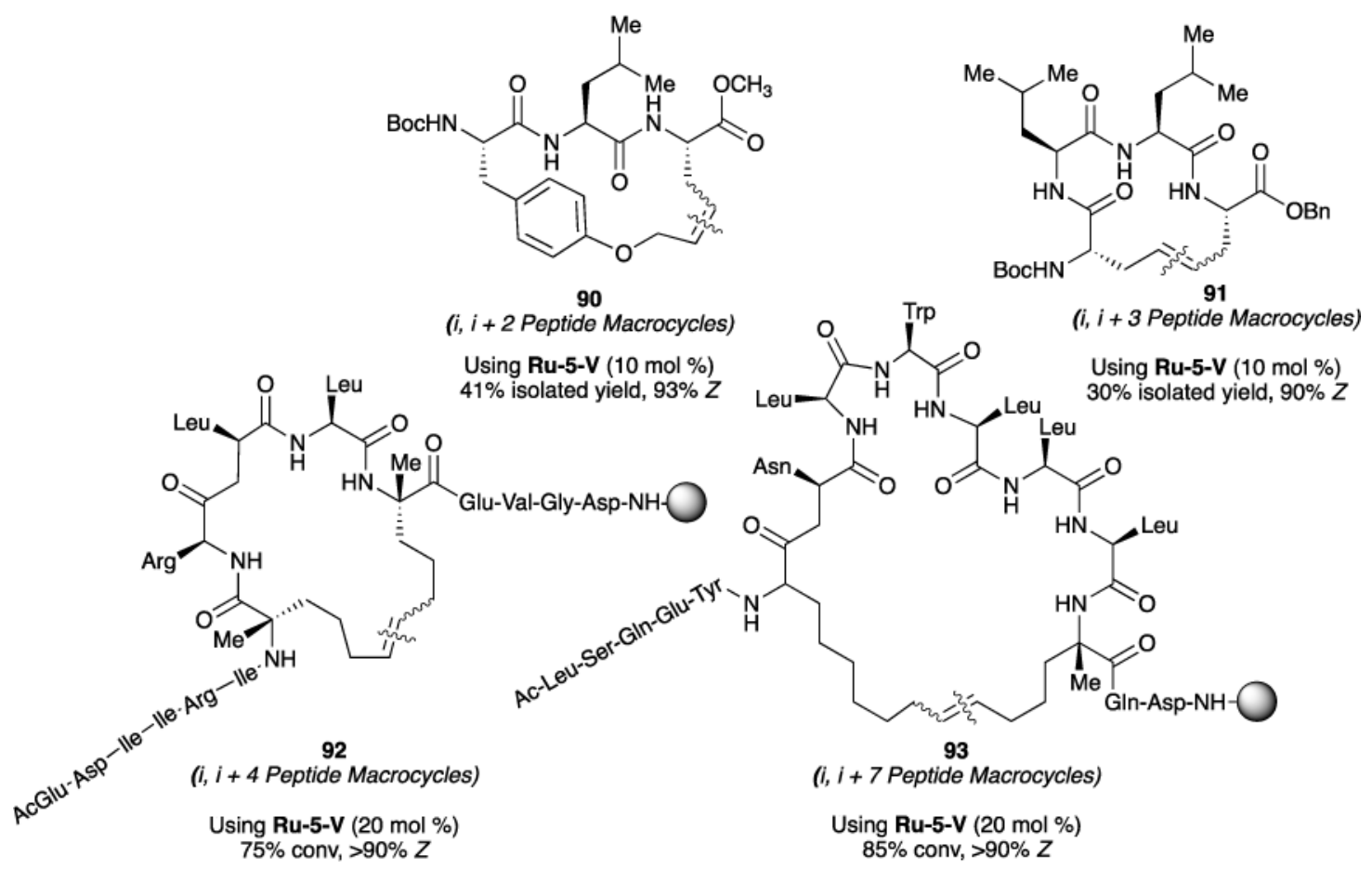

Figure 22.

$Z$-selective RCM to form peptide macrocycles. 

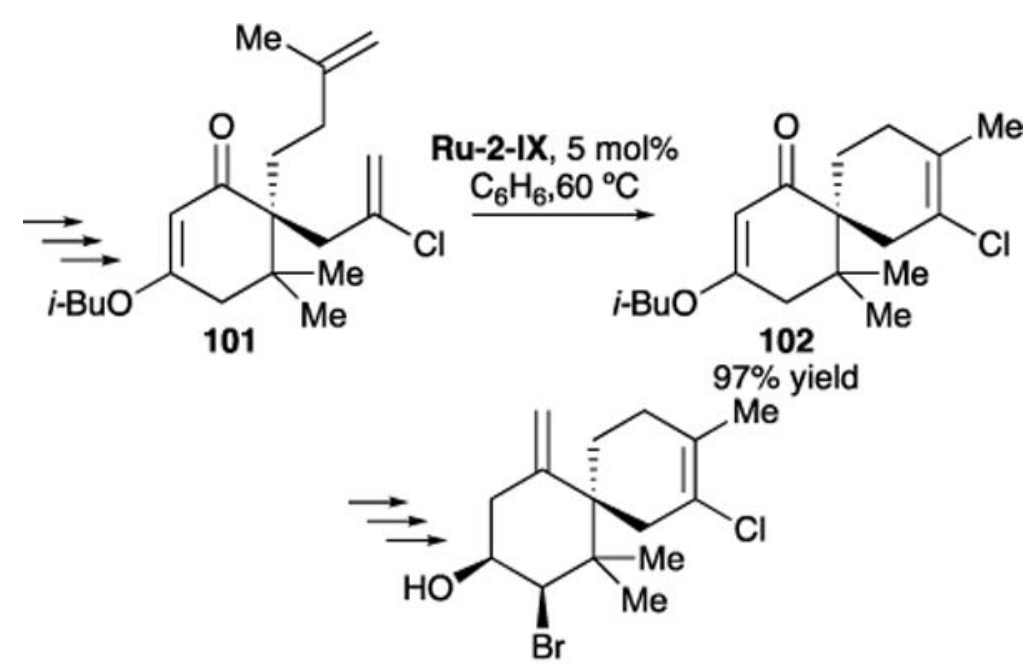

(+)-Elatol 103

Figure 23.

Using RCM for the synthesis of (+)-Elatol 103. 

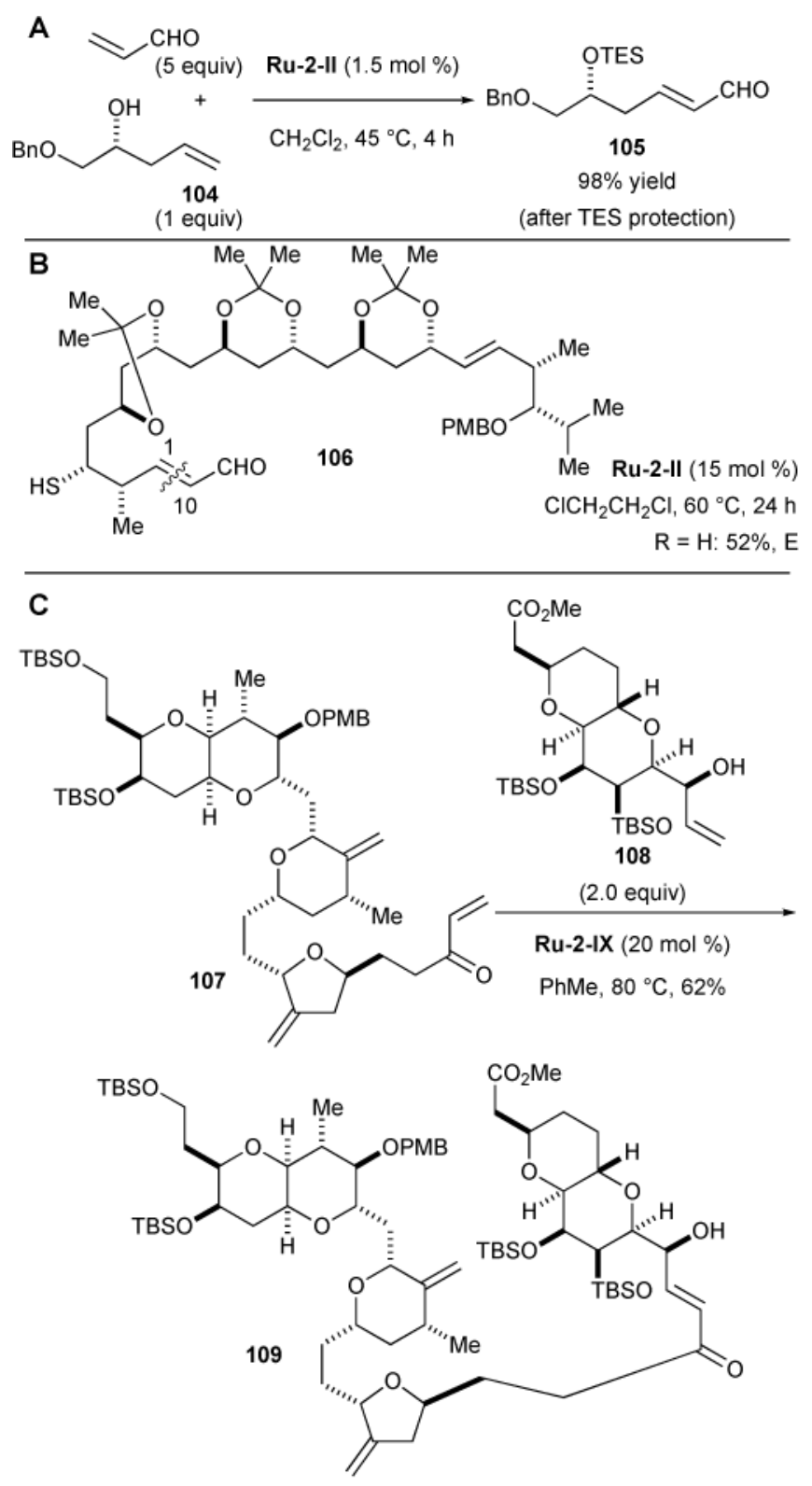

Figure 24.

Examples of cross metathesis $(\mathrm{CM})$ reactions used in natural product or natural productinspired syntheses. 


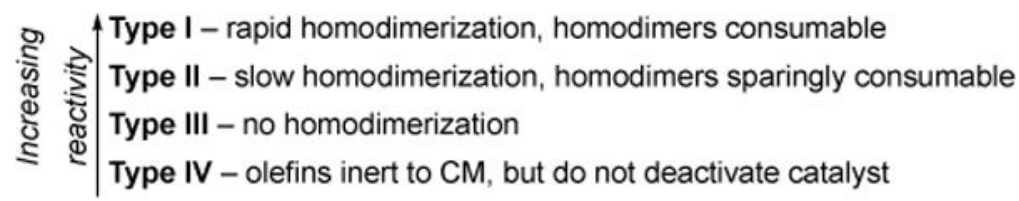

Reaction betweeen:

two olefins of type $\mathrm{I}$ = statistical $\mathrm{CM}$

two olefins of the same type (non-type $\mathrm{I}$ ) = nonselective $\mathrm{CM}$

olefins of two different types $=$ selective $\mathrm{CM}$

Figure 25.

Olefin categories and rules for selectivity in cross metathesis (CM) reactions. 
Non selective/statistical CM with two type I olefins:

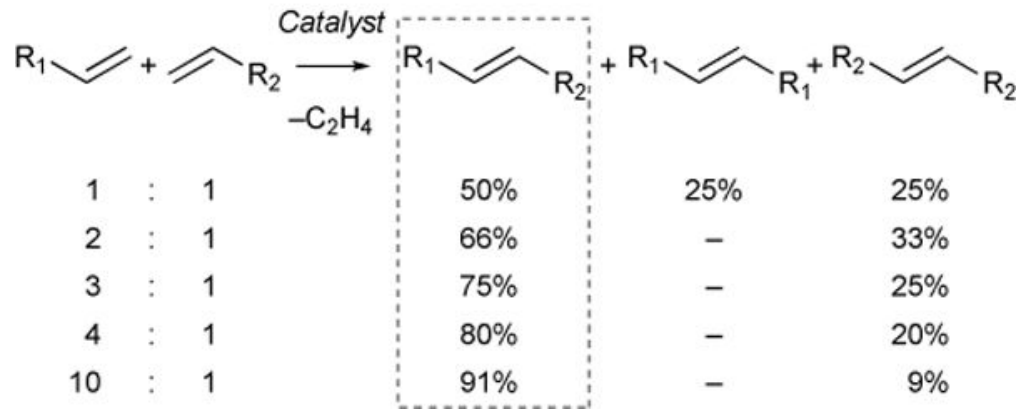

Figure 26.

Statistical cross-metathesis with type I olefins as a function of relative stoichiometry. 


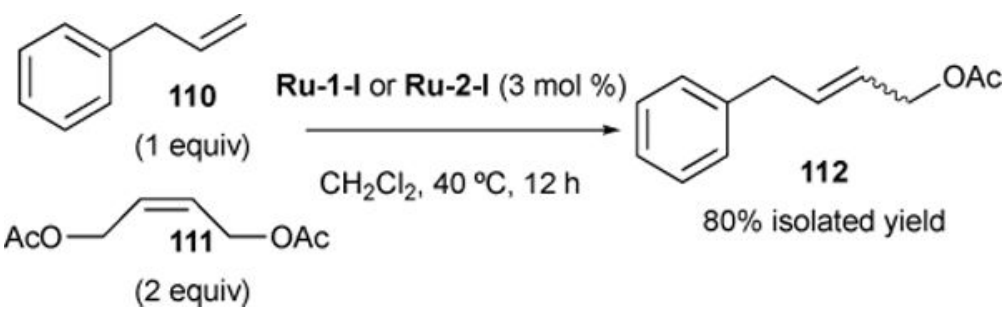

Figure 27.

Nonselective CM with two type I olefins. 


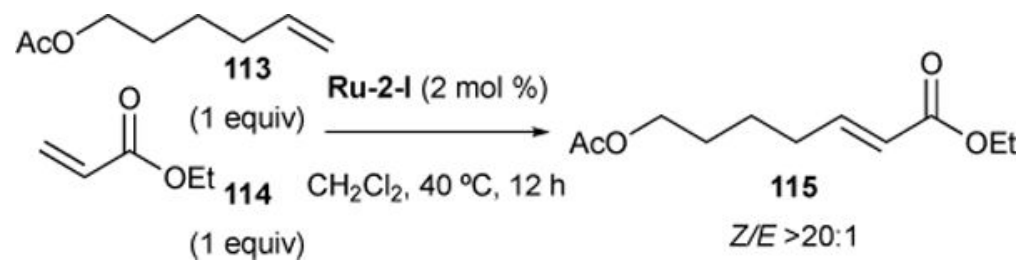

Figure 28.

Selective CM with type I and type II olefins. 

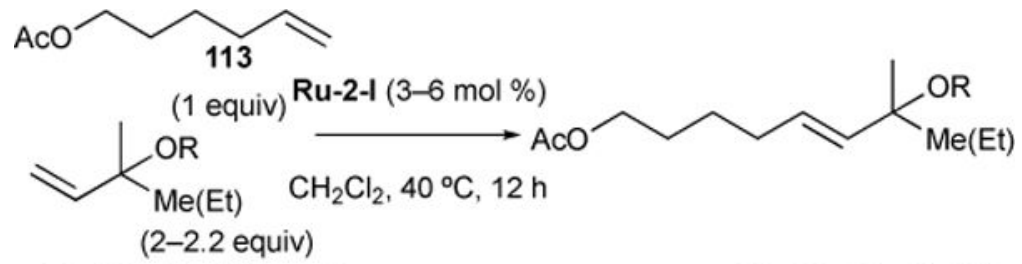

116. Me; $\mathrm{R}=\mathrm{H}$ (type II)

119. $\mathrm{Me} ; \mathrm{R}=\mathrm{H} ; 58 \%$

117. Et; $R=H$ (type II)

120. Et; $R=H ; 93 \%$

118. Me; R = TBS (type III)

121. $\mathrm{Me} ; \mathrm{R}=\mathrm{TBS} ; 97 \%$

Figure 29.

Selective CM of type I with type II vs type III olefins. 


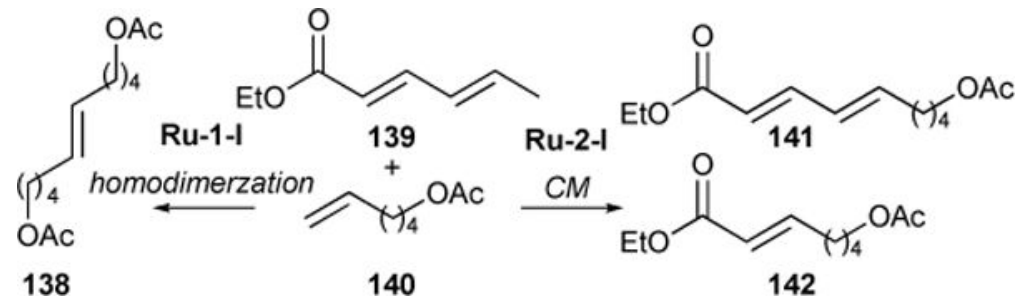

Figure 30.

Achieving cross metathesis (CM) using more active $\mathbf{R u - 2 - I}$ catalyst. 
A

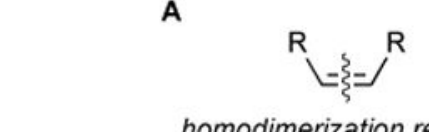

homodimerization reaction

up to $>95 \% Z$ using Ru-5-II
B

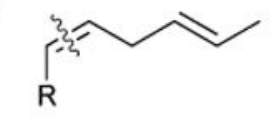

Non-conjugated dienes

$>95 \%$ Z using Ru-5-IV

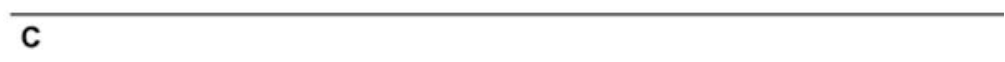

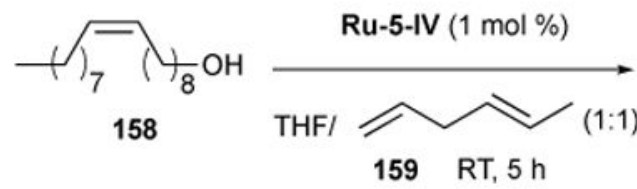

$159 \mathrm{RT}, 5 \mathrm{~h}$

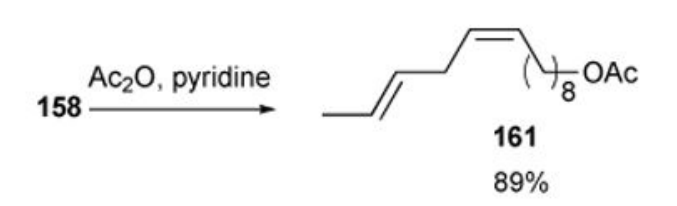

E

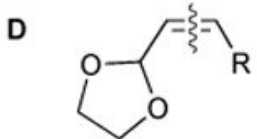

with allylic substituted olefins

up to $>95 \%$ Z using Ru-5-IV

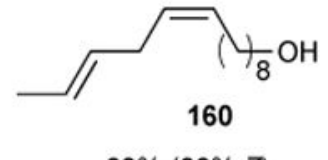

$68 \%(88 \% Z)$

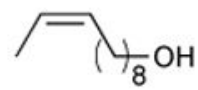

162

trace

Figure 31.

Scope of $Z$-selective cross-metathesis (CM) using Ru-5 catalysts. 

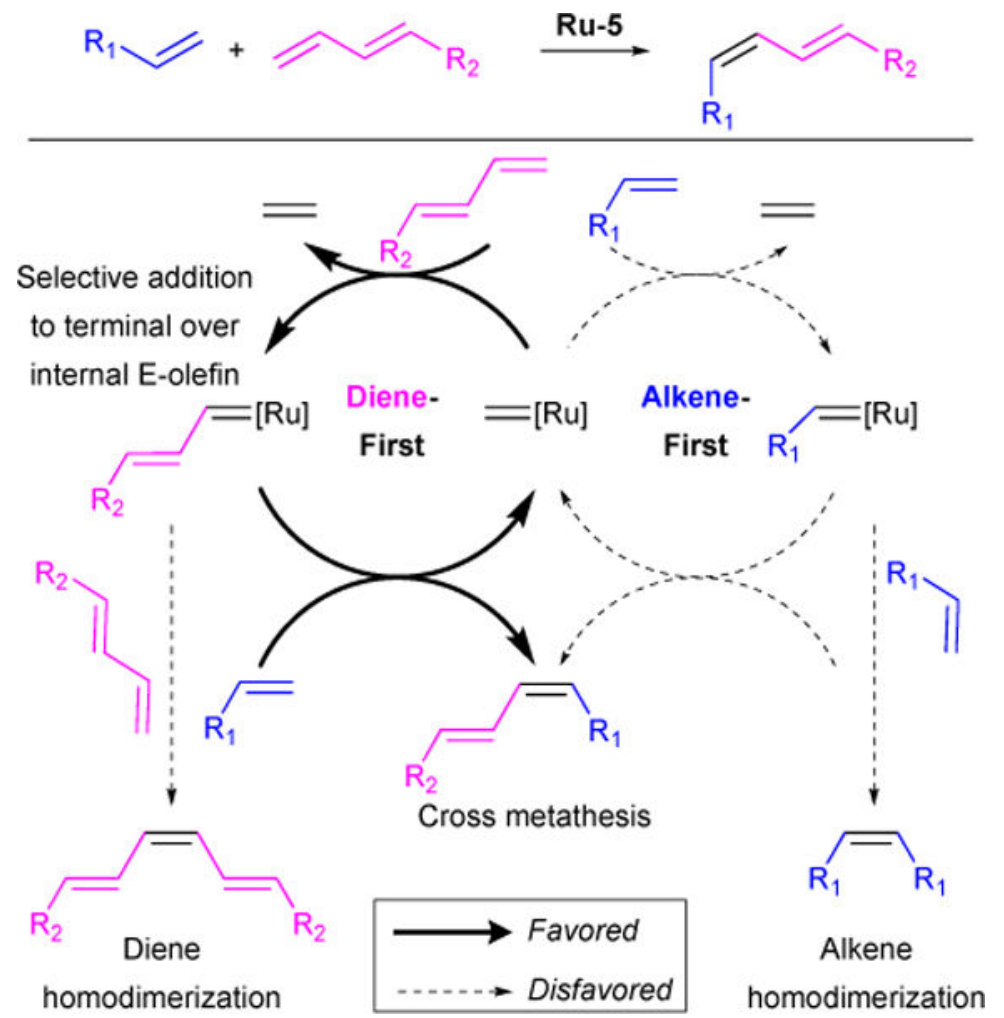

Figure 32.

Overall reaction and catalytic cycle of diene-alkene cross metathesis. 


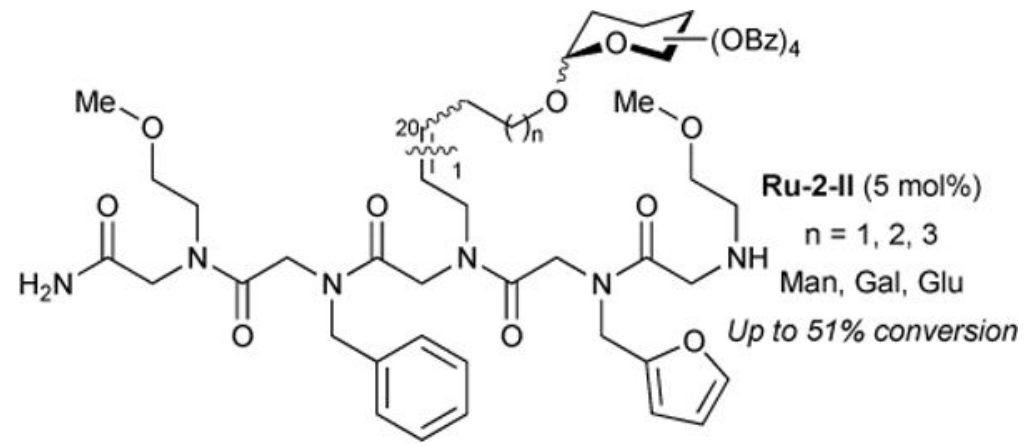

Figure 33.

CM assisted solid-phase synthesis of glycopeptoids. 

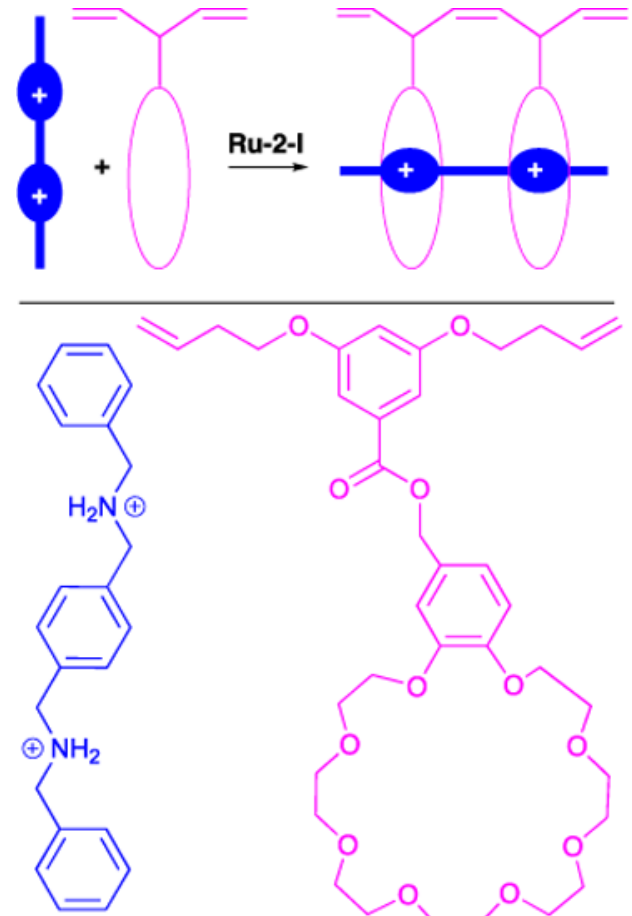

166

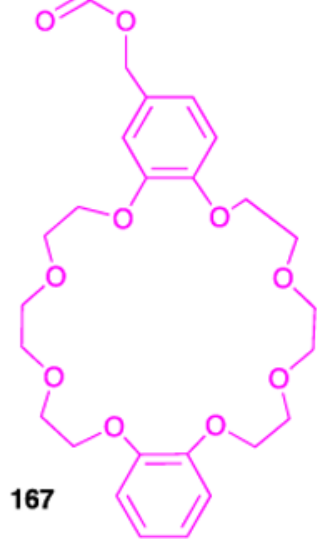

Figure 34.

Template-driven olefin cross-metathesis. 


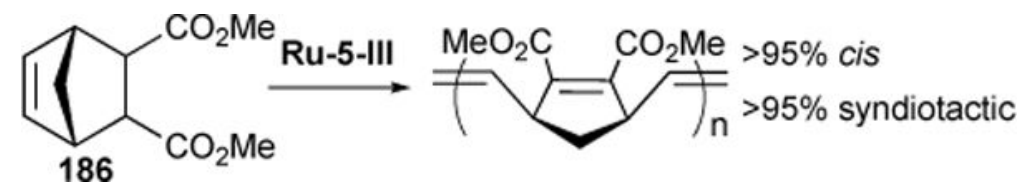

Figure 35.

Synthesis of a single microstructure polymer by ROMP with a stereoselective rutheniumbased catalyst. Conditions: [monomer]/[initiator] $=100: 1$ in THF ( $0.25 \mathrm{M}$ in substrate) at room temperature. 
A

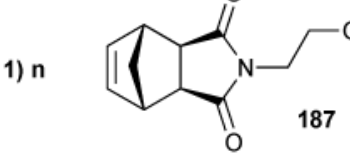

Ru-3-I
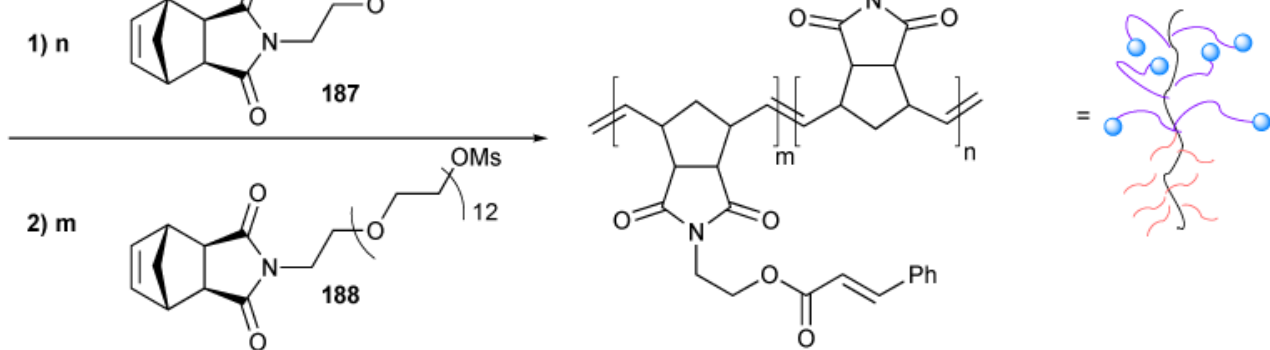

○
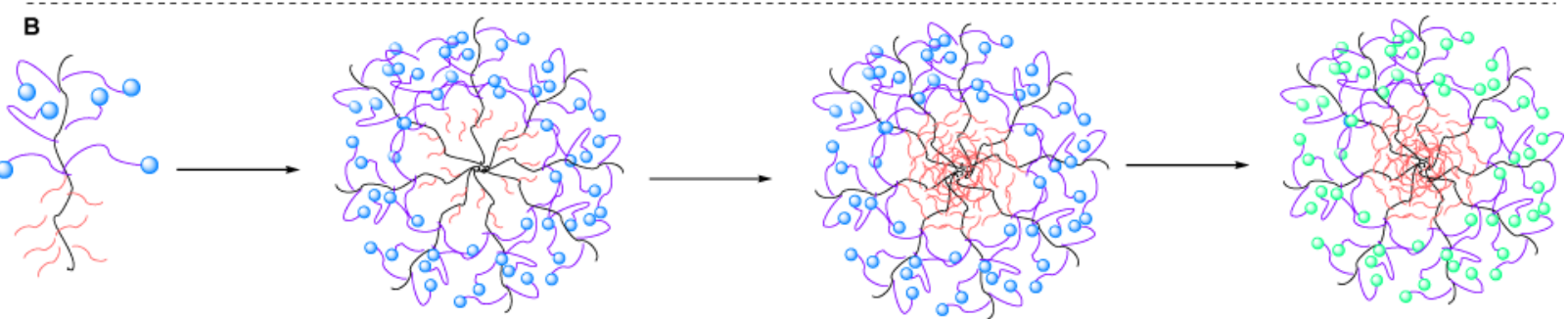

Figure 36.

Synthesis of PET-active fluorinated nanoparticles. Blacklines of polymer backbone. Purple lines are pendant PEG groups. Red lines are cinnamoyl groups. Blue and green spheres are mesylate groups and fluorine atoms, respectively. (A) Ru-3 mediated sequential ROMP. (B) i) Dialysis against $\mathrm{H}_{2} \mathrm{O}$. (ii) $h v, 3$ min. (iii) $1 . \mathrm{K}^{18} \mathrm{~F}$, kryptofix-222, $\mathrm{K}_{2} \mathrm{CO}_{3}, \mathrm{BHT}, \mathrm{MeCN}$, $120^{\circ} \mathrm{C}, 60 \mathrm{~min} .2 \mathrm{~K}^{19} \mathrm{~F}$, kryptofix-222, $\mathrm{MeCN}, 80^{\circ} \mathrm{C}, 30 \mathrm{~min}$. 


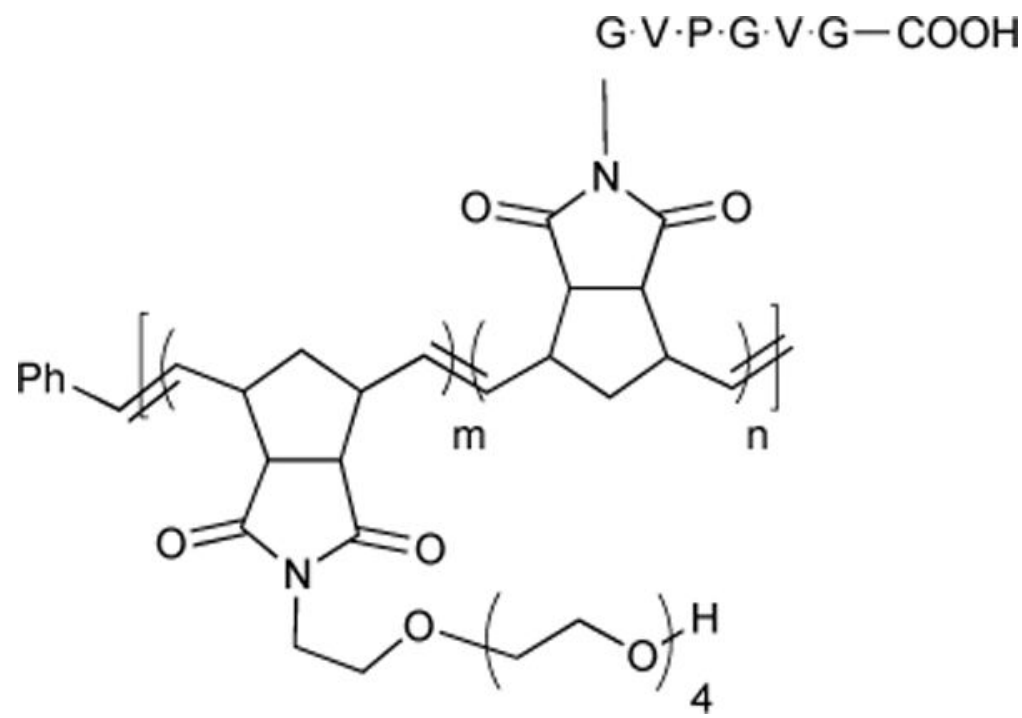

Figure 37.

Structure of an elastin-based random copoly(norbornene) with tunable temperature responsive behavior. 

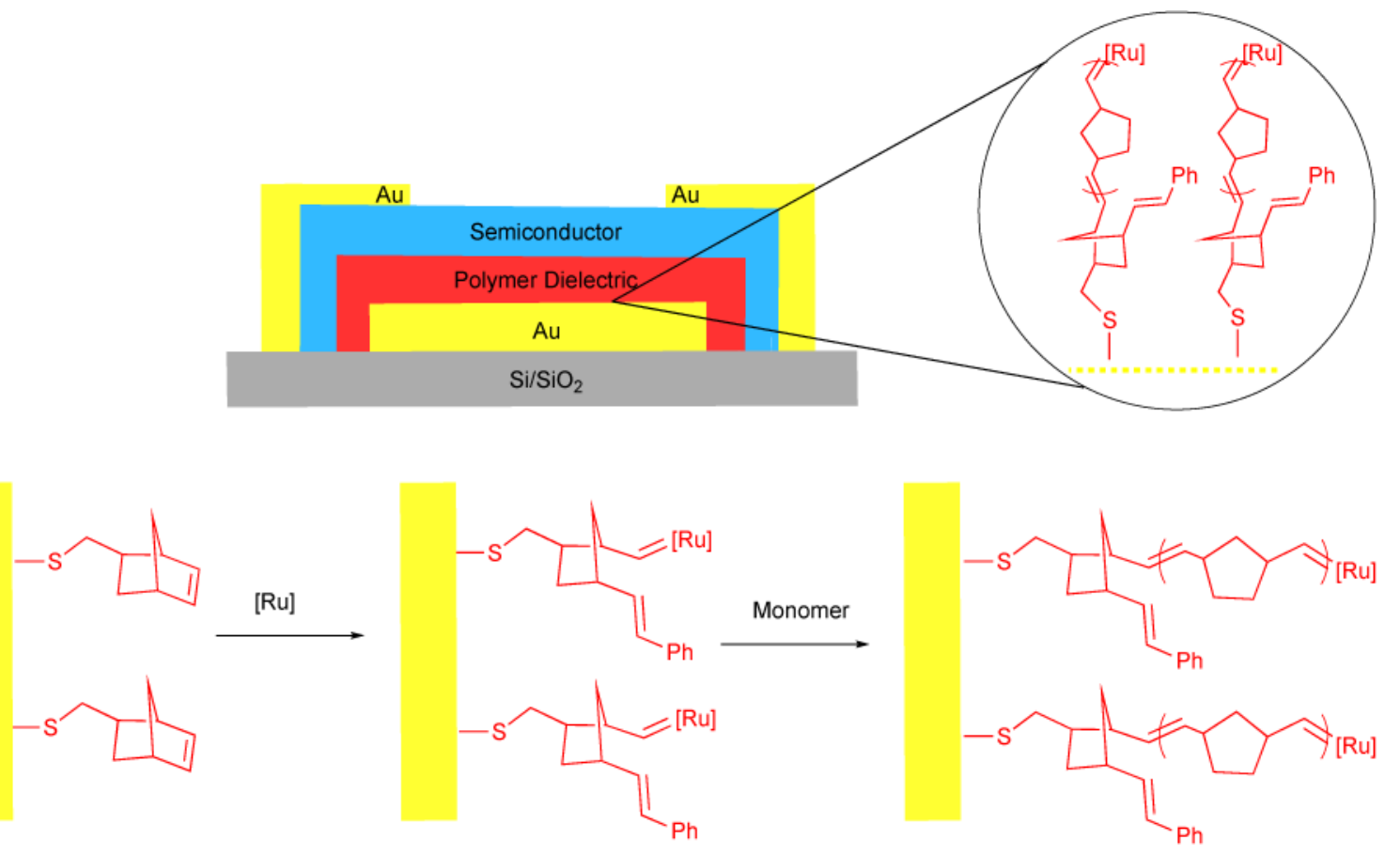

Figure 38.

FET fabricated from an SI-ROMP polymer dielectric layer.

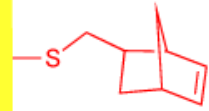

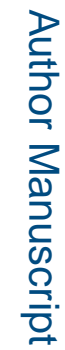



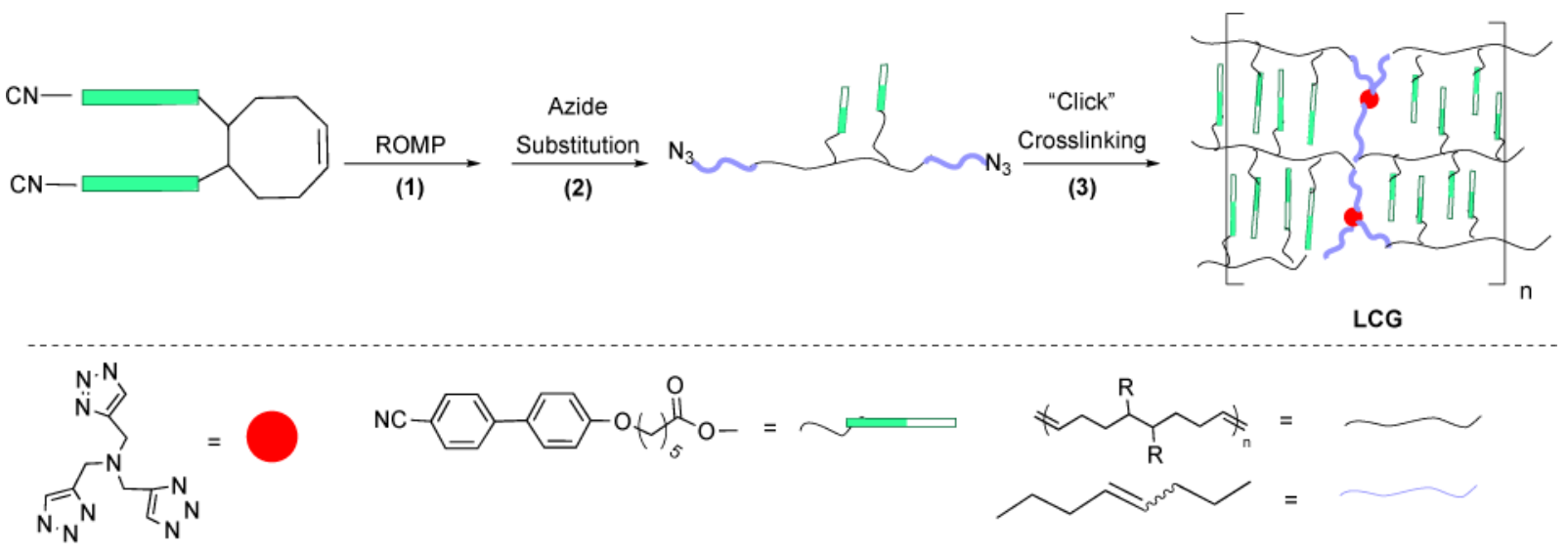

Figure 39.

Preparation well-defined liquid crystal gels from telechelic ROMP polymers. (1) Ru-2-I, dichloroethane, 1,8-dibromo-4-octene, $55^{\circ} \mathrm{C}, 24 \mathrm{hr}$. (2) $\mathrm{NaN}_{3}$, DMF. (3) Triacetylene, tripropylargylamine, cat. CBr, PMDETA, DMF, 5 min (gelation) +2 days (curing at $50^{\circ} \mathrm{C}$ ). 

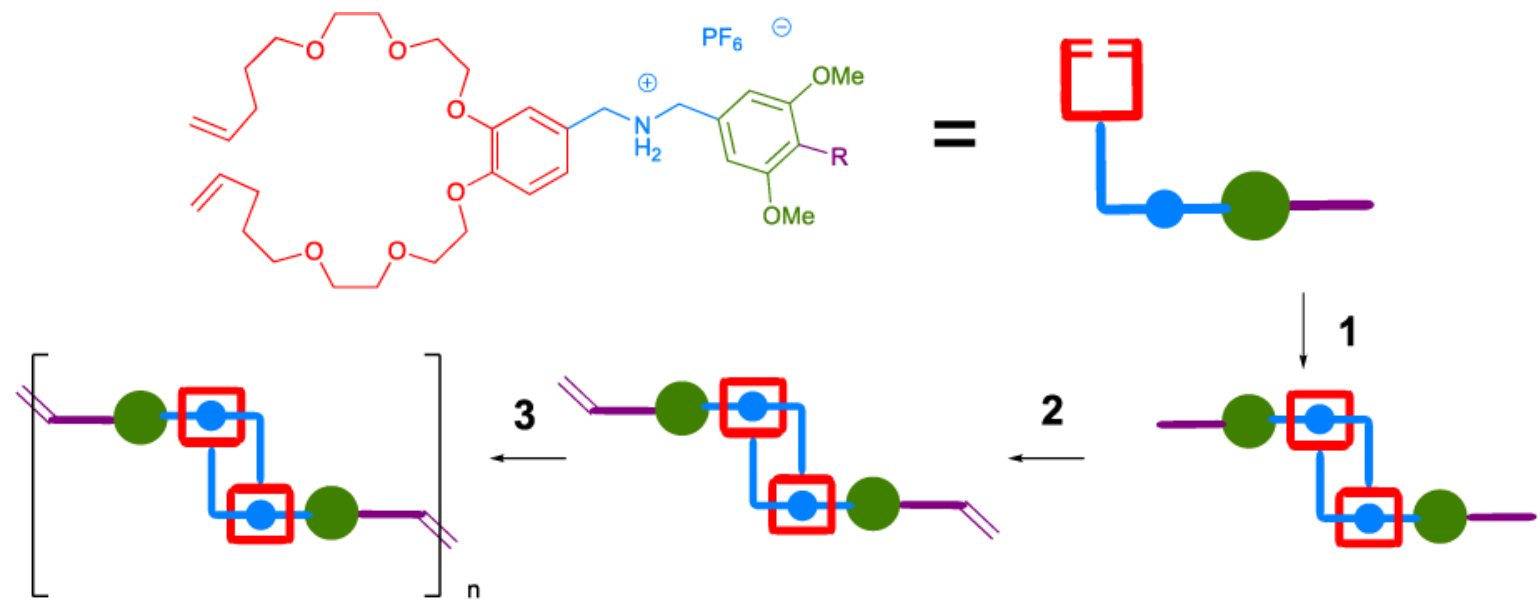

Figure 40.

Dual-metathesis mediated preparation of mechanically-interlocked polymers based on a [c2]daisy-chain motif. $\mathrm{R}=\mathrm{H}, \mathrm{O}\left(\mathrm{CH}_{2}\right)_{6} \mathrm{OH}$. (1) i. Ru-2-I, DCM. ii. $\mathrm{H}_{2} \backslash \mathrm{PtO}_{2}$, EtOAc. (2) 4Pentenoic acid, EDC, DMF. (3) DCM, $45^{\circ} \mathrm{C} .164$ 


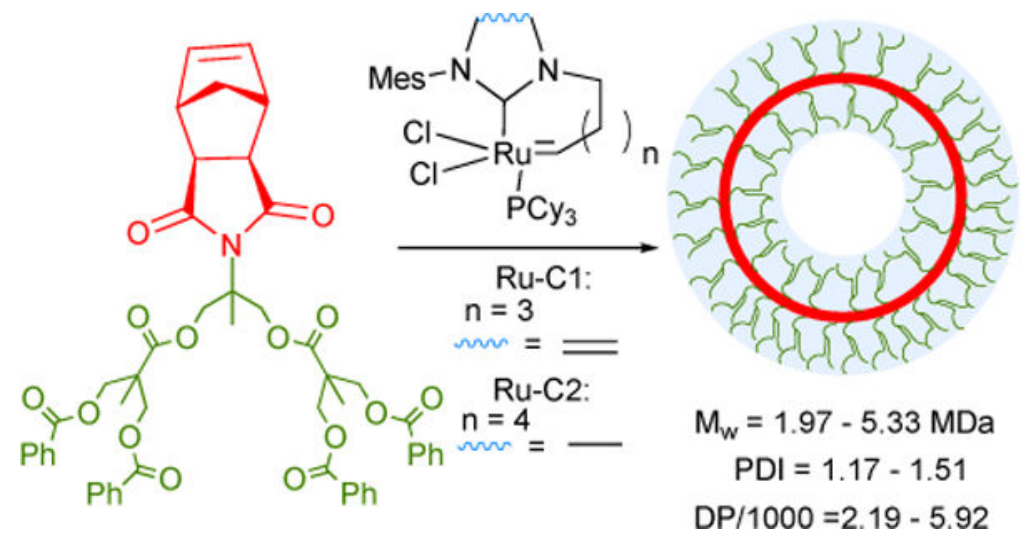

Figure 41.

REMP of dendronized macromonomer. 


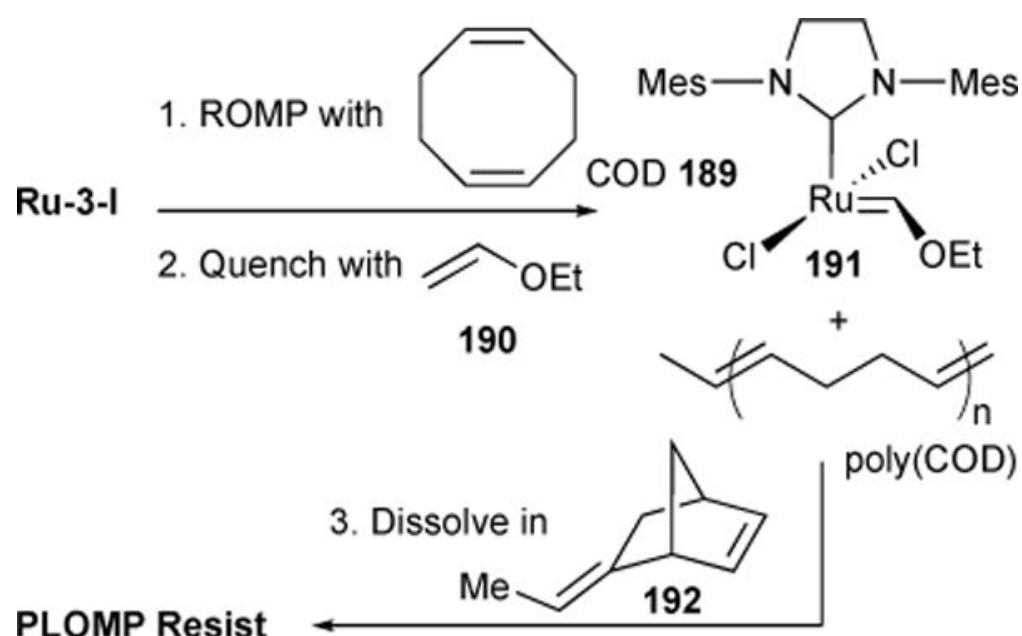

Figure 42.

Preparation of latent metathesis photocatalyst 189 via ROMP of 1,5-cyclooctadiene (COD) using Ru-3-I followed by quenching with ethyl vinyl ether 190. The resulting polyCOD is dissolved in 5-ethylidene-2-norbonene 192 to yield highly viscous resist material stabilizing 191. 

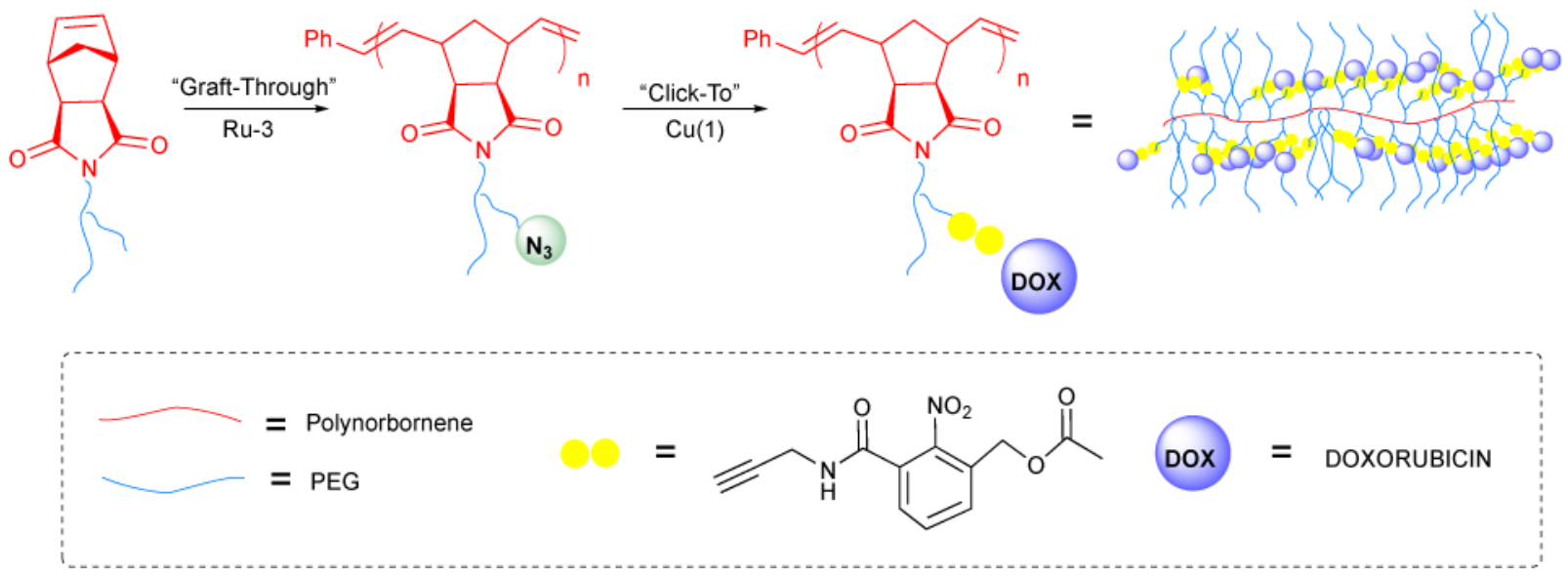

Figure 43.

Adaptable "Graft-Though" then "Click-To" synthesis of bivalent bottle-brush polymers for triggered drug release. 

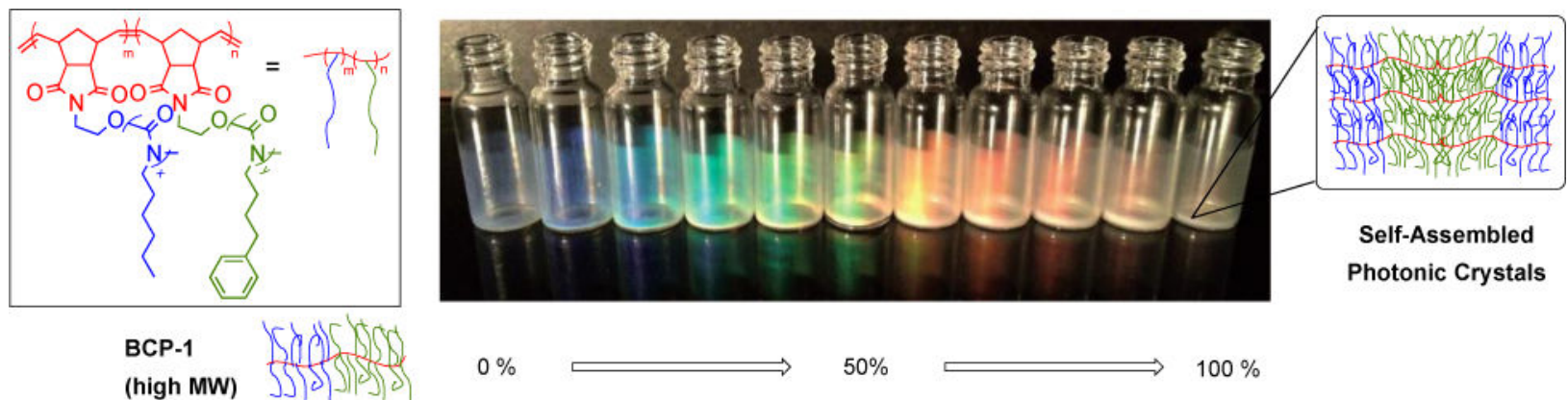

(high MW)

$0 \%$

$50 \%$

$100 \%$

BCP-2

(low MW)

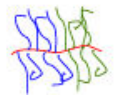

$100 \%$

$50 \%$

$0 \%$

Figure 44.

PCs tuned to have bandgaps across the visible spectrum by way of intervaled variance in brush BCP ratios. Brush BCP blends are composed of high $\mathrm{MW}\left(\mathrm{M}_{\mathrm{W}}=4167 \times 10^{3} \mathrm{~g} / \mathrm{mol}\right)$ and low $\mathrm{MW}\left(\mathrm{M}_{\mathrm{W}}=1512 \times 10^{3} \mathrm{~g} / \mathrm{mol}\right)$ otherwise equivalent brush BCPs varied in composition from 0 to $100 \%$ at $10 \%$ intervals. 

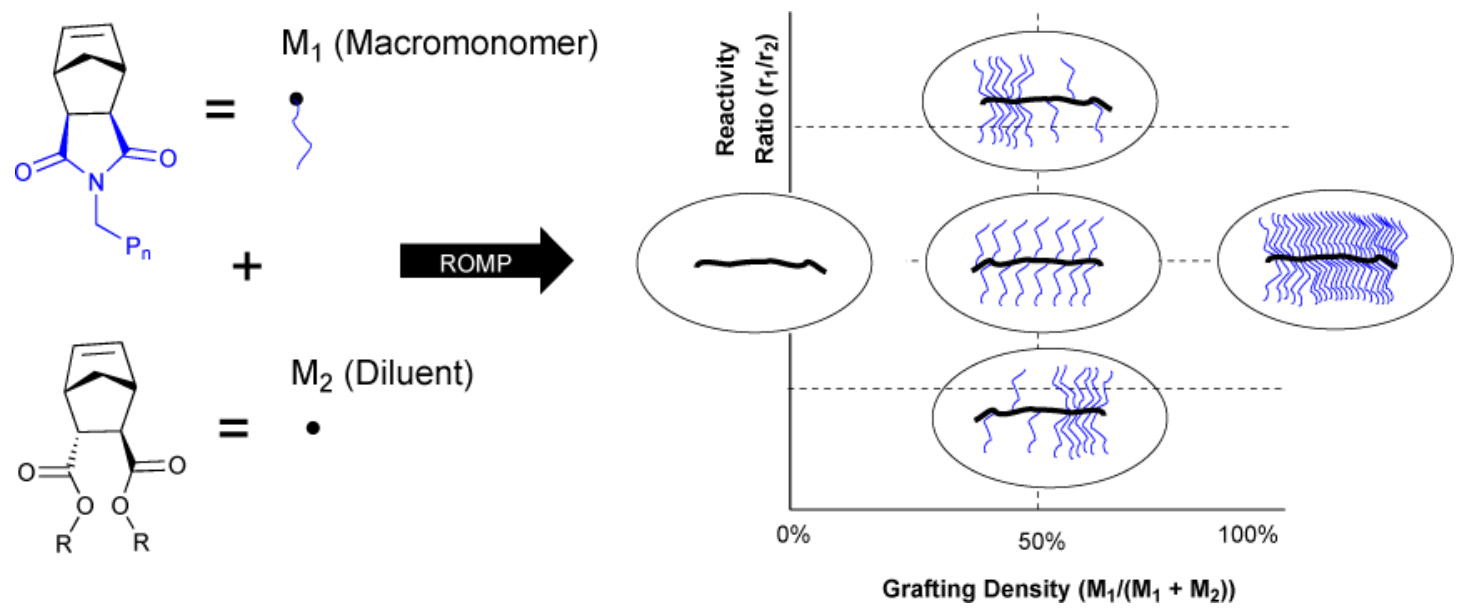

Figure 45.

A method for simultaneously controlling the grafting density and side chain distribution in ROMP-derived brush copolymers by way of rational monomer design. $\mathrm{P}_{\mathrm{N}}$ is poly(styrene, lactide, or dimethyl siloxane). $\mathrm{R}$ is methyl, ethyl, or ${ }^{\mathrm{n}} \mathrm{Bu}$. 


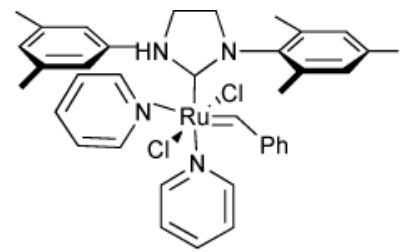

n<smiles>CCOC(=O)CN1C(=O)C2C3C=CC(C3)C2C1=O</smiles>

$\mathrm{m}$
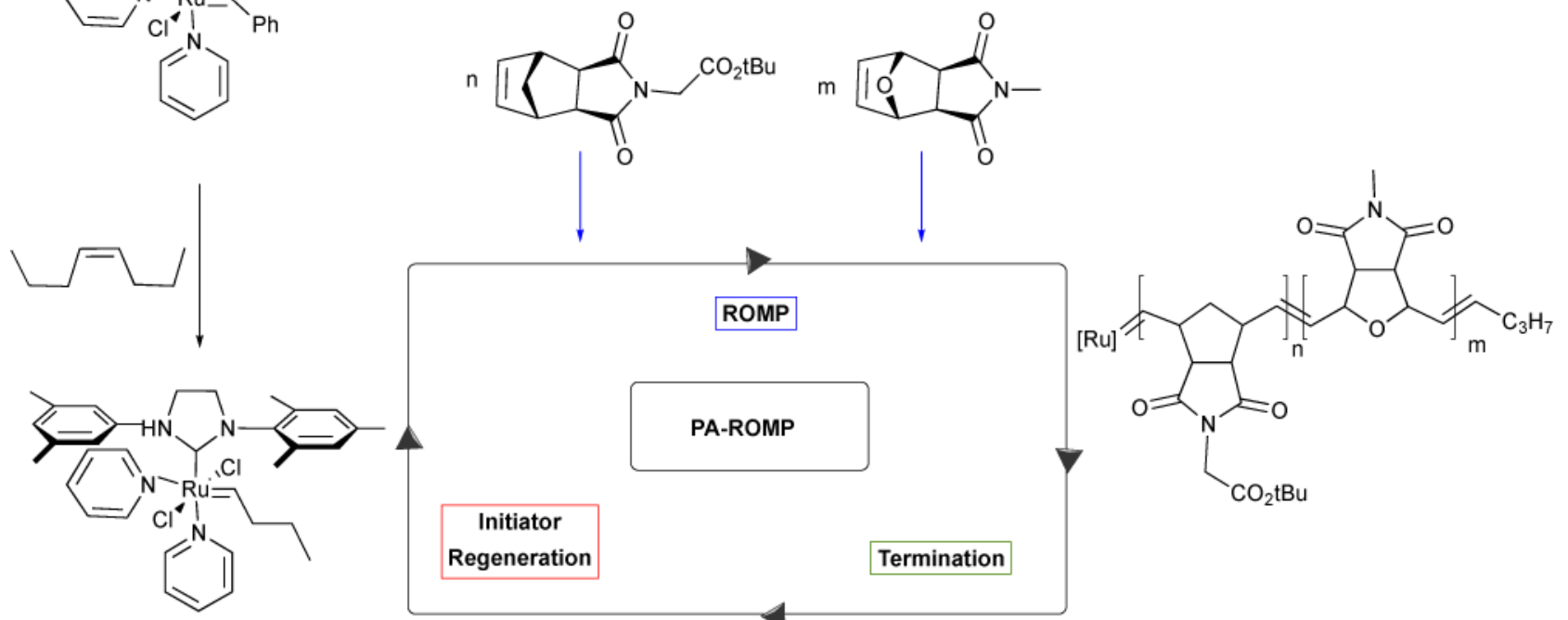

Regeneration

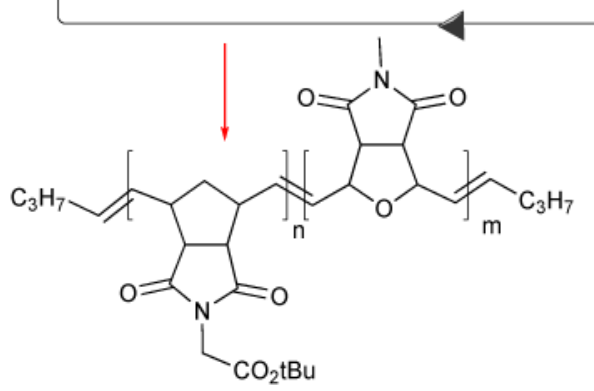

Termination

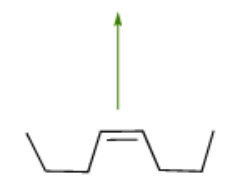

Figure 46.

General scheme for the PA-ROMP of an exemplary poly(norbornene)-poly(oxanorbornene) block copolymer. 


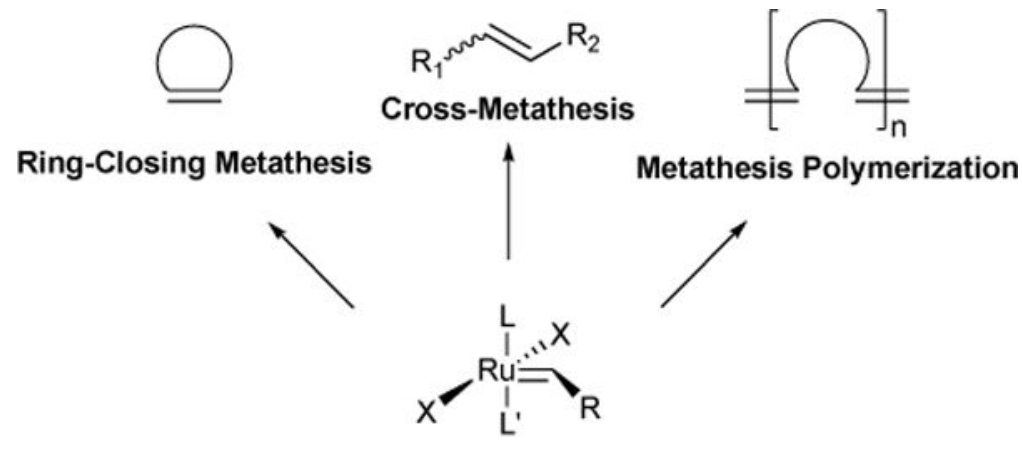

Catalyst Development

Scheme 1.

General $\mathrm{Ru}(\mathrm{II})$ catalyst structure and metathesis applications. 
Table 1

Effects of Ru-2-I phosphine substitution on initiation kinetics.

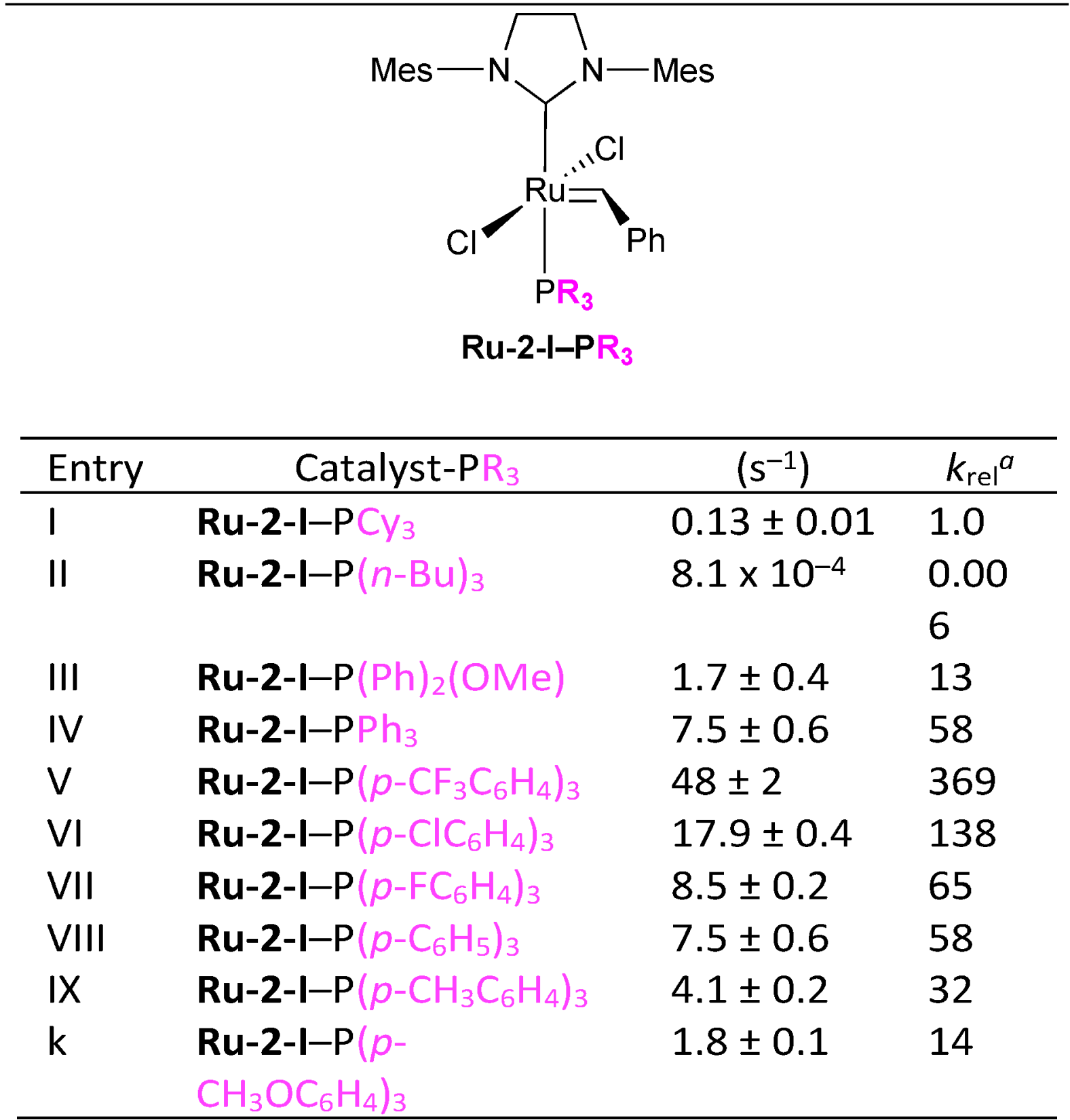

${ }^{a} k_{\text {rel }}=k_{1}$ for each catalyst entry $/ k_{1}$ for catalyst in entry i 


\section{Table 2}

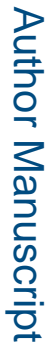

$\mathrm{Ru}-2$ asymmetric ring-closing metathesis catalysts.

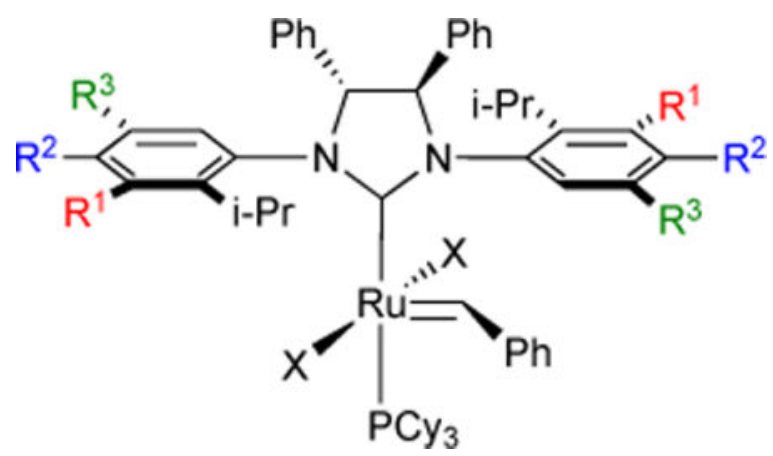

\begin{tabular}{ll}
\hline Catalyst & C \\
\hline Ru-2-X & $\mathrm{Cl}$ \\
Ru-2-XI & I \\
Ru-2-XII & $\mathrm{Cl}$ \\
Ru-2-XIII & I \\
Ru-2-XIV & $\mathrm{Cl}$ \\
Ru-2-XV & I \\
Ru-2-XVI & $\mathrm{Cl}$ \\
Ru-2-XVII & I \\
Ru-2-XVIII & $\mathrm{Cl}$ \\
Ru-2-XIX & I \\
\hline
\end{tabular}

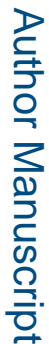


Table 3

Survey of some Ru-2 catalysts for asymmetric ring-closing metathesis.

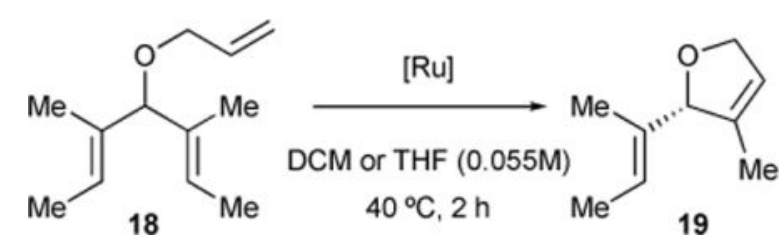

\begin{tabular}{ccc}
\hline Catalyst & $\boldsymbol{e e}(\%)$ & $\operatorname{conv}(\%)$ \\
\hline Ru-2-X & 35 & $>98$ \\
Ru-2-XII & 31 & $>98$ \\
Ru-2-XIV & 30 & $>98$ \\
Ru-2-XVI & 46 & $>98$ \\
Ru-2-XI & 90 & $>98$ \\
Ru-2-XIII & 84 & $>98$ \\
Ru-2-XV & 87 & $>98$ \\
Ru-2-XVII & 90 & $>98$ \\
\hline
\end{tabular}




\section{Table 4}

Survey of some Ru-2 catalysts for asymmetric ring-opening cross metathesis.
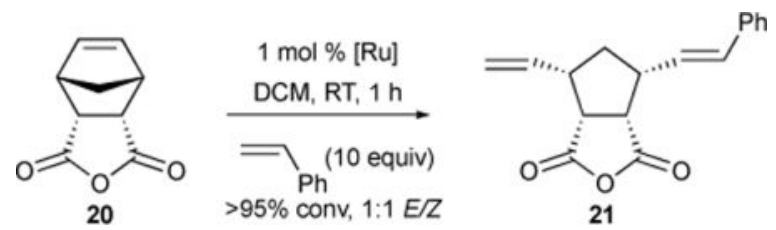

\begin{tabular}{ccc}
\hline Catalyst & Product & $\boldsymbol{e e}(\boldsymbol{\%})$ \\
\hline Ru-2-XVI & ent-21 & 47 \\
Ru-2-X & ent-21 & 29 \\
Ru-2-XII & $\mathbf{2 1}$ & 62 \\
Ru-2-XIV & $\mathbf{2 1}$ & 76
\end{tabular}

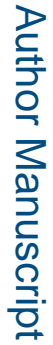

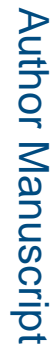

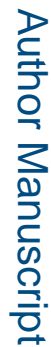

Chem Soc Rev. Author manuscript; available in PMC 2019 June 18 
Table 5

Comparison of Ru Catalysts with Standard RCM, CM, and ROMP Reactions.

\begin{tabular}{|c|c|c|c|}
\hline Reaction (time) & Ru-1-I & Ru-2-I & Ru-2-II \\
\hline $1(30 \mathrm{~min})$ & $66 \%$ & $97 \%$ & $99 \%$ \\
\hline $2(60 \mathrm{~min})$ & $21 \%$ & $98 \%$ & $98 \%$ \\
\hline $3(4 d)$ & $0 \%$ & $17 \%$ & $6 \%$ \\
\hline $4(30 \mathrm{~min})$ & $18 \%$ & $79 \%$ & $72 \%$ \\
\hline $5(2 \mathrm{hr})$ & $\sim 10 \%$ & $98 \%$ & $\sim 90 \%$ \\
\hline $6(5 \mathrm{~min})$ & $\sim 5 \%$ & $98 \%$ & $99 \%$ \\
\hline
\end{tabular}


Table 6

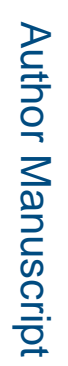

$Z$-selective macrocyclization using Ru-5-V.

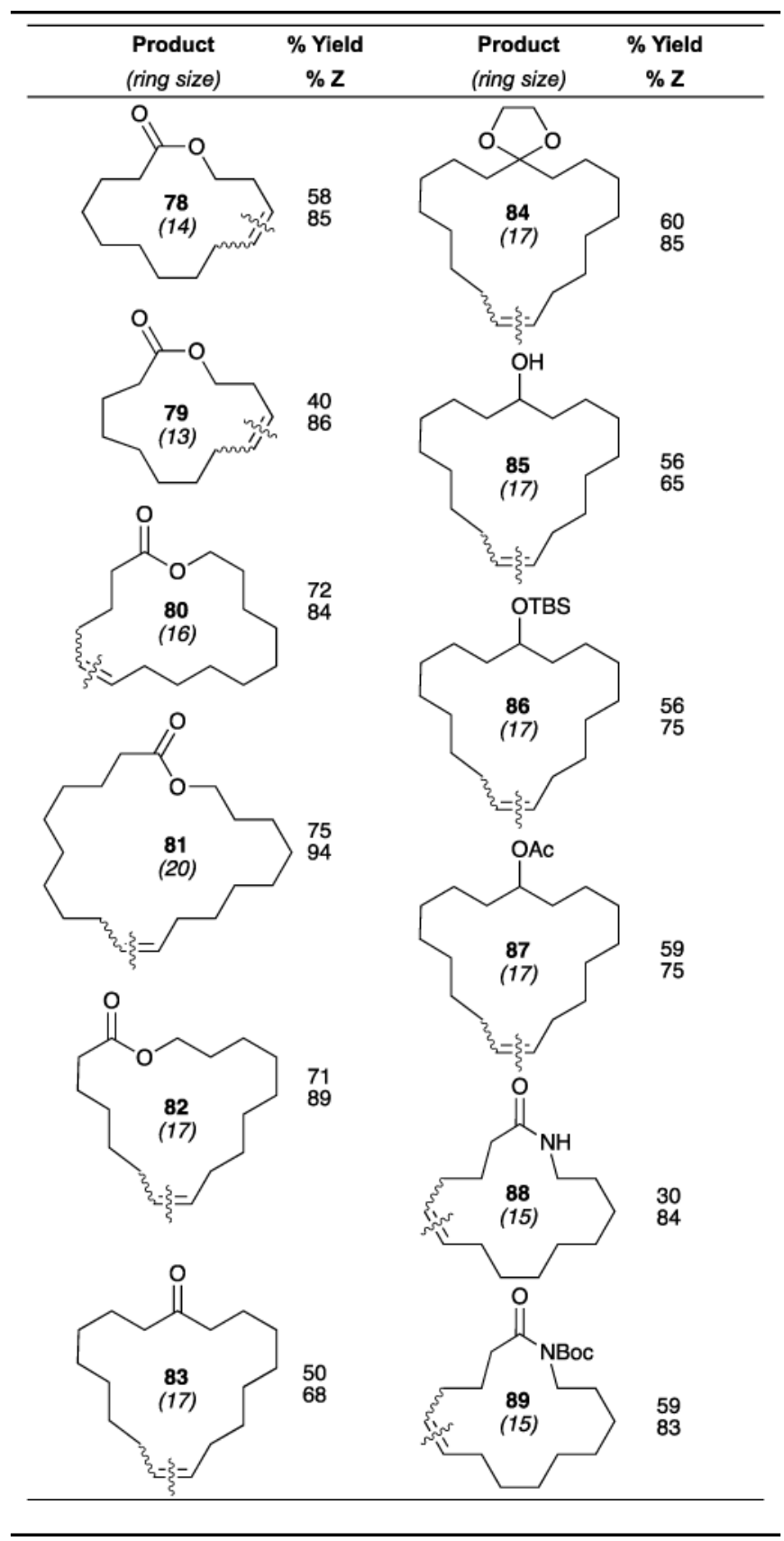

로을

Chem Soc Rev. Author manuscript; available in PMC 2019 June 18. 
Table 7

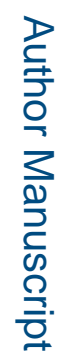

Asymmetric ring-closing metathesis with Ru-5-IV.

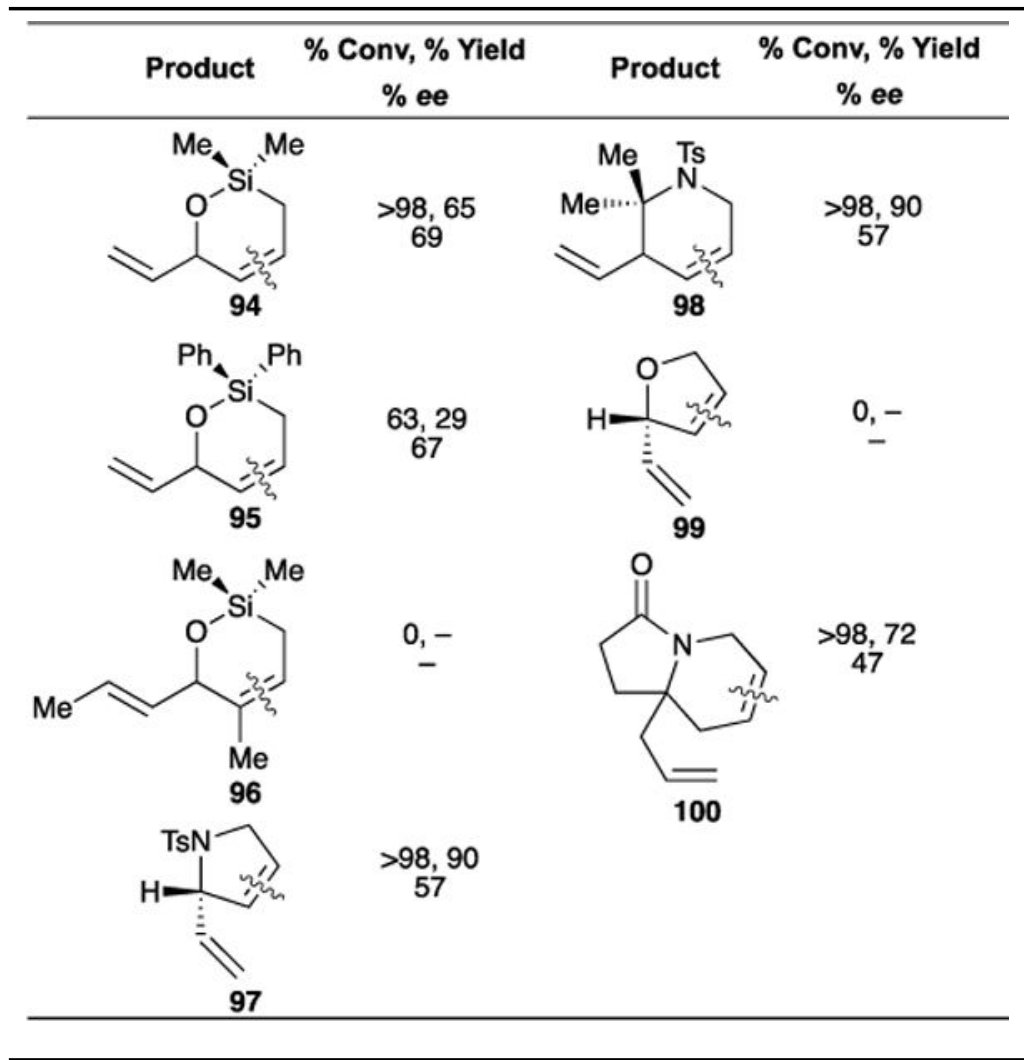

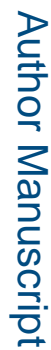

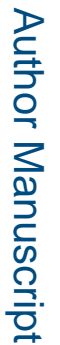

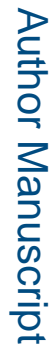


Table 8

Vinyl, 1-propenyl, and 2-propenyl pinacol and MIDA boronate (BPin, BMIDA) CM and halogenation processes.

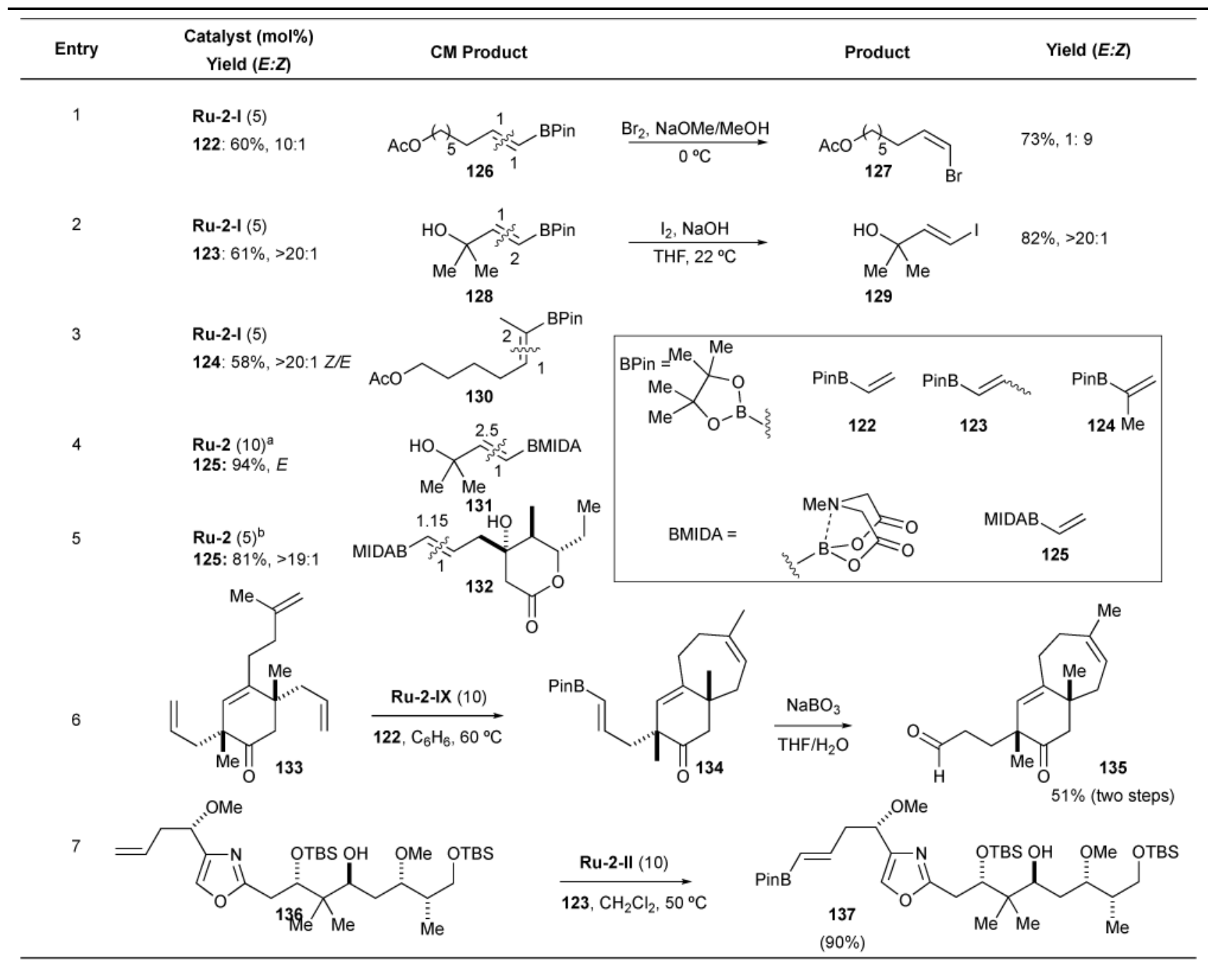

Chem Soc Rev. Author manuscript; available in PMC 2019 June 18. 
Table 9

Electronic control of chemoselective construction of conjugated dienes via olefin cross-metathesis.
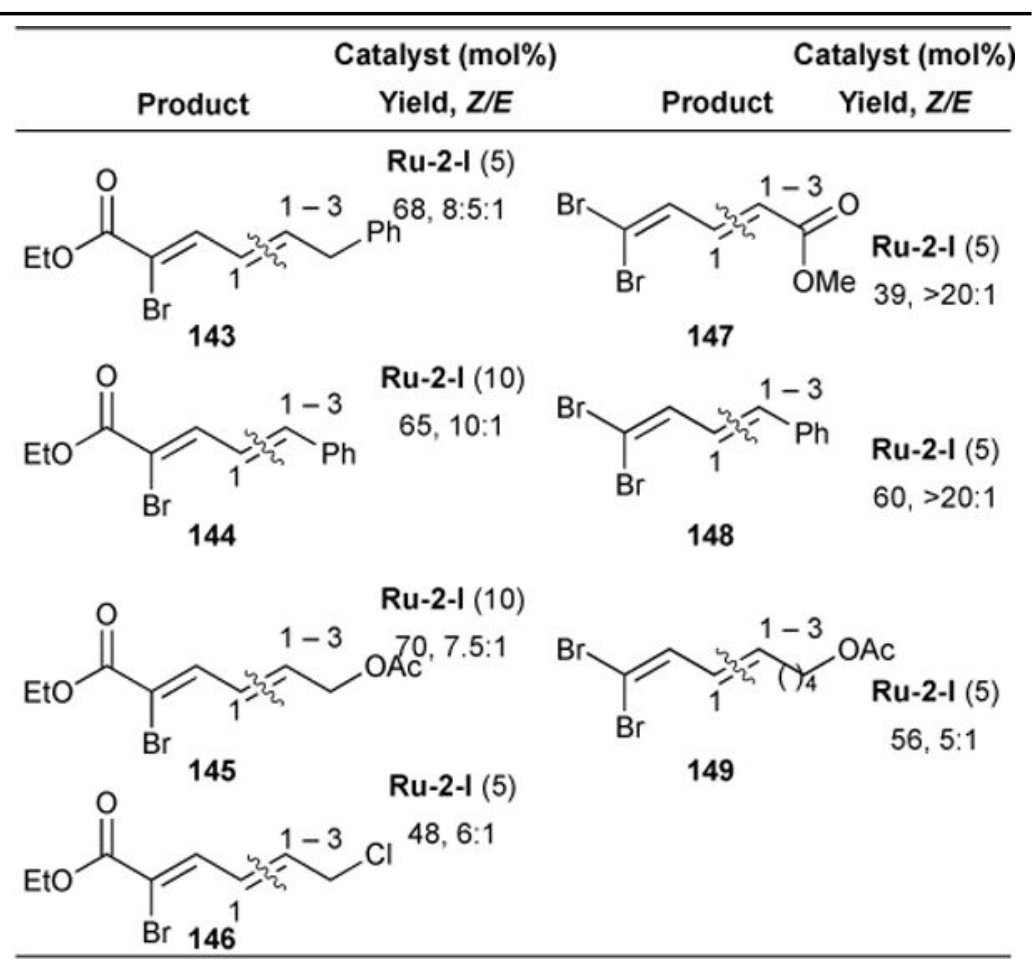


\section{Table 10}

Steric control of chemoselective construction of conjugated dienes via olefin cross-metathesis

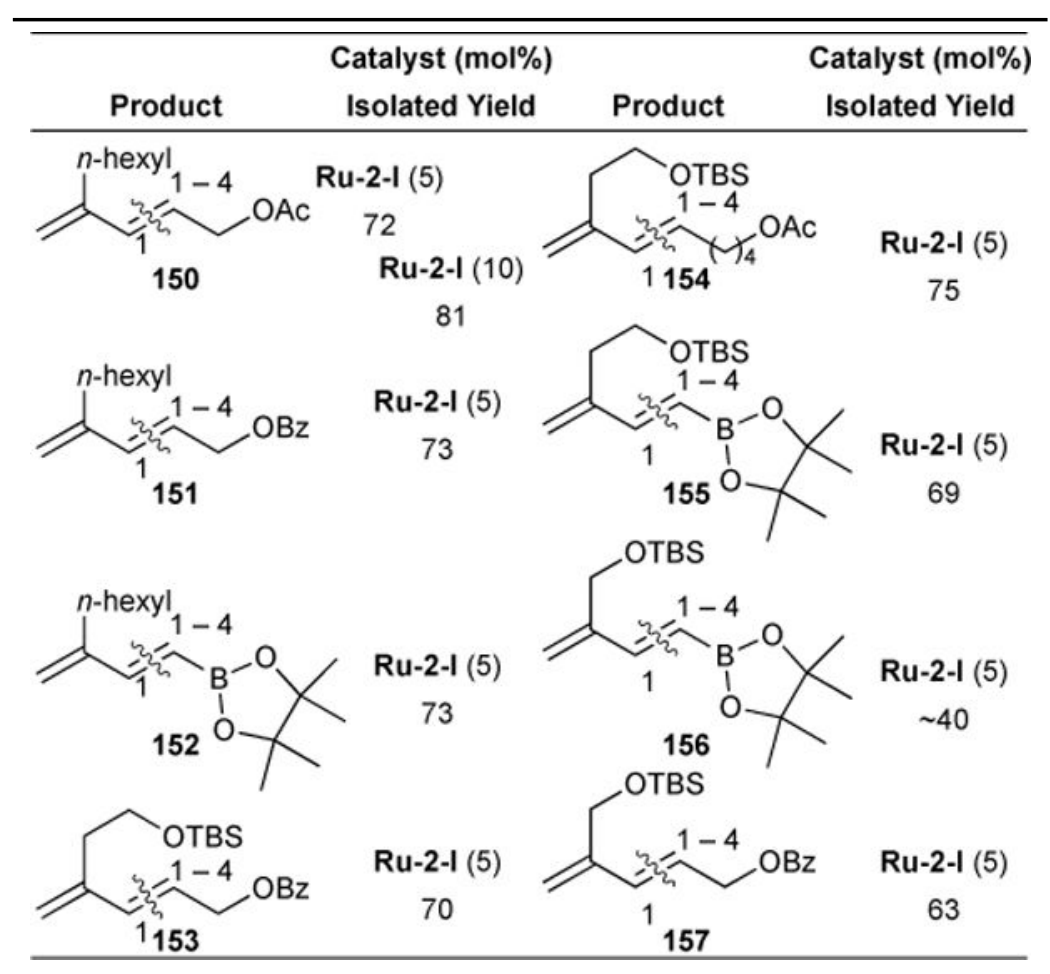

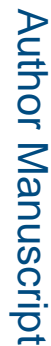

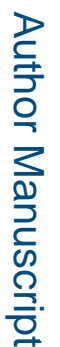

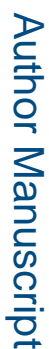


Table 11

Stereoretentive CM of 1-decene and 4-octene.

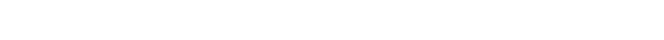

\begin{tabular}{lllll}
\hline Ru-6 & $\mathbf{1 5 9}$ & \% conv & \% yield & $\boldsymbol{X} / \boldsymbol{E}$ \\
\hline Ru-6-II & cis & 89 & 74 & $96 / 4$
\end{tabular}

Ru-6-II trans 92

Ru-6-I cis 8

Ru-6-I trans

$92 \quad 4$

$13 / 88$

Ru-6-III

cis $\quad 88$

58

$>99 / 1$

Ru-6-III trans 53

Ru-6-IV cis 79

Ru-6-IV

trans

55

$7 \quad<1 / 99$

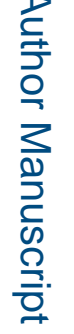

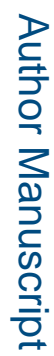

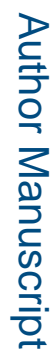

Chem Soc Rev. Author manuscript; available in PMC 2019 June 18. 


\section{Table 12}

Ethenolysis of methyl oleate

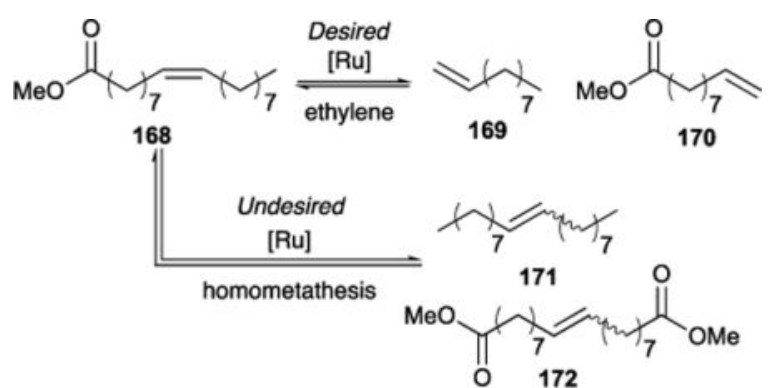

\begin{tabular}{lllll}
\hline [Ru] & \% Conv & \% Select & \% Yield & TON \\
\hline Ru-1-I & 65 & 96 & 62.4 & 5800 \\
Ru-1-IV & 39 & 94.8 & 37.0 & 7500 \\
Ru-2-II & 58 & 45 & 26.1 & 11000 \\
Ru-2-V & 54 & 52 & 28.1 & 13500 \\
Ru-2-VI & 61 & 58 & 35.4 & 22300 \\
Ru-4-I & 80 & 87 & 69.6 & 27200 \\
\hline
\end{tabular}

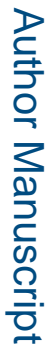

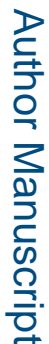

Chem Soc Rev. Author manuscript; available in PMC 2019 June 18 
Table 13

$Z$-selective and Enantioselective Ring-Opening Cross Metathesis

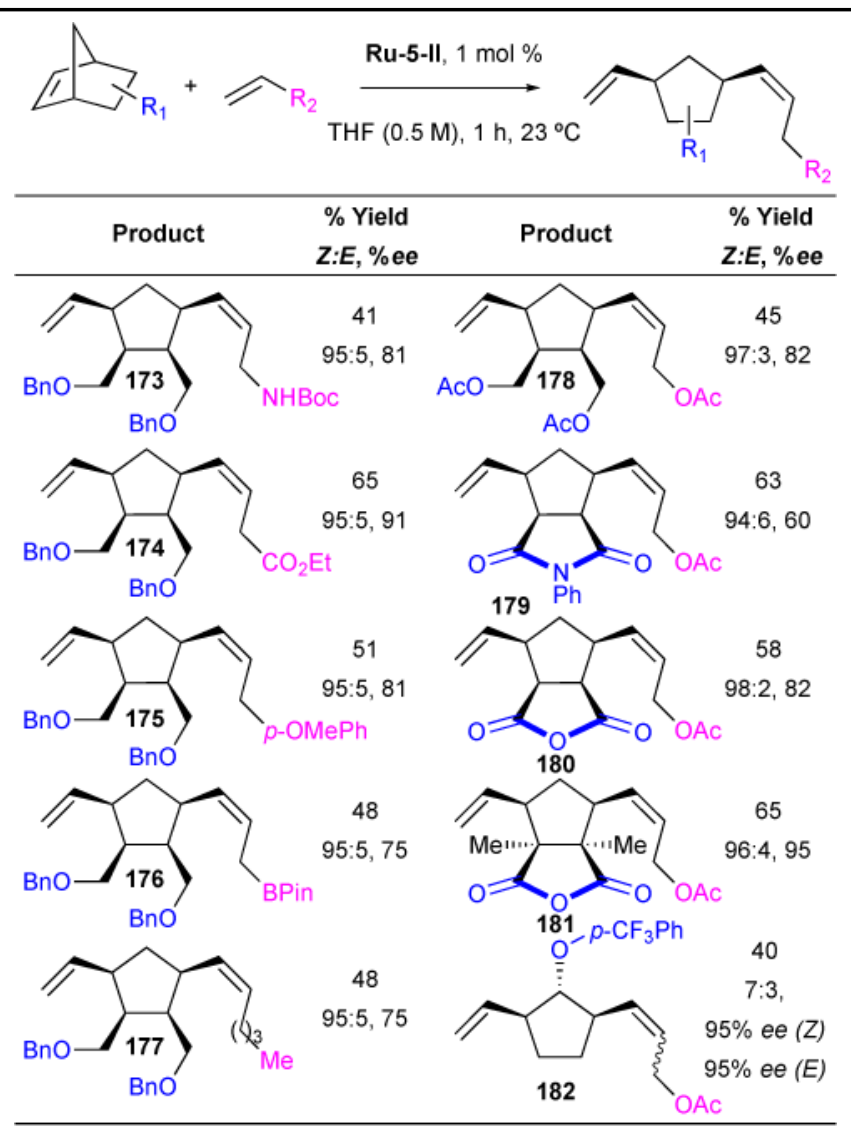

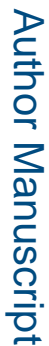

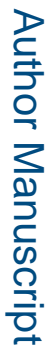


Table 14

Examples of the living ROMP of low strain or unhindered cyclic olefins with polar functionalities.
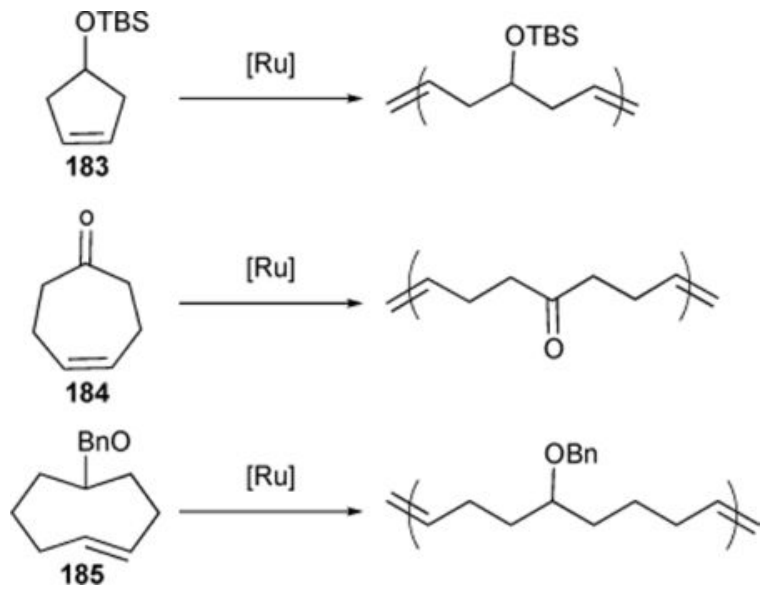

\begin{tabular}{ccccc}
\hline Monomer & Limitation & {$[\mathbf{R u}]$} & Yield (\%) & PDI \\
\hline $\mathbf{1 8 3}$ & insufficient ring strain & $\mathbf{R u}-3-$ II & 71 & 1.3 \\
$\mathbf{1 8 4}$ & insufficient ring strain & $\mathbf{R u}-\mathbf{3}-\mathbf{I I}$ & 88 & 1.2 \\
$\mathbf{1 8 5}$ & unhindered alkene & $\mathbf{R u - 1 - I}+\mathbf{P P h}_{\mathbf{3}}$ & 97 & 1.06 \\
\hline
\end{tabular}




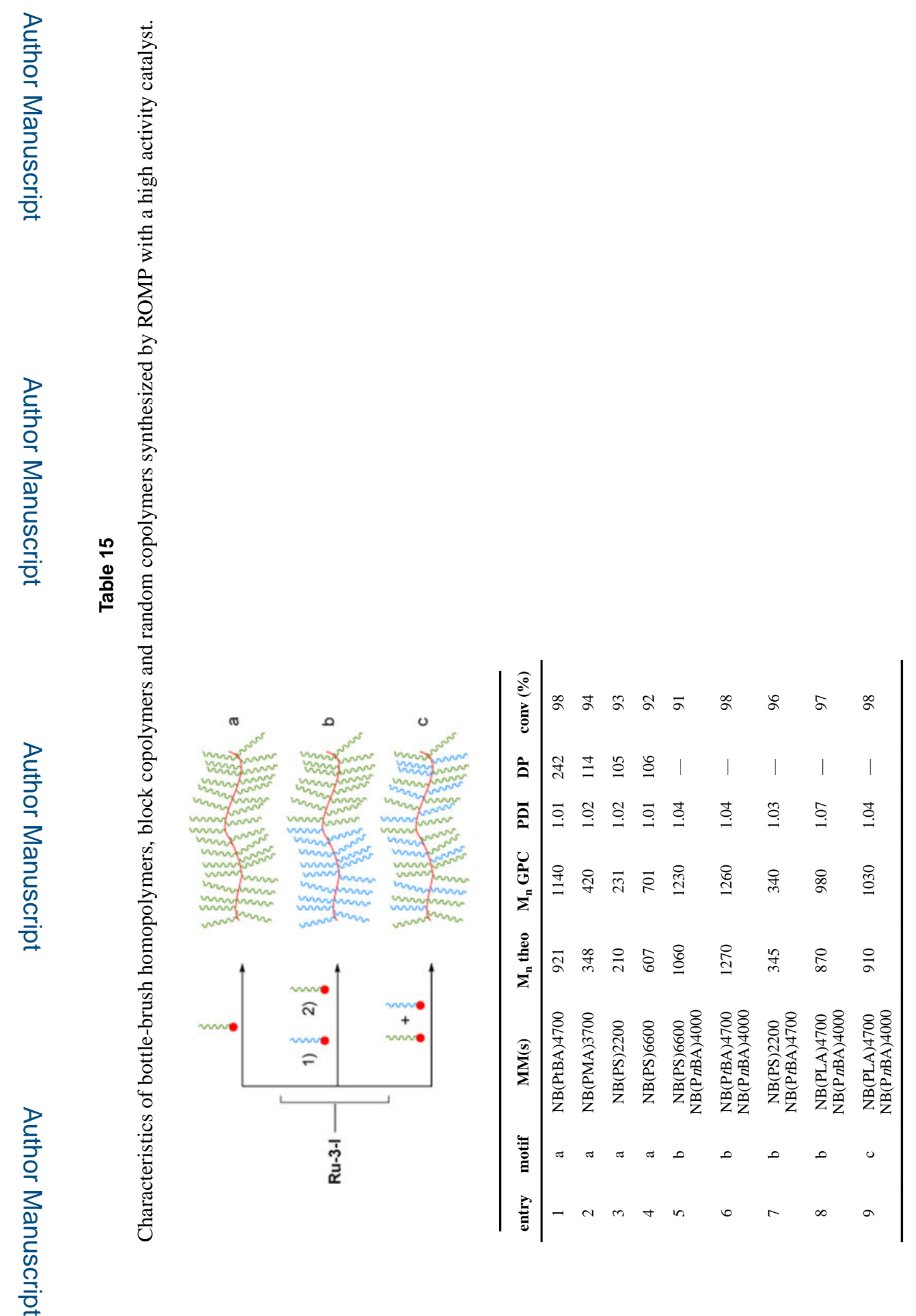

Chem Soc Rev. Author manuscript; available in PMC 2019 June 18. 